\title{
Relação da pressão intra-ocular e paquimetria corneal com os diferentes estágios de desenvolvimento das cataratas diabéticas e não diabéticas em cães da raça Poodle
}

Dissertação apresentada ao
Programa de Pós-Graduação em
Clínica Cirúrgica Veterinária da
Faculdade de Medicina Veterinária e
Zootecnia da Universidade de São
Paulo para obtenção do título de
Mestre em Medicina Veterinária

Departamento:

Cirurgia

Área de concentração:

Clínica Cirúrgica Veterinária

Orientador:

Prof. Dr. Paulo Sergio de Moraes

Barros 
Autorizo a reprodução parcial ou total desta obra, para fins acadêmicos, desde que citada a fonte.

DADOS INTERNACIONAIS DE CATALOGAÇÃO-NA-PUBLICAÇÃO

(Biblioteca Virginie Buff D’Ápice da Faculdade de Medicina Veterinária e Zootecnia da Universidade de São Paulo)

T.2067 Helzel, Milena Sefrin

FMVZ Relação da pressão intra-ocular e paquimetria corneal com os diferentes estágios de desenvolvimento das cataratas diabéticas e não diabéticas em cães da raça Poodle / Milena Sefrin Helzel. São Paulo : M. S. Helzel, 2008.

99 f. : il.

Dissertação (mestrado) - Universidade de São Paulo.

Faculdade de Medicina Veterinária e Zootecnia. Departamento de Cirurgia, 2008.

Programa de Pós-Graduação: Clínica Cirúrgica Veterinária. Área de concentração: Clínica Cirúrgica Veterinária.

Orientador: Prof. Dr. Paulo Sergio de Moraes Barros.

1. Pressão intra-ocular. 2. Paquimetria. 3. Cães. 4. Catarata. 5. Diabetes mellitus. I. Título. 


\title{
UNIVERSIDADE DE SÃO PAULO \\ Faculdade de Medicina Veterinária e Zootecnia
}

\author{
Comissão Bioética
}

\section{CERTIFICADO}

Certificamos que o Projeto intitulado "Paquimetria corneana e pressão intraocular no desenvolvimento da diabetes mellitus em cães", protocolado sob o n¹152/2007, utilizando 100 (cem) cães, sob a responsabilidade do Prof. Dr. Paulo Sergio de Moraes Barros, está de acordo com os princípios éticos de experimentação animal da Comissão de Bioética da Faculdade de Medicina Veterinária e Zootecnia da Universidade de São Paulo e foi aprovado em reunião de 19/09/07.

We certify that the Research "Corneal thickness and intraocular pressure related to duration in diabetes mellitus in dogs", protocol number 1152/2007, utilizing 100 (one hundred) dogs, under the responsibility Prof. Dr. Paulo Sergio de Moraes Barros, agree with Ethical Principles in Animal Research adopted by Bioethic Commission of the School of Veterinary Medicine and Animal Science of University of São Paulo and was approved in the meeting of day 09/19/07.

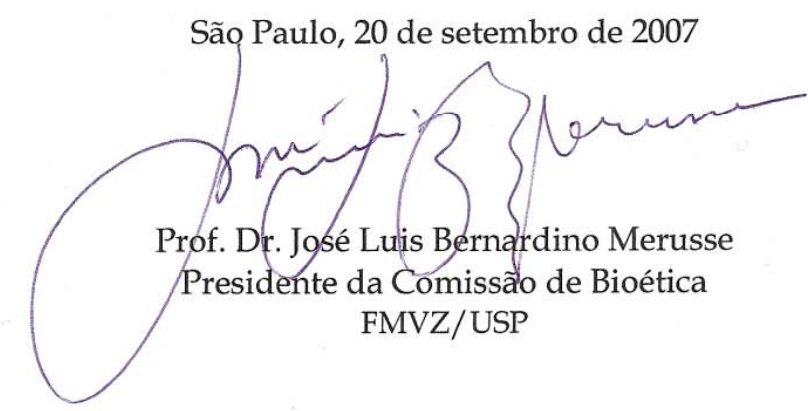

Av. Prof. Dr. Orlando Marques de Paiva, n 87 - 05508-270 - Cidade Universitária "Armando de Salles Oliveira". Fax: (11) 3032-2224 - fones: (11) 309107676/7671 - e-mail: fmvz@edu.usp.br 


\section{FOLHA DE AVALIAÇÃO}

Nome: HELZEL, Milena Sefrin

Título: Relação da pressão intra-ocular e paquimetria corneal com os diferentes estágios de desenvolvimento das cataratas diabéticas e não diabéticas em cães da raça Poodle

Dissertação apresentada ao Programa de PósGraduação em Clínica Cirúrgica Veterinária da Faculdade de Medicina Veterinária e Zootecnia da Universidade de São Paulo para obtenção do título de Mestre em Medicina Veterinária

Data:

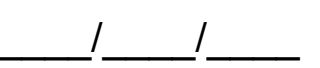

Banca Examinadora

Prof. Dr. Instituição:

Assinatura: Julgamento:

Prof. Dr. Instituição:

Assinatura: Julgamento:

Prof. Dr. Instituição:

Assinatura: Julgamento: 
À minha mãe Frida, por todo amor, dedicação e compreensão, a qual amo mais que tudo nesse mundo. Ao meu pai Alberto, que me ensinou os verdadeiros valores que me guiarão pelo resto de minha vida, minha imensa saudade. 
À minha irmã Letícia, a qual amo imensamente, pela grandiosa habilidade de ser minha irmã, amiga e mãe. Ao meu irmão e cunhado Rafael pelo simples fato de ser um dos melhores seres humanos que conheço. À minha futura sobrinha, que já faz tão bem a todos nós. 
Aos meus irmãos: Guilherme, Albertinho e Anne, por todo ensinamento aprendido.

Ao meu orientador Prof. Dr. Paulo Sergio de Moraes Barros, pelo qual desenvolvi uma imagem paternal, por toda confiança em mim depositada, meu muitíssimo obrigada. 
À Médica Veterinária, amiga e irmã Ana Paula Hvenegaard, profissional de excelência, ser humano de intenções impecáveis, com a qual divido qualquer mérito que este trabalho venha a ter.

À minha amiga e conselheira Dra. Tereza Cristina Gonçalves, pelos anos de dedicação, amizade e carinho. Este mestrado é fruto de todo um processo de aprendizado e amadurecimento, que também são méritos seus. 
À DEUS, acima de tudo, por tudo que vivi, por todos com os quais convivi. 


\section{AGRADECIMENTOS}

Às minhas colegas de mestrado, Adriana Cabral Lustoza, Graziele Massae Shimamura, Márcia Pansera Galego e Renata Squarzoni, amigas e irmãs. Jamais poderia escrever um agradecimento à altura, mas posso dizer que vocês não apenas me ergueram como profissional, como fizeram com que eu me tornasse um ser humano melhor. Vocês são verdadeiros exemplos.

À Dra. Angélica M. V. Safatle, amiga, colega de pós-graduação e mestra, meu muito obrigada por todos os ensinamentos e todo o convívio.

Aos Médicos Veterinários Daniela de Castro Leandro, Eduardo Perlmann e Luiz Felipe de M. Barros, por toda amizade, colaboração e carinho.

À Dra. Andréa Antunes, por todos os conselhos e ajuda.

Aos secretários do departamento de Cirurgia, Alessandra Sousa e Belarmino Ney Pereira presentes durante toda minha caminhada, agradeço toda a paciência e dedicação.

Aos funcionários do Hospital Veterinário/USP, Cledson Lelis dos Santos, Jesus dos Anjos Vieira e Otávio Rodrigues dos Santos, por todo apoio e carinho.

Aos funcionários da Biblioteca Virginie Buff D'Ápice da FMVZ/USP, Anderson Alves Santana, Elena Ap. Tanganini, Elza Maria Rosa Bernardo Faquim, Fernanda Cesar Ribeiro, Maria Fátima dos Santos, Rosângela Rodrigues Pereira e Solange Alves Santana, pelo auxílio ao longo de todo processo.

À Faculdade de Medicina Veterinária e Zootecnia, que me acolheu, formou e deu condições para a realização deste trabalho

Ao CNPQ (Conselho Nacional de Desenvolvimento Científico e Tecnológico) pela bolsa concedida.

Aos pequenos grandes Poodles que fizeram parte deste trabalho, com sua alegria e, às vezes, mau humor, e aos proprietários que assim consentiram, todo meu respeito e carinho.

A todos que participaram dessa minha jornada de alguma forma. 


\section{RESUMO}

HELZEL, M. S. Relação da pressão intra-ocular e paquimetria corneal com os diferentes estágios de desenvolvimento das cataratas diabéticas e não diabéticas em cães da raça Poodle. [Relationship of intraocular pressure and corneal thickness to diabetic and nondiabetic cataracts in Poodles]. 2008. $99 \mathrm{f}$. Dissertação (Mestrado em Medicina Veterinária) - Faculdade de Medicina Veterinária e Zootecnia, Universidade de São Paulo, São Paulo, 2008.

A diabetes mellitus (DM) causa alterações em todas as camadas da córnea. Córneas de pacientes diabéticos têm controle de sua hidratação prejudicado e são mais propensas à descompensação após injúria. A uveíte faco-induzida (UFI) ocorre em grandes proporções associada à catarata hipermatura em cães. A UFI também acarreta danos ao endotélio da córnea e pode levar ao edema estromal, usualmente transitório. Cães diabéticos são particularmente predispostos ao desenvolvimento de catarata e UFI associada. Os efeitos da DM e UFI podem potencialmente vir a se somar em córneas de cães com catarata diabética. A pressão intra-ocular (PIO) e paquimetria podem ser ferramentas úteis na determinação dessas alterações. $O$ objetivo deste estudo foi determinar a relação entre pressão intra-ocular e paquimetria nos diferentes estágios de desenvolvimento das cataratas diabéticas e não diabéticas em cães da raça Poodle. Cento e vinte e dois cães adultos da raça Poodle, 134 fêmeas e 99 machos, com idades de 2 a 16 anos, foram admitidos no Serviço de Oftalmologia do Hospital Veterinário da Universidade de São Paulo e incluídos no trabalho. Afecções oculares concomitantes, ou doenças sistêmicas com manifestação ocular, foram consideradas fatores de exclusão. Após exame clínico oftalmológico, coletou-se dados referentes ao tempo de leucocoria e tempo de desenvolvimento da DM. Os cães tiveram a PIO mensurada por meio do TonoPen$\mathrm{XL} \circledast$ e a paquimetria mensurada com o uso do PachPen®. Para isso realizou-se anestesia tópica (colírio de Proximetacaína a 0,5\% - Anestalcon®, Alcon). As comparações estatísticas entre as variáveis foram realizadas utilizando os testes de Spearman, Mc-Nemar e Mann-Whitney quando apropriados. As distribuições das variáveis entre os grupos foram avaliadas pelo test de Kruskal-Wallis, e quando significantes, o teste de Dunn foi utilizado para descriminar as diferenças encontradas. O nível de significância foi estabelecido em $p<0,05$. Dos 122 cães, 233 olhos foram incluídos e classificados em grupo controle $(n=39)$, catarata incipiente 
$(n=20)$, imatura $(n=29)$, matura $(n=20)$, hipermatura $(n=80)$, catarata diabética imatura $(n=9)$, diabética matura $(n=11)$ e diabética hipermatura $(n=25)$. As distribuições das variáveis (sexo, idade, peso, presença de uveíte, tempo de leucocoria, PIO e paquimetria) foram estatisticamente diferentes entre os diversos grupos. Fêmeas apresentaram-se mais acometidas por catarata diabética. A idade média dos animais variou de 7,03 a 10,73 anos entre os grupos, e os animais diabéticos foram estatisticamente mais velhos. A PIO foi estatisticamente menor e os sinais clínicos de UFI mais prevalentes nos grupos de cataratas hipermaturas, tanto diabéticas, quanto não diabéticas. A PIO correlacionou-se negativamente com a idade e a paquimetria. Houve correlação positiva da paquimetria com a idade e o peso; e correlação negativa com o tempo de leucocoria e a PIO. Olhos acometidos por UFI tiveram PIO estatisticamente menor e paquimetria maior, com diferença de 2 $\mathrm{mmHg}$ e $60 \mu \mathrm{m}$, respectivamente. Nos cães acometidos por catarata diabética, a paquimetria encontrou-se particularmente aumentada, e a UFI particularmente presente. Esse aumento possivelmente reflete a somatória dos efeitos da DM e UFI sobre a córnea. A hipermaturidade foi correlacionada à presença da UFI. A PIO e paquimetria mostraram-se instrumentos valiosos na determinação da UFI, principalmente se forem negativamente correlacionadas entre si.

Palavras-chave: Pressão intra-ocular. Paquimetria. Cães. Catarata. Diabetes mellitus. 


\begin{abstract}
HELZEL, M. S. Relationship of intraocular pressure and corneal thickness to diabetic and nondiabetic cataracts in Poodles. [Relação da pressão intra-ocular e paquimetria corneal com os diferentes estágios de desenvolvimento das cataratas diabéticas e não diabéticas em cães da raça Poodle]. 2008. 99 f. Dissertação (Mestrado em Medicina Veterinária) - Faculdade de Medicina Veterinária e Zootecnia, Universidade de São Paulo, São Paulo, 2008.
\end{abstract}

Diabetes mellitus (DM) causes different alterations in all corneal layers, such as deficient control of hydration, what makes them prone to decompensate after injury. Lens induced uveitis (LIU) occurs mainly in dogs presenting hypermature cataracts, what causes irreversible damages to the corneal endothelium and may lead to stromal edema, usually transient. DM dogs are particularly predisposed to cataract with LIU associated. Intraocular pressure (IOP) and pachymetry measurements may be useful procedures capable to detect such alterations. The aim of this study was to determinate the relationship between intraocular pressure and pachymetry on diabetic and nondiabetic Poodles, presenting different stages of cataracts. One hundred twenty-two Poodles, 134 females and 99 males, with ages varying from 2 to 16 years, were admitted at the Ophthalmology Service, of the Veterinary Hospital, of the University of São Paulo. After complete identification of the animals, anamnese (time of DM and cataract formation) and ophthalmological exam, dogs were included in the study. Dogs affected by other systemic diseases inducing ocular manifestation or other primary ocular alteration were excluded. LIU was diagnosed by observation of congestion of the episcleral vases and resistence to midriasis after induction with Mydriacy|®. IOP was measured by TonoPen-XL® and pachymetry by PachPen $\circledast$ after instillation of anesthetic eyedrop (Proximetacaine 0,5\% - Anestalcon, Alcon). Statistical comparison between factors were made using Spearman, Mc-Nemar and Mann-Whitney tests when appropriated. The distributions of the factors among the groups were compared by Krusskal-Wallis's test, and when significant, Dunn's test was used to describe the differences found. The level of significance was set at $p<0,05$. Two hundred thirty-three eyes of 122 Poodles were evaluated. Eyes were classified in different groups: healthy dogs without cataracts $(n=39)$; dogs presenting incipient cataract $(n=20)$; with immature cataracts $(n=29)$; mature cataracts $(n=20)$; or hypermature cataracts $(n=80)$; DM dogs presenting immature cataract $(n=9)$; DM 
with mature cataracts $(n=11)$; and DM with hypermature cataracts $(n=25)$. Distribution of factors, such as age, sex, weight, time of DM and cataract, presence of LIU, IOP and pachymetry were statistically different between groups. Female Poodles were more affected by diabetic cataract and diabetic dogs were older than the other ones. IOP was statistically lower and LIU alterations more prevalent in the hypermature cataract groups (diabetic and no diabetics). IOP was negatively correlated to age and pachymetry measures. Pachymetry was positively correlated to age and weight. Negative correlation was observed between pachymetry and time of cataracts formation. LIU eyes presented lower IOP and higher pachymetry. The difference found at pachymetry and IOP measurements in LIU and non LIU eyes were $60 \mu \mathrm{m}$ and $2 \mathrm{mmHg}$ respectively. In diabetic dogs, pachymetry was particularly higher and LIU particularly present. The higher corneal thickness may possible be related to the sum of alterations caused by DM and LIU to those corneas. Hypermaturity was directly related to LIU. We concluded that pachymetry and IOP measurements are important procedures to the LIU diagnosis, mainly when negatively correlated.

Key words: Intraocular pressure. Pachymetry. Dogs. Cataracts. Diabetes mellitus. 


\section{LISTA DE FIGURAS}

Figura 1 - Representação fotográfica do tonômetro TonoPen-XL® utilizado

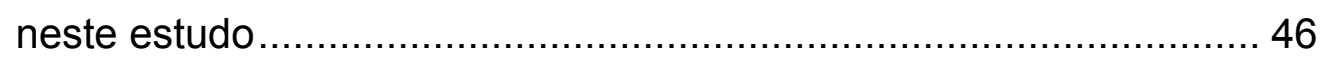

Figura 2 - Representação fotográfica da realização da tonometria por meio do tonômetro de aplanação TonoPen-XL® em cão da raça Poodle 46

Figura 3 - Representação fotográfica do paquímetro PachPen® utilizado neste estudo

Figura 4- Representação fotográfica da realização da paquimetria utilizando paquímetro ultra-sônico PachPen® em cão da raça Poodle. 


\section{LISTA DE GRÁFICOS}

Gráfico 1 - Representação gráfica da distribuição percentual dos olhos segundo o sexo masculino e os grupos ...

Gráfico 2 - Representação gráfica da distribuição dos olhos segundo a idade e os grupos

Gráfico 3 - Representação gráfica da distribuição dos olhos segundo o peso e os grupos

Gráfico 4 - Representação gráfica da distribuição dos olhos segundo o tempo de leucocoria e os grupos

Gráfico 5 - Representação gráfica da distribuição dos olhos segundo o tempo de diabetes mellitus e os grupos.

Gráfico 6 - Representação gráfica da distribuição dos olhos segundo o tempo de desenvolvimento da catarata após o diagnóstico da diabetes mellitus e os grupos

Gráfico 7 - Representação gráfica da distribuição percentual dos olhos segundo a presença de uveíte faco-induzida e os grupos

Gráfico 8 - Representação gráfica da distribuição dos olhos segundo a pressão intra-ocular e os grupos

Gráfico 9 - Representação gráfica da distribuição dos olhos segundo a paquimetria e os grupos 


\section{LISTA DE TABELAS}

Tabela 1 - Distribuição dos olhos segundo as fases das cataratas 51

Tabela 2 - Distribuição dos olhos segundo o sexo e os grupos 52

Tabela 3 - Distribuição dos olhos segundo a idade e os grupos

Tabela 4 - Comparação estatística (discriminação) da idade entre os grupos

Tabela 5 - Distribuição dos olhos segundo o peso e os grupos 55

Tabela 6 - Comparação estatística (discriminação) do peso entre os grupos

Tabela 7 - Distribuição dos olhos segundo o tempo de formação da catarata (tempo de leucocoria) e os grupos

Tabela 8 - Comparação estatística (discriminação) do tempo de leucocoria entre os grupos.

Tabela 9 - Distribuição dos olhos segundo o tempo de diabetes mellitus e os grupos.

Tabela 10 -Distribuição dos olhos segundo o tempo de desenvolvimento da catarata após o diagnóstico da diabetes mellitus e os grupos

Tabela 11 -Distribuição dos olhos segundo a presença de uveíte facoinduzida e os grupos

Tabela 12 -Distribuição dos olhos segundo os lados direito e esquerdo e a presença de uveíte faco-induzida

Tabela 13- Distribuição dos olhos segundo a pressão intra-ocular e os grupos

Tabela 14 -Comparação estatística (discriminação) da pressão intraocular entre os grupos

Tabela 15 -Correlação entre pressão intra-ocular e paquimetria e as outras variáveis

Tabela 16 -Associação da pressão intra-ocular e paquimetria com a presença de uveíte faco-induzida.

Tabela 17 -Distribuição dos olhos segundo a paquimetria e os grupos

Tabela 18 -Comparação estatística (discriminação) da paquimetria entre os grupos. 


\section{LISTA DE ABREVIATURAS E SIGLAS}

$\begin{array}{ll}\text { ATPase } & \text { adenosina trifosfato } \\ \text { BUT } & \text { "break up time" } \\ \text { DM } & \text { diabetes mellitus } \\ \text { DP } & \text { desvio padrão } \\ \text { ed. } & \text { edição } \\ \mathrm{f} & \text { fêmea } \\ \text { GSH } & \text { glutationa } \\ \text { Kg } & \text { quilograma } \\ \mathrm{m} & \text { macho } \\ \mathrm{Máx} . & \text { máxima } \\ \mathrm{mg} & \text { miligrama } \\ \mathrm{MHz} & \text { mega Hertz } \\ \mathrm{Mín} & \text { mínima } \\ \mathrm{Mm}{ }^{2} & \text { milímetros ao quadrado } \\ \mathrm{mmHg} & \text { milímetros de mercúrio } \\ \mathrm{m} / \mathrm{s} & \text { metros por segundo } \\ \mathrm{n} & \text { número da amostra } \\ \mathrm{p} & \text { probabilidade de significância } \\ \mathrm{PAQ} & \text { paquimetria } \\ \mathrm{PIO} & \text { micrômetros } \\ \mathrm{s} & \text { segundo intra-ocular } \\ \mathrm{UFI} & \text { uveíte faco-induzida } \\ \mathrm{HH} & \end{array}$




\section{LISTA DE SÍMBOLOS}

$\alpha$

$\beta$

Y

$\mu$

$\%$

$\mathrm{Ca}^{+}$

$\mathrm{Na}^{+}$

$\mathrm{K}^{+}$

®

$>$

$<$

$=$

$\pm$ alfa

beta

gama

micron

porcento

cálcio

sódio

potássio

registrado

maior

menor

igual

mais ou menos 


\section{SUMÁRIO}

1 INTRODUÇÃO

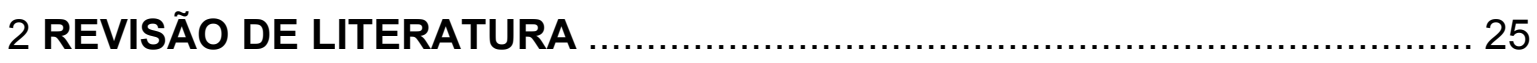

2.1 Alterações oculares na diabetes mellitus ............................................ 25

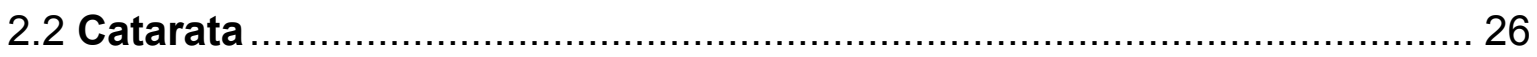

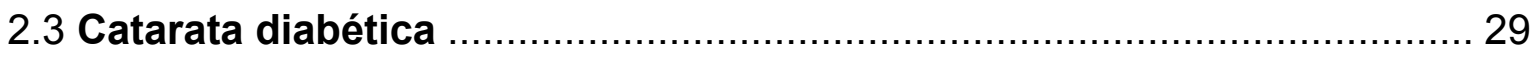

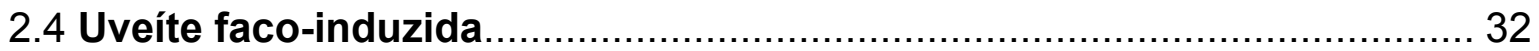

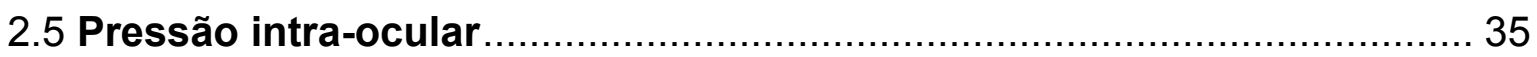

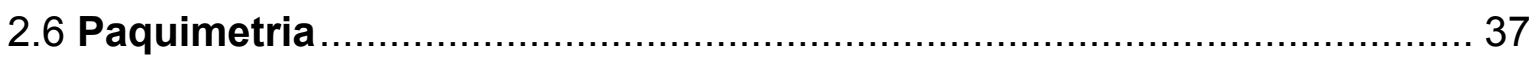

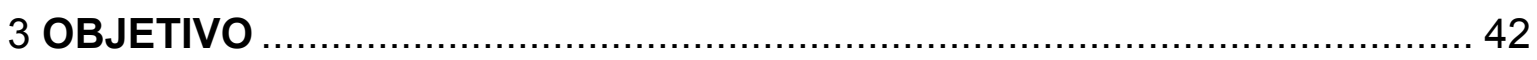

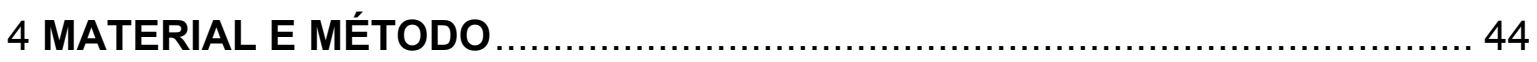

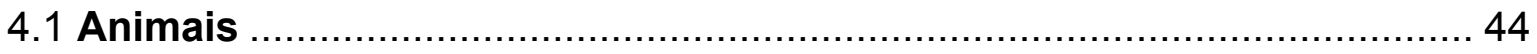

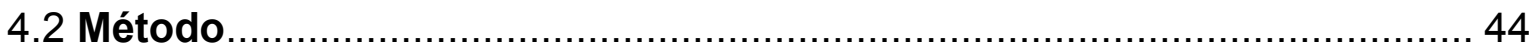

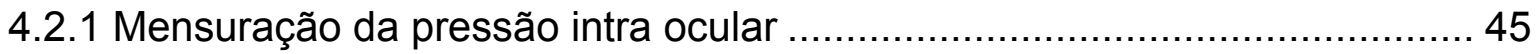

4.2.2 Mensuração da espessura corneal ......................................................... 45

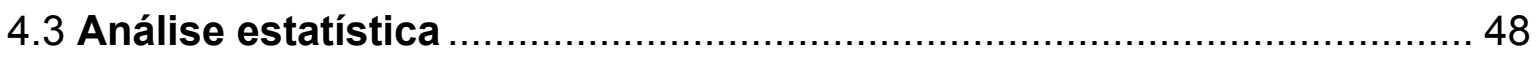

5 RESULTADOS

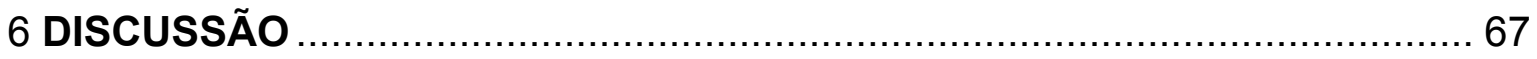

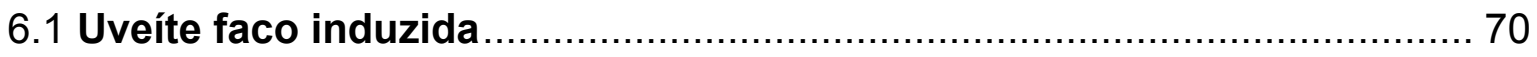

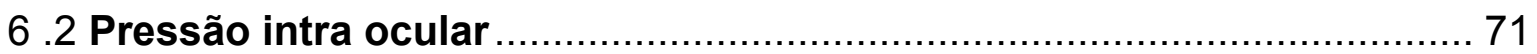

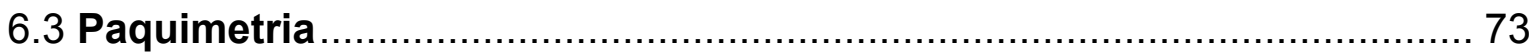

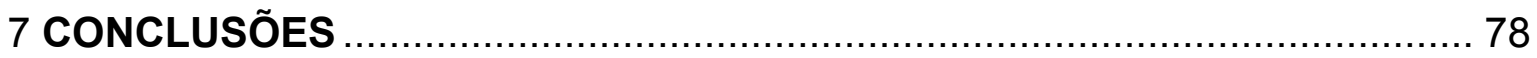

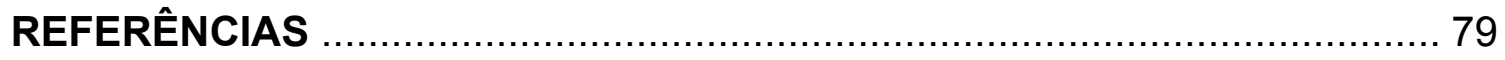

APÊNDICE 


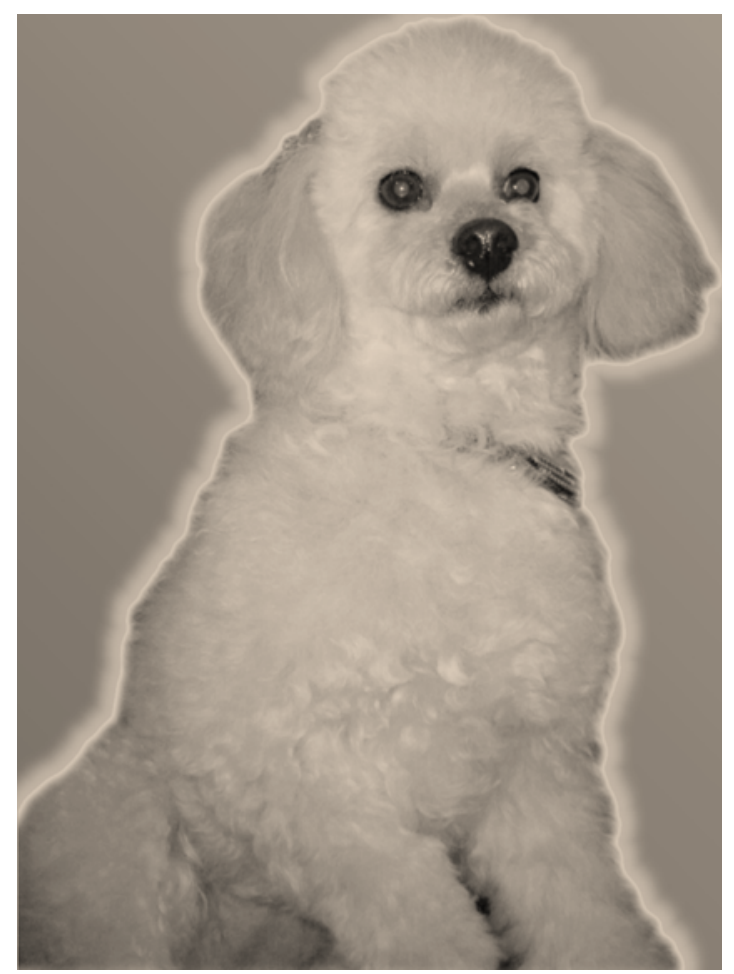




\section{INTRODUÇÃO}

A diabetes mellitus (DM) é uma endocrinopatia comum em cães, que afeta cerca de 1 em 500 a 1 em 100 cães (MARMOR et al., 1982). A DM é responsável por inúmeras alterações nos tecidos oculares, bem como acomete todas as camadas da córnea (CULLEN et al., 2005; CISARIK-FREDENBURG, 2001; SWANN, 1999). Córneas de pacientes diabéticos apresentam polimegatismo, pleomorfismo e diminuição da densidade das células endoteliais; fragilidade da barreira epitelial; diminuição da atividade das bombas de $\mathrm{Na}^{+} / \mathrm{K}^{+}$ATPase; e são mais propensas à descompensação após injúria pela perda do controle hídrico (HERSE, 1990; KEOLEIAN et al., 1992; SWANN, 1999; GEKKA et al., 2004; CULLEN et al., 2005). Em córneas de cães acometidos pela DM, Yee et al. (1985) comprovaram a presença de pleomorfismo e polimegatismo, e Lynch e Brinkis (2006) encontraram aumento da espessura corneal.

A catarata, por simples definição, é a opacificação do cristalino ou de sua cápsula (PLAYTER, 1977; BARNETT, 1985); é a afecção intra-ocular mais comum em cães e uma importante causa de perda de visão nessa espécie (DAVIDSON; NELMS, 2007). Cataratas de diferentes etiologias podem acometer as lentes de cães e, certas raças, como os Poodles e os Cockers Spaniel, são predispostas a mais de uma etiologia (ANDERSEN; SHULTZ, 1958; KOCH; RUBIN, 1967; RUBIN; FLOWERS, 1972; BARNETT, 1985; DAVIDSON; NELMS, 2007).

Cães possuem susceptibilidade única ao desenvolvimento de catarata secundária à DM (WYMAN et al.,1988; BEAM; CORREA; DAVIDSON, 1999). Em diferentes estudos, 66 e $68 \%$ dos cães diabéticos encontraram-se acometidos pela formação de catarata (BASHER; ROBERTS, 1995; BEAM; CORREA; DAVIDSON, 1999).

Freqüentemente inflamação do tecido uveal é associada à liberação de proteínas lenticulares por lentes com catarata, através de sua cápsula intacta (GELLAT, 1975; WOERDT, 2000). Paulsen et al. (1986) reportaram que $71 \%$ dos cães com formação de catarata em seu estudo apresentavam uveíte faco induzida (UFI) concomitante. Cães diabéticos foram particularmente acometidos pela UFI (92\%). A UFI ocorre principalmente em associação com cataratas hipermaturas (RUBIN; GELATT, 1968; GELATT, 1975; PLAYTER, 1977; WILCOCK; PEIFFER, 
1987; WOERDT; NASISSE; DAVIDSON, 1992; WOERDT, 2000; DENIS et al., 2003), embora já tenha sido reportada nas outras fases de desenvolvimento (WOERDT; NASISSE; DAVIDSON, 1992; KROHNE et al., 1995; DENIS et al., 2003). Usualmente é uma inflamação de grau leve (WOERDT; NASISSE; DAVIDSON, 1992; WOERDT, 2000), podendo passar despercebida pelo exame oftalmológico (HAKANSON; FORRESTER, 1990; WOERDT; NASISSE; DAVIDSON, 1992).

Em 1987, Macdonald, Geroski e Edelhauser correlacionaram o aumento da permeabilidade endotelial, diminuição da atividade de bombeamento do endotélio e aumento da espessura corneal como efeito da inflamação ocular.

Os efeitos da DM e UFI podem potencialmente vir a se somar em córneas de cães com cataratas diabéticas. Não foram encontrados, até o presente momento, estudos na literatura veterinária referentes à correlação entre a espessura corneal e os diferentes estágios de desenvolvimento das cataratas diabéticas e não diabéticas. O conhecimento dos comportamentos da paquimetria e pressão intraocular nas cataratas de cães podem vir a se tornar importantes instrumentos na pesquisa ou rotina oftalmológica. Enquanto as alterações corneais não forem melhor conhecidas e permanecerem não mensuráveis, sua presença poderá levar a acometimentos que não serão corretamente previstos. 


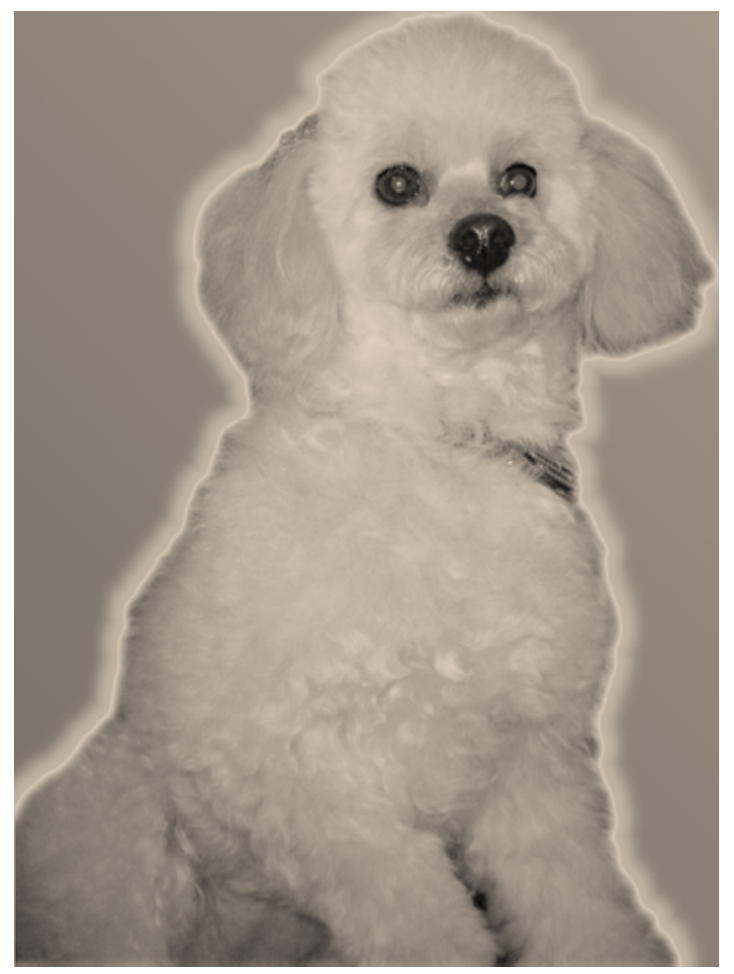

REVISÃO DE LITERATURA 


\section{REVISÃO DE LITERATURA}

A revisão de literatura foi dividida em alguns tópicos relevantes descritos a seguir:

\subsection{Alterações oculares na diabetes mellitus}

A diabetes mellitus (DM) é uma endocrinopatia comum de cães, que afeta cerca de 1 em 500 a 1 em 100 cães (MARMOR et al., 1982). As manifestações oculares da DM em cães incluem o desenvolvimento de catarata; a perda de células endoteliais; pleomorfismo e polimegatismo de células endoteliais; redução da sensibilidade corneal; e alterações vasculares da retina, como a formação de microaneurismas (CULLEN et al., 2005). A DM pode causar impacto em todas as camadas da córnea, além da superfície ocular. Cullen et al. (2005) estudaram os efeitos ceratoconjuntivais da diabetes em cães e demonstraram modificações no teste de Schirmer, na sensibilidade corneal, no tempo de ruptura do filme lacrimal (BUT), na concentração de glicose lacrimal, além de alterações na citologia e histologia conjuntivais. O epitélio corneal pode apresentar uma variedade de alterações, que incluem a diminuição do número de células, edema celular e alterações da membrana basal, afetando a aderência epitelial e reepitelização (SWANN, 1999). Gekka et al. (2004) comprovaram que a função da barreira epitelial corneal é prejudicada nos pacientes diabéticos.

Herse, em 1990, desenvolveu estudo em coelhos, o qual fortemente sugere que a disfunção endotelial pela bomba de $\mathrm{Na}+/ \mathrm{K}+$ ATPase é a principal responsável pela perda do controle da hidratação corneal na DM. As alterações estruturais e funcionais do endotélio corneal na diabetes incluem a variação da área celular, a diminuição de células endoteliais hexagonais e o aumento da autofluorescência corneal (KEOLEIAN et al., 1992). Em cães diabéticos, encontrou-se polimegatismo e pleomorfismo semelhantes aos encontrados em pacientes humanos diabéticos (YEE et al., 1985). 
Neste sentido, é de grande interesse na pesquisa oftalmológica prever manifestações das alterações oculares que ocorrem na diabetes mellitus.

\subsection{Catarata}

O cristalino (lente) é uma estrutura avascular, transparente, e formada por fibras cristalinianas altamente organizadas, onde os raios luminosos sofrem refração para incidir num ponto específico da retina. $O$ cristalino possui uma série refinada de processos bioquímicos que mantêm sua transparência ao longo de toda vida do animal. A perda de transparência é a mais comum de todas as afecções do cristalino; devido à prevalência de doenças hereditárias nas lentes de cães, a catarata é a afecção intra-ocular mais comum e uma importante causa de perda de visão nessa espécie (DAVIDSON; NELMS, 2007).

A catarata, por simples definição, é a opacificação do cristalino ou de sua cápsula (PLAYTER, 1977; BARNETT, 1985). A transparência da lente é mantida por inúmeros fatores, incluindo uma baixa densidade citoplasmática devido à perda de organelas e do núcleo celular das fibras cristalinianas, flutuações mínimas no índice refrativo do citoplasma, e um arranjo altamente organizado das fibras celulares (BASHER; ROBERTS, 1995; DAVIDSON; NELMS, 2007). O índice refrativo é dependente do peso molecular das cristalinas (proteínas solúveis), da concentração e volume fracional das proteínas intracelulares, e da organização dessas proteínas no citoplasma. Esses fatores são influenciados pela hidratação do citoplasma, força iônica, e outras funções metabólicas específicas da lente (DAVIDSON; NELMS, 2007).

No momento em que a catarata é evidente clinicamente, alterações irreversíveis no metabolismo da lente ocorreram decorrentes de uma série de eventos relacionados ao seu conteúdo protéico, trocas metabólicas, concentrações iônicas e atividade antioxidante (DAVIDSON; NELMS, 2007).

Cataratas estão associadas a um aumento na concentração de proteínas insolúveis de alto peso molecular (albuminóides) e diminuição na concentração relativa das proteínas solúveis (cristalinas) (DAVIDSON; NELMS, 2007). Nas lentes de cães acometidos por catarata ocorre um aumento na proporção relativa das alfa e 
beta L-cristalinas, e uma diminuição das beta $\mathrm{H}$ e gama cristalinas. As sub-unidades das alfa cristalinas também sofrem modificações na sua composição (DANIEL; NOONAN; GELATT, 1984). Williams, Heath e Wallis (2004) salientam que diferenças no estado de oxido-redução intralenticular são particularmente importantes na fisiopatologia da catarata, pois alteram a atividade das alfa cristalinas da lente.

A glutationa (GSH), um tripeptídeo, possui papel fundamental na manutenção da transparência do cristalino. A GSH em seu estado reduzido ocorre em altas concentrações nas lentes normais, mas esses valores diminuem com a formação de vários tipos de cataratas. Inúmeras funções biológicas têm sido propostas para a GSH, como prevenir a formação de agregados de proteínas de alto peso molecular pela manutenção dos grupos $-\mathrm{SH}$ das proteínas no estado reduzido. A GSH também protege os grupos -SH de membrana que são importantes no transporte de cátions e na permeabilidade. O ciclo de oxi-redução da glutationa é intimamente relacionado à detoxificação de $\mathrm{H}_{2} \mathrm{O}_{2}$, normalmente presente no humor aquoso. Lentes com atividade diminuída da glutationa redutase são mais susceptíveis a danos oxidativos (GELATT et al., 1982; REDDY; GIBLIN, 1984; REDDY, 1990; GIBLIN, 2000). Gelatt et al., em 1982, demonstraram a diminuição da glutationa reduzida intracelular em lentes acometidas por catarata em cães das raças Beagle e Schnauzer Miniatura, o que antes só havia sido demonstrado em humanos e ratos.

Além das enzimas antioxidantes (como a glutationa redutase e a superóxido desmutase), pequenas moléculas antioxidantes (vitamina $C$, vitamina $E$, glutationa e carotenóides) compõem as defesas primárias que protegem diretamente as lentes dos danos oxidativos. Os altos níveis de ácido ascórbico no humor aquoso e cristalino têm sido propostos como proteção natural contra a foto-oxidação. Em 1999, Barros et al. reportaram a diminuição dos níveis de ácido ascórbico no humor aquoso e plasma de cães da raça Cocker Spaniel portadores de catarata. Posteriormente, em 2004, Barros et al. comprovaram a diminuição de três importantes enzimas antioxidantes (glutationa peroxidase, catalase e superóxido desmutase) em Poodles com catarata, dando maior suporte à contribuição do stress oxidativo na fisiopatogenia das cataratas em cães.

Os eventos progridem conforme a catarata se torna mais matura; ocorre aumento da atividade de enzimas proteolíticas e hidrolíticas, ruptura da membrana celular (que é associada com dano irreversível), perda de proteínas de baixo peso molecular, e aumento do conteúdo de água. A mudança na pressão coloide- 
osmótica causa aumento da concentração de cátions (aumento da concentração de sódio e diminuição de potássio). A degradação de proteínas em aminoácidos e peptídeos progride e permite a difusão de produtos da proteólise através da lente. $A$ perda de água e nitrogênio pode acarretar o encolhimento da lente observado na catarata hipermatura (DAVIDSON; NELMS, 2007).

A catarata pode ser classificada de diferentes formas; de acordo com a posição anatômica da opacidade, com seu estágio de desenvolvimento, sua etiologia, e também pela idade do animal acometido (PLAYTER, 1977; BARNETT, 1985). Também é correto descrever a catarata como sendo primária ou secundária, sendo que as cataratas secundárias estão associadas a outras afecções do olho, como a atrofia progressiva de retina, displasias retinianas, luxação do cristalino, glaucoma, uveíte, persistência da membrana pupilar, coloboma e persistência da artéria hialóide. As cataratas podem inclusive estar associadas à doenças sistêmicas, como a diabetes mellitus, deficiências nutricionais e uso de fármacos (BARNETT, 1985).

A definição do estágio de desenvolvimento e maturação de uma catarata é importante na determinação de sua progressão e baixa de visão (PLAYTER, 1977). Davidson e Nelms (2007) defendem que de todos os meios de classificação, o estágio de desenvolvimento da catarata é o mais utilizado e o mais útil nas cataratas de cães. Assim, as cataratas são classificadas como incipientes (pequenos vacúolos e áreas isoladas de acúmulo de fluídos acometendo principalmente o córtex da lente, que usualmente são negligenciados pelos proprietários), imaturas (aumento do tamanho da lente pela entrada de água, e áreas de transparência intercaladas com opacidades, que ainda permitem algum grau de visão), maturas (opacidade total da lente, nem sempre uniforme, levando à cegueira) e hipermaturas (liquefação das fibras e ruptura das paredes celulares permitindo a difusão de água e produtos solúveis através da cápsula intacta ou afilada, o que leva à diminuição do tamanho da lente e "enrugamento" da cápsula) (PLAYTER, 1977).

Inúmeras raças de cães são afetadas por cataratas primárias hereditárias e a aparência dessas cataratas é específica de cada raça. Entretanto, em certas raças, diferentes tipos de catarata podem ocorrer (BARNETT, 1985). As cataratas hereditárias tipicamente ocorrem ao redor dos 3 meses de idade e progridem para opacidade total da lente entre 1 e 2 anos de idade. Nos cães da raça Poodle Standard a catarata hereditária é descrita como bilateral, simétrica e progressiva, 
acometendo cães de poucos meses de idade. A opacidade se desenvolve em toda a lente, mas com uma porção central mais densa. A catarata se torna total entre 1 e 3 anos de idade, quando a visão é nitidamente afetada. A transmissão hereditária provavelmente é devida a um gene simples, autossômico e recessivo (BARNETT, 1985). Em 1972, Rubin e Flowers descreveram uma família de Poodle Standard acometida hereditariamente por catarata. Essa catarata primeiro se desenvolvia na região equatorial em animais bastante jovens, ainda filhotes. Posteriormente a região pupilar também era tomada pela catarata, ocorrendo baixa de visão evidente entre 6 e 18 meses de idade. A transmissão foi determinada como autossômica recessiva.

Em estudo para determinar a prevalência da catarata canina, Williams, Heath e Wallis (2004) examinaram uma população de cerca de 2000 cães em diferentes instituições na Inglaterra. A média \pm desvio-padrão de idade em que $50 \%$ dessa população se encontrava acometida por catarata era de $9,4 \pm 3,3$ anos. A prevalência de catarata aumentava com o avançar da idade, sendo que aos 13,5 anos nenhum dos cães dessa população se encontravam livres de algum grau de opacidade na lente. Essas opacidades raramente eram maturas, e não necessariamente iriam progredir para este estágio. Houve uma correlação positiva entre a idade de desenvolvimento da catarata e a longevidade em cada raça. Essas cataratas relacionadas a idades avançadas e envelhecimento parecem compartilhar uma fisiopatologia semelhante entre as diferentes espécies.

\subsection{Catarata diabética}

Sem dúvida a manifestação ocular mais comum da diabetes mellitus (DM) em cães é a formação de catarata. As afecções de retina em cães diabéticos são menos importantes e usualmente limitadas à formação de microaneurismas devido à perda de pericitos das paredes dos capilares retinianos, em conjunto com outras alterações morfológicas dos vasos retinianos. A maioria dos cães diabéticos irá desenvolver catarata, e muitos irão progredir rapidamente para a cegueira. A remoção da catarata por meio da faco-emulsificação oferece a melhor chance de restauração da visão (WYMAN et al., 1988; BASHER; ROBERTS, 1995; BEAM, CORREA; DAVIDSON, 1999). 
Cães e seres humanos desenvolvem alterações morfológicas e lesões muito semelhantes na formação das cataratas diabéticas. Além de sua susceptibilidade única ao desenvolvimento de catarata secundária à DM, em comparação a seres humanos e gatos, os cães também desenvolvem rapidamente cataratas hipergalactosêmicas experimentais. Assim, cães são modelos de excelência para estudo da fisiopatogenia e manejos das lesões diabéticas (WYMAN et al.,1988; BEAM; CORREA; DAVIDSON, 1999).

As cataratas associadas à DM e galactosemia ocorrem por um mecanismo osmótico comum. Esse mecanismo é desencadeado pelo excesso de sorbitol e galactitol intracelular, que gera um efeito hiperosmótico levando ao edema celular. Esse edema é acompanhado por alterações nos níveis de eletrólitos da lente, aumento de permeabilidade da membrana, e a formação de vacúolos que causam opacidades corticais reversíveis. Conforme a entrada de água na lente progride outros eventos ocorrem, como ruptura das fibras lenticulares e formação de catarata nuclear irreversível. Esses metabólitos (sorbitol) resultam da redução da glicose em galactose catalisada pela aldose redutase. A progressão dessas cataratas é diretamente proporcional ao nível de atividade da aldose redutase nas lentes (WYMAN et al.,1988; SATO et al., 1991).

Conforme as células epiteliais do cristalino transformam-se em fibras lenticulares, as organelas intracelulares são perdidas, incluindo a mitocôndria. A glicólise anaeróbia provém mais de $70 \%$ da energia da lente e a via metabólica do sorbitol é responsável por apenas $5 \%$ do seu metabolismo. A hiperglicemia faz com que maiores quantidades de glicose entrem nessa via e os metabólitos resultantes acumulem na lente. A embebição da lente por água causa modificações em sua arquitetura que rapidamente levam à opacificação. A formação da catarata inicia-se nas células epiteliais devido à produção do sorbitol nesta camada. Conforme a lente começa a se tornar edematosa em resposta ao efeito osmótico do acúmulo de sorbitol, as alterações da permeabilidade de membrana resultam em diminuição da relação potássio:sódio por meio da entrada de sódio nas células por difusão. As concentrações lenticulares de glutationa, mioinositol, adenosina trifosfato (ATP) e aminoácidos livres começam a diminuir, e assim, a síntese de proteína lenticular. Alterações morfológicas acompanham essas modificações metabólicas (BASHER; ROBERTS, 1995). 
Há evidências que os poliols (sorbitol) interagem diretamente com as proteínas lenticulares por um processo não-enzimático de glicosilação (ligação covalente). Glicosilação envolve a ligação de glicose a resíduos de aminoácidos nas proteínas lenticulares (cristalinas) causando agregação protéica permanente e comprometendo a integridade da membrana celular. A glicosilação também pode interferir na atividade de enzimas como a glutationa redutase (BASHER; ROBERTS, 1995).

A lente é protegida do dano oxidativo por uma série de moléculas localizadas nas membranas e citosol, que incluem a vitamina $\mathrm{E}$, a glutationa reduzida, o ácido ascórbico, a superóxido desmutase, catalase, taurina e beta-caroteno. As lentes de diabéticos estão sujeitas a maior stress oxidativo, que causa danos à membrana lenticular (BASHER; ROBERTS, 1995). Além da diminuição de importantes antioxidantes no humor aquoso de cães portadores de catarata (BARROS et al., 1999; BARROS et al., 2004), Barros et al., em 2002, comprovaram a diminuição dos níveis de ácido ascórbico no plasma e humor aquoso de cães acometidos por catarata diabética.

Provavelmente os mecanismos patológicos da catarata diabética são uma combinação de alterações na permeabilidade e função da membrana celular, glicosilação, efeitos osmóticos e dano oxidativo (BASHER; ROBERTS, 1995).

A formação da catarata diabética nos cães progride de uma acentuação inicial das suturas da lente para a formação de vacúolos corticais equatoriais e, eventualmente, densas cataratas corticais (SATO et al., 1991). Cães e seres humanos usualmente desenvolvem catarata diabética sem envolvimento inicial da região nuclear (WYMAN et al.,1988).

A incidência de catarata em cães diabéticos é muito alta, sendo que cerca de 66 a $68 \%$ dos cães diabéticos apresentam-se acometidos (BASHER; ROBERTS, 1995; BEAM; CORREA; DAVIDSON, 1999). Existe uma variação dependente da raça, sendo que as raças braquicefálicas e os Shar Peis desenvolvem mais rapidamente catarata (cerca de 10 dias após o diagnóstico da DM). A média estimada de tempo entre o diagnóstico da DM e a formação de catarata é de 170 dias para todas as raças de cães (BEAM; CORREA; DAVIDSON, 1999). 


\subsection{Uveíte faco-induzida}

O sistema imunológico não é exposto às proteínas lenticulares durante o desenvolvimento embrionário. Nos olhos há ausência de drenagem linfática; o processamento antigênico deve ocorrer em um sítio distante, visto que linfócitos $B$ e T não são nativos nos olhos. Essas células são atraídas para o olho pela presença de antígeno, multiplicam-se para formar células de memória, e congregam-se na úvea e limbo que atuam como nódulos linfáticos acessórios. A liberação de proteínas lenticulares irá causar sensibilização das células $B$ e $T$ e a subseqüente exposição resulta em uma resposta inflamatória imuno-mediada, a uveíte faco-induzida (PAULSEN et al., 1986). No desenvolvimento da catarata as proteínas lenticulares (beta cristalinas e albuminas) podem sofrer hidrólise quando $\circ \mathrm{pH}$ se acidifica. A cápsula do cristalino permite a passagem de pequenas substâncias de baixo peso molecular, como a água, alcoóis e alguns eletrólitos, mas a cápsula normalmente é impermeável à albumina e globulinas (RUBIN; GELATT, 1968). A cápsula lenticular intacta parece ser uma barreira formidável para proteínas e anticorpos, mas na catarata avançada sua permeabilidade pode encontrar-se aumentada (GELLAT, 1975).

A uveíte faco-induzida (UFI) é a resposta inflamatória da úvea contra proteínas lenticulares (WOERDT, 2000). Wilcock e Peiffer (1987) salientaram a existência de distintos tipos de uveíte faco-induzida e a dificuldade em diferenciá-las e classificá-las. Na literatura veterinária, a UFI é dividida em duas síndromes denominadas "uveíte facoclástica" e "uveíte facolítica" (WOERDT, 2000).

A uveíte facoclástica ocorre quando há liberação de proteína lenticular após ruptura de cápsula espontânea ou traumática. A causa mais comum desta afecção é lesão por arranhadura de gato. As lesões histopatológicas mostram ruptura capsular com neutrofilia intra-lenticular. Ocorre inflamação peri-lenticular que varia de supurativa à linfocítica e uma iridociclite linfocítica-plasmocítica se instala (WOERDT, 2000).

A uveíte facolítica é uma uveíte anterior linfocítica-plasmocítica que pode ocorrer secundariamente à liberação de proteínas lenticulares através da cápsula lenticular intacta. Histopatologicamente se observa uma iridociclite não-supurativa com infiltrados de linfócitos e plasmócitos no estroma uveal. Na uveíte facolítica, as 
proteínas lenticulares são liberadas para a câmara anterior e expostas ao sistema imune. Os linfócitos $\mathrm{T}$ preservam certa tolerância a pequenas quantidades de proteínas lenticulares, principalmente às alfa cristalinas em relação às beta e gama cristalinas. As proteínas lenticulares liberadas por uma catarata hipermatura são fagocitadas por macrófagos sem ativação importante de células T. No caso de ruptura lenticular, os macrófagos e células $T$ ligadas à classe 2 de histocompatibilidade podem reagir às inúmeras cristalinas e proteínas de membrana. Isto pode resultar em resposta inflamatória severa vista na endoftalmite facoanafilática (WOERDT, 2000).

As proteínas lenticulares solúveis em mamíferos são divididas em três classes principais: as $\alpha, \beta$ e $\gamma$-cristalinas. Essas proteínas já foram encontradas em tecidos não lenticulares, como retina, cérebro e testículos. Limitada tolerância imunológica de células $\mathrm{T}$ é mantida pelo escape de pequenas quantidades de proteínas lenticulares através da cápsula intacta. Denis et al., em 2003, encontraram associação negativa tanto da fase de desenvolvimento quanto da presença de catarata com a presença de anticorpos séricos anti-cristalinas; além de associação negativa entre os títulos de anticorpos e severidade da UFI. Alterações nos epítopos das cristalinas durante a maturação da catarata, afinidade dos anticorpos com a maturação, e desvio da resposta imune associada à câmara anterior podem explicar essas correlações.

A uveíte facolítica é mais comumente associada com a presença de catarata hipermatura (RUBIN; GELATT, 1968; GELATT, 1975; PLAYTER, 1977; WILCOCK; PEIFFER, 1987; WOERDT, 2000; DENIS et al., 2003), mas tem sido observada clinicamente em associação com cataratas imatura, matura e intumescente (WOERDT, NASISSE; DAVIDSON, 1992; WOERDT, 2000; DENIS et al., 2003). aumento de permeabilidade da barreira hemato-aquosa e consequente aumento de proteínas e células no humor aquoso ocorre nas uveítes de diferentes etiologias, e reflete a severidade do processo inflamatório. Em 1995, Krohne et al. confirmaram essa quebra de barreira hemato-aquosa em cães com cataratas nas diferentes fases de desenvolvimento.

A catarata hipermatura pode sofrer reabsorção pela liquefação do conteúdo lenticular. Nesta fase a permeabilidade de sua cápsula pode encontrar-se aumentada, situação que facilita o escape de fluidos e proteínas degradadas. As proteínas do córtex lenticular parecem ser mais susceptíveis à degradação; o 
núcleo, que consiste de albuminóides insolúveis, pode resistir à desintegração (RUBIN; GELATT, 1968; GELATT, 1975).

A maioria dos casos de reabsorção da lente com catarata ocorre em cães jovens, com menos de 6 anos de idade. Cães da raça Poodle e Cocker Spaniel sofrem essa reabsorção mais jovens e com uma prevalência maior que cães de outras raças (RUBIN; GELATT, 1968; WOERDT; NASISSE; DAVIDSON, 1992). Woerdt, Nasisse e Davidson (1992) observaram que 72\% das cataratas associadas à UFI tinham evidência visível de reabsorção. Se o cão possui mais de 4 ou 5 anos de idade, o núcleo pode resistir à degradação e persistir. Nos cães, a uveíte facoinduzida associada com reabsorção espontânea da catarata é usualmente de intensidade leve a moderada (GELLAT, 1975; WOERDT; NASISSE; DAVIDSON, 1992).

O córtex lenticular liquefeito usualmente provoca uma resposta macrofágica ao escapar para as câmaras anterior e posterior. Esses macrófagos contendo material cortical fagocitado podem ser carreados para o ângulo de drenagem e ficar contidos no ângulo e espaço trabecular, levando a uma obstrução aguda do fluxo de humor aquoso e glaucoma facolítico (PLAYTER, 1977). Em levantamento contendo 1.592.831 cães atendidos durante um período de 39 anos, Gelatt e MacKay (2004) encontraram o glaucoma secundário à formação de catarata como sendo o mais prevalente, totalizando $19,3 \%$ de todos os glaucomas secundários. De 40.979 cães que apresentaram catarata, 7.890 cães desenvolveram glaucoma secundariamente. A idade dos pacientes com catarata e glaucoma secundário pode variar, mas os animais mais velhos parecem ser mais comumente afetados. Os glaucomas secundários ocorrem mais freqüentemente em cães da raça Poodle e Cocker. A alta prevalência de formação de catarata e glaucoma provavelmente está relacionada com a alta prevalência de cataratas primárias e secundárias no cão. Os resultados de estudos têm indicado que a formação de catarata com UFI associada é uma causa freqüente de glaucoma secundário, atingindo cerca de 7,9\% dos olhos e 10,6\% dos cães acometidos por UFI (RUBIN; GELATT, 1968; WOERDT; NASISSE; DAVIDSON, 1992; WOERDT, 2000; GELATT; MACKAY, 2004).

Os cães da raça Poodle e Cocker Spaniel são mais comumente afetados pela uveíte faco-induzida, o que reflete a alta incidência de catarata nessas raças (RUBIN; GELATT, 1968; GELATT, 1975; PAULSEN ET AL., 1986; WOERDT, 2000). A idade em que a UFI se instala é variável entre as raças, a média de idade de 
Poodles afetados (9,0 anos) é significativamente maior que de Cockers Spaniel afetados (7,0 anos) (WOERDT; NASISSE; DAVIDSON, 1992). Existe controvérsia na literatura quanto à relação entre idade e severidade da UFI (WOERDT, 2000). Woerdt, Nasisse e Davidson, em 1992, observaram que a UFI se desenvolve rapidamente após a formação da catarata e é menos responsiva a tratamento em cães jovens. Paulsen et al., em 1986, encontraram evidências de UFI em $71 \%$ dos cães com catarata, sendo que as cataratas congênitas e diabéticas apresentaram maior acometimento ( $86 \%$ e 92\%, respectivamente). Provavelmente cataratas diabéticas se encontram particularmente afetadas por sua rápida progressão de desenvolvimento (BASHER; ROBERTS, 1995).

Paulsen et al., em 1986, também estabeleceram que o sucesso da cirurgia de extração da catarata por meio de facectomia extracapsular é muito maior em cães sem UFI (95\%) do que em cães que apresentam UFI (50\%). Woerdt, Nasisse e Davidson, em 1992, encontraram resultados semelhantes, com taxas de sucesso de $71 \%$ contra 39\% nos cães acometidos por UFI. Devido a UFI ser mais prevalente em cães com catarata hipermatura, é preferível a realização da cirurgia de extração quando a catarata encontra-se imatura ou matura (WOERDT, 2000).

\subsection{Pressão intra-ocular}

Inúmeros estudos foram dirigidos para determinar a pressão intra-ocular (PIO) em cães. A tonometria é a mensuração indireta ou estimação da pressão intra-ocular (PIO) ou tensão (OLLIVIER; PLUMMER; BARRIE, 2007). As mensurações tonométricas podem variar pela $\mathrm{PIO}$, tipo de equipamento, experiência do examinador e comportamento do animal (GELATT; MACKAY, 1998). Similarmente, a PIO pode variar conforme inúmeros fatores.

A pressão intra-ocular média em cães foi estabelecida com o uso de inúmeros tonômetros. Em 1951, Magrane descreveu a mensuração da PIO em cães por meio de identação da córnea com o uso do tonômetro de Schiötz. Heywood (1971), utilizando o mesmo método tonométrico, encontrou valores de 16 a $31 \mathrm{mmHg}$, com média de $19 \mathrm{mmHg}$, em cães da raça Beagle. Gelatt e MacKay, em 1998, estabeleceram a pressão intra-ocular com o uso de 4 diferentes tonômetros; 
MacKay-Marg, TonoPen-XL, MMAC II e Mentor pneumatográfico. As PIO médias aferidas foram diferentes entre os instrumentos, variando de uma média mais baixa pelo MMAC-II (15,7 mmHg), uma concordância estatística entre o MacKay-Marg e o TonoPen-XL (18,8 e 19,2 mmHg), e um valor mais alto pelo Mentor (22,9 mmHg).

A PIO sofre variações diurnas de cerca de 2 a $4 \mathrm{mmHg}$ nos cães, sendo maior pela manhã. Outros fatores que podem influenciar a PIO incluem a idade, 0 sexo, a raça e alterações patológicas (GELATT; MACKAY, 1998).

Em seres humanos, a PIO usualmente aumenta com a idade nas populações do Ocidente, entretanto decresce nas populações do Oriente (KLEIN; KLEIN; MOSS, 1984; SHIOSE, 1984; COSTAGLIOLA; TRAPANESE; PAGANO, 1990; QURESHI, 1997; LEE et al., 2002; NOMURA et al., 2002; ROCHTCHINA; MITCHELL; WANG, 2002; KASHIWAGI; SHIBUYA; TSUKAHARA, 2005; GONZÁLEZ-MÉIJOME et al., 2006). Em cães, um declínio gradual na PIO de cerca de 2 a $4 \mathrm{mmHg}$ foi demonstrado entre animais jovens (até 2 anos de idade) e mais velhos (mais de 6 anos de idade) (GELATT; MACKAY, 1998).

Mulheres tendem a ter PIO mais elevadas que homens, mas as causas para esta diferença ainda não foram bem estabelecidas. Um possível fator atribuído é a menopausa (KLEIN; KLEIN; MOSS, 1984; COSTAGLIOLA; TRAPANESE; PAGANO, 1990; QURESHI, 1997; DOHADWALA; MUNGER; DAMJI, 1998). A PIO em cães não sofre modificações decorrentes do sexo e da raça (GELATT; MACKAY, 1998).

A PIO também é associada com importantes características sistêmicas e oculares. Em humanos existe associação entre PIO e pressões arteriais sistólica e diastólica, índice de massa corporal, hematócrito, glicose sérica, níveis de colesterol, pulso e esclerose nuclear (KLEIN; KLEIN; MOSS, 1984; SHIOSE, 1984; SHIOSE, 1990; KLEIN; KLEIN; LINTON, 1992; LEE et al., 2002; PERLMAN et al., 2007).

Pessoas diabéticas tendem a ter PIO mais elevada que as não diabéticas. A ausência de catarata também é associada com PIO mais elevadas (KLEIN; KLEIN; MOSS, 1984; KEOLEIAN et al., 1992). Toris et al., em 2006, comprovaram a redução na taxa de produção do humor aquoso em cães galactosêmicos, o que já havia sido comprovado em pacientes humanos com diabetes insulina-dependente. Esses achados vão em desencontro com os dados relativos a PIO aumentada em pacientes humanos diabéticos. Entretanto, Toris et al. (2006) não encontraram diferenças na PIO em relação a cães normais, o que pode ser explicado por 
modificações compensatórias nos tecidos responsáveis pela drenagem do humor aquoso.

Diminuição da PIO é um achado clínico comum nas uveítes anteriores de cães. A redução da PIO é associada com a liberação de prostaglandinas, e com o aumento da drenagem uveoescleral de humor aquoso através do estroma e musculatura do corpo ciliar. Alterações na velocidade de produção do humor aquoso nas uveítes anteriores em cães ainda não foram comprovadas, mas em outras espécies (como coelhos e o homem) a taxa de formação do humor aquoso é usualmente normal (LEASURE; GELATT; MACKAY, 2001). As uveítes em cães usualmente são associadas com uma PIO igual ou menor a $12 \mathrm{mmHg}$ (BASHER; ROBERTS, 1995).

Uveítes faco-induzidas de grau leve podem passar despercebidas caso a tonometria não seja realizada em animais com catarata, especialmente aqueles que não exibem miose (HAKANSON; FORRESTER, 1990).

\subsection{Paquimetria}

A espessura corneal é um indicador sensível do estado de deturgescência da córnea e de inúmeras afecções que podem acometer o segmento anterior do olho ou a córnea em particular (OLLIVIER; PLUMMER; BARRIE, 2007). A paquimetria ultra-sônica é o método in vivo mais acurado de mensuração da espessura corneal, na qual o tempo requerido para a energia ultra-sônica atravessar a córnea é utilizado para calcular sua espessura (GILGER et al., 1991).

O estroma é responsável por cerca de $90 \%$ da espessura corneal e sua hidratação é controlada principalmente pela ação da bomba de $\mathrm{Na}^{+} / \mathrm{K}^{+}$ATPase encontrada nas células endoteliais. Quando há uma disfunção do endotélio corneal em retirar o fluido que adentra o estroma vindo do humor aquoso, pode se desenvolver o edema estromal, o que aumenta sua espessura (MAURICE, 1972; MACDONALD; GEROSKI; EDELHAUSER, 1987; HERSE, 1990).

A capacidade do epitélio corneal de ser uma barreira impermeável à entrada de fluido da lágrima também é um mecanismo pelo qual a espessura corneal é mantida. Edema estromal também pode ocorrer se a glicose nas células epiteliais é 
metabolizada anaerobicamente, como em condições de hipóxia. O ácido lático produzido causa uma mudança na osmolaridade celular, o que permite a entrada de fluidos no estroma através do epitélio (CISARIK-FREDENBURG, 2001).

A transparência da córnea é dependente da manutenção de um grau de relativa desidratação do estroma altamente hidrofílico (HERSE, 1990). Danos ao endotélio rompem o bombeamento ativo de fluido para fora da córnea, permitindo embebição aquosa e edema corneal. A mensuração da espessura corneal é um método útil para avaliação da função das células endoteliais e da integridade epitelial. A paquimetria e a hidratação corneal são linearmente correlacionadas (GILGER et al., 1991).

A espessura da córnea central em cães adultos saudáveis, mensurada por meio de paquimetria ultra-sônica, varia de 409 a $743 \mu \mathrm{m}$, com média de $562 \pm 6,2$ $\mu \mathrm{m}$ (GILGER et al., 1991). Montiani-Ferreira e Petersen-Jones (2003) estudaram o desenvolvimento da espessura corneal pós natal em cães e reconheceram o seu aumento fisiológico até as 30 semanas de idade.

A densidade celular média do endotélio corneal em cães é de 2.335 e $3.175 \pm$ 776 células $/ \mathrm{mm}^{2}$ segundo diferentes autores (GWIN et al., 1982; KAFARNIK; FRITSCHE; REESE, 2007). O endotélio corneal de cães adultos jovens pode sofrer regeneração parcial por meio de mitose das células endoteliais, o que não ocorre em seres humanos e gatos, nos quais a recuperação desta camada se dá por aumento e migração das células remanescentes apenas (BEFANIS; PEIFFER; BROWN, 1981).

Os valores da paquimetria em cães adultos aumentam significativamente com o aumento da idade e do peso (GWIN et al., 1982; GILGER et al., 1991). Da mesma forma, cães mais velhos exibem diminuição da densidade celular do endotélio, além de aumento do grau de pleomorfismo (variações no formato das células) e polimegatismo (aumento do tamanho celular). Outros fatores como variações no número e arquitetura das fibrilas de colágeno e espessamento da membrana de Descemet podem contribuir para o aumento da espessura corneal (GWIN et al., 1982).

Dentre os fatores que alteram os valores da paquimetria em cães saudáveis também estão o sexo, sendo que fêmeas apresentam córneas mais afiladas que machos (GILGER et al., 1991), e a raça, o que provavelmente está relacionado ao peso (MONTIANI-FERREIRA; PETERSEN-JONES, 2003). 
Animais diabéticos apresentam córneas mais espessas (cães e coelhos) assim como os seres humanos (BUSTED; OLSEN; SCHMITZ, 1981; HERSE, 1990; WESTON et al., 1995; MACNAMARA et al., 1998; ROSENBERG et al., 2000; LEE et al., 2006; LYNCH; BRINKIS, 2006). Pierro, Brancato e Zaganelli (1993) não encontraram correlação entre os valores séricos de glicose, a duração da diabetes e os valores da paquimetria corneana.O aumento da paquimetria em humanos diabéticos já foi relacionado, por outros pesquisadores, com o tempo de duração da doença (BUSTED; OLSEN; SCHMITZ, 1981; LEE et al., 2006). Em coelhos experimentalmente induzidos à diabetes, não se associou variações diurnas dos valores de paquimetria com as variações da hiperglicemia (HERSE, 1990).

O local primário das alterações corneais na diabetes provavelmente se encontra fora do estroma, visto que os pesquisadores não demonstraram aumento da pressão osmótica estromal relacionada à doença (HERSE, 1990), assim como não demonstraram presença da aldose redutase nessa camada (CISARIKFREDENBURG, 2001). De fato, o estroma corneal se encontra mais hidratado na diabetes (HERSE, 1990).

O epitélio corneal pode apresentar uma variedade de alterações decorrentes da doença, que incluem a diminuição do número de células, edema celular e alterações da membrana basal, afetando a aderência epitelial e reepitelização (SWANN, 1999). Gekka et al. (2004) comprovaram que a função da barreira epitelial corneana é prejudicada nos pacientes diabéticos.

O endotélio corneal em pacientes diabéticos é considerado um tecido em estresse metabólico constante, com conseqüente aumento de sua vulnerabilidade, especialmente nos casos de insulto externo (ROSZKOWSKA et al., 1999). Barros et al. (2002) encontraram diminuição da concentração de ácido ascórbico no humor aquoso e plasma de cães portadores de catarata diabética, demonstrando a susceptibilidade dos tecidos oculares ao stress oxidativo na DM. Goebbels e Spitznas (1991) pesquisaram o reestabelecimento da barreira endotelial após facoemulsificação em pacientes diabéticos e não diabéticos, e estabeleceram que a função da barreira endotelial é mais tardiamente reestabelecida em pacientes diabéticos. As alterações estruturais e funcionais do endotélio corneano na diabetes incluem a variação da área celular, a diminuição de células endoteliais hexagonais e o aumento da autofluorescência corneal (KEOLEIAN et al., 1992). Em cães 
diabéticos, encontrou-se polimegatismo e pleomorfismo semelhantes aos encontrados em pacientes humanos diabéticos (YEE et al., 1985).

Inúmeros estudos vêm comprovando que não há quebra da barreira endotelial na doença (WESTON et al., 1995; MACNAMARA et al., 1998; ROSENBERG et al., 2000). Entretanto, os achados de diminuição da atividade das bombas de $\mathrm{Na}^{+} / \mathrm{K}^{+}$ ATPase presentes no endotélio revela que este é o principal responsável pela perda do controle da hidratação corneal na diabetes mellitus (HERSE, 1990).

Em 1987, Macdonald, Geroski e Edealhauser correlacionaram o aumento da permeabilidade endotelial, diminuição da atividade de bombeamento do endotélio e aumento da espessura corneal como efeito da inflamação ocular. Barros et al. (1999; 2002; 2004) comprovaram a diminuição de importantes anti-oxidantes no humor aquoso de cães portadores de cataratas; e Ishimoto et al. (1996) notificaram que em uveíte auto-imunes, os radicais livres gerados no segmento anterior do olho causam importantes lesões teciduais, inclusive na córnea. Os danos pelo stress oxidativo e radicais livres podem explicar parte das alterações corneais encontradas em olhos de cães acometidos por catarata e UFI.

A córnea retorna à sua espessura normal em paralelo com o desaparecimento dos outros sinais da inflamação ocular (OLSEN, 1981), apesar da diminuição na densidade celular endotelial. Em seres humanos, ocorre edema corneal permanente apenas se a densidade for reduzida a menos de 500 a 1.040 células/mm2 (GILGER et al., 1991). 


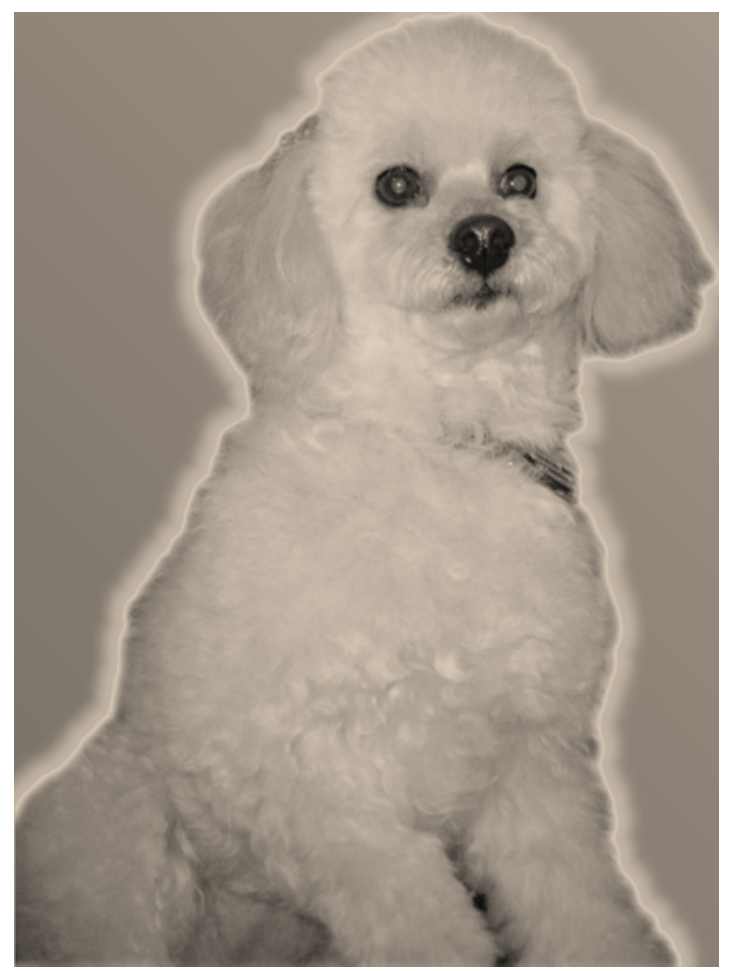




\section{OBJETIVO}

Objetivou-se determinar a pressão intra-ocular, por meio de tonômetro de aplanação, e paquimetria corneal, usando paquímetro ultra-sônico, nos diferentes estágios de desenvolvimento das cataratas não diabéticas e diabéticas em cães da raça Poodle. 


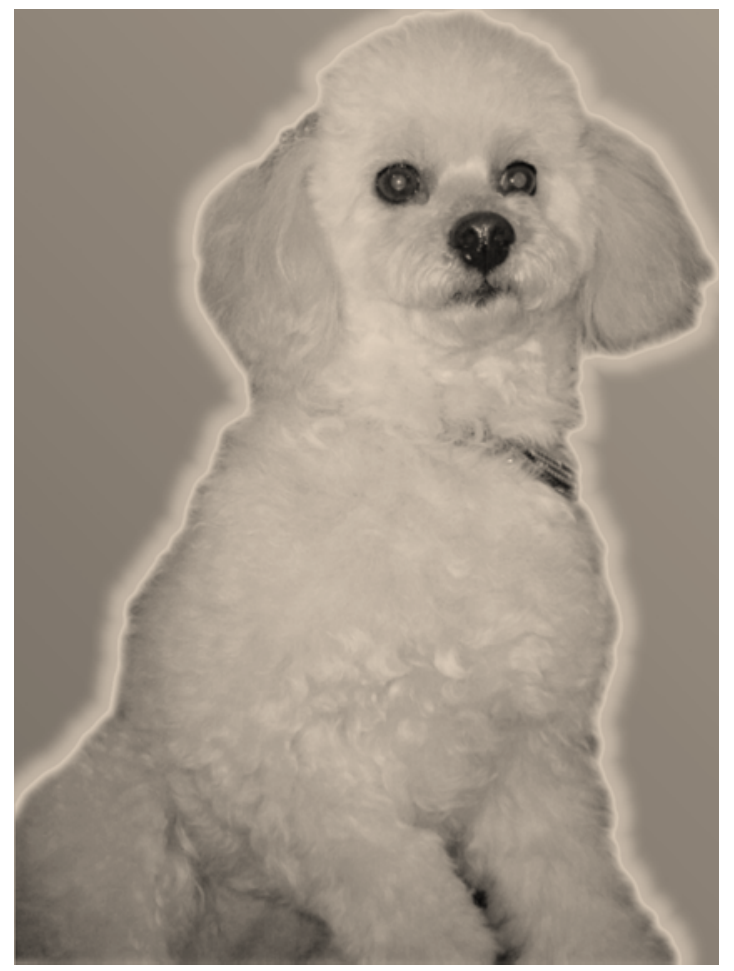

MATERIAL E MÉTODO 


\section{MATERIAL E MÉTODO}

\subsection{Animais}

Foram selecionados 122 cães adultos da raça Poodle que deram entrada no Serviço de Oftalmologia do Hospital Veterinário da Universidade de São Paulo e que inicialmente foram avaliados por exame oftalmológico completo. Os cães sem alterações oculares de qualquer natureza formaram o grupo controle. Os animais diabéticos tiveram acompanhamento clínico da diabetes mellitus pelo Serviço de Atendimento Clínico do Hospital Veterinário da Universidade de São Paulo. Cães que possuíam alterações oculares, tais como ceratoconjuntivite seca e glaucoma; ou doenças sistêmicas que possuem manifestações oculares, como insuficiência renal e infecções de diversas etiologias, não foram incluídos no projeto, e estes foram considerados fatores de exclusão. Todos os animais sob medicação antiinflamatória tópica ou sistêmica, corticóides ou antiinflamatórios não esteroidais, foram excluídos do estudo.

Este estudo foi aprovado pela Comissão de Bioética da Faculdade de Medicina Veterinária e Zootecnia da Universidade de São Paulo e pela Comissão de Ética do Hospital Veterinário da Universidade de São Paulo, tendo seguido suas normas.

\subsection{Método}

As informações referentes aos pacientes coletadas foram: idade, sexo, peso, tempo de desenvolvimento da catarata (tempo de leucocoria) e tempo de desenvolvimento da diabetes (informado pelo proprietário ou pela data do diagnóstico). As cataratas foram consideradas secundárias a DM baseado em histórico de rápida progressão de opacidade, usualmente bilateral e com aspecto entumescente. Ao exame oftalmológico, os cães que apresentavam catarata tiveram seu estágio de desenvolvimento classificado em cada lente segundo o modelo de 
classificação proposto por Playter em 1977. Todos os cães foram submetidos à dilatação pupilar por meio de colírio midriático de curta duração (Mydriacyl 1\% Alcon Labs). Os sinais oculares atribuídos às uveítes secundárias à formação de catarata foram: congestão dos vasos episclerais e midríase incompleta após 30 minutos da instilação do colírio midriático.

\subsubsection{Mensuração da pressão intra-ocular}

A tensão intra-ocular foi aferida no centro corneal por meio de tonometria de aplanação com o uso do TonoPen-XL ${ }^{\circledR}$ (Figuras 1 e 2), após anestesia tópica utilizando colírio de Cloridrato de Proximetacaína a 0,5\% (Anestalcon ${ }^{\circledR}$, Alcon). Os animais tiveram mínima contenção da cabeça possível, e nenhum foi submetido a tranqüilizantes ou anestésicos sistêmicos. As aferições foram realizadas aproximadamente no mesmo horário, sempre pela manhã. Foram consideradas as médias obtidas de 4 mensurações consecutivas cujas variações foram menores que $5 \%$ e os valores foram obtidos em $\mathrm{mmHg}$.

\subsubsection{Mensuração da espessura corneal}

A paquimetria corneal foi realizada por meio de anestesia tópica e contenção física anteriormente descritas. Utilizou-se um paquímetro PachPen $®$ (Accutome UltraSound), que realiza aferição ultra-sônica (figuras 3 e 4). Os valores foram mensurados no centro corneal e dados em mícrons. A probe deste paquímetro emite ondas de intensidade de 10,5 MHz a uma velocidade de $1.640 \mathrm{~m} / \mathrm{s}$. Utilizou-se a média de 10 aferições consecutivas, sendo que cada aferição é resultado de 20 sinais individuais. 


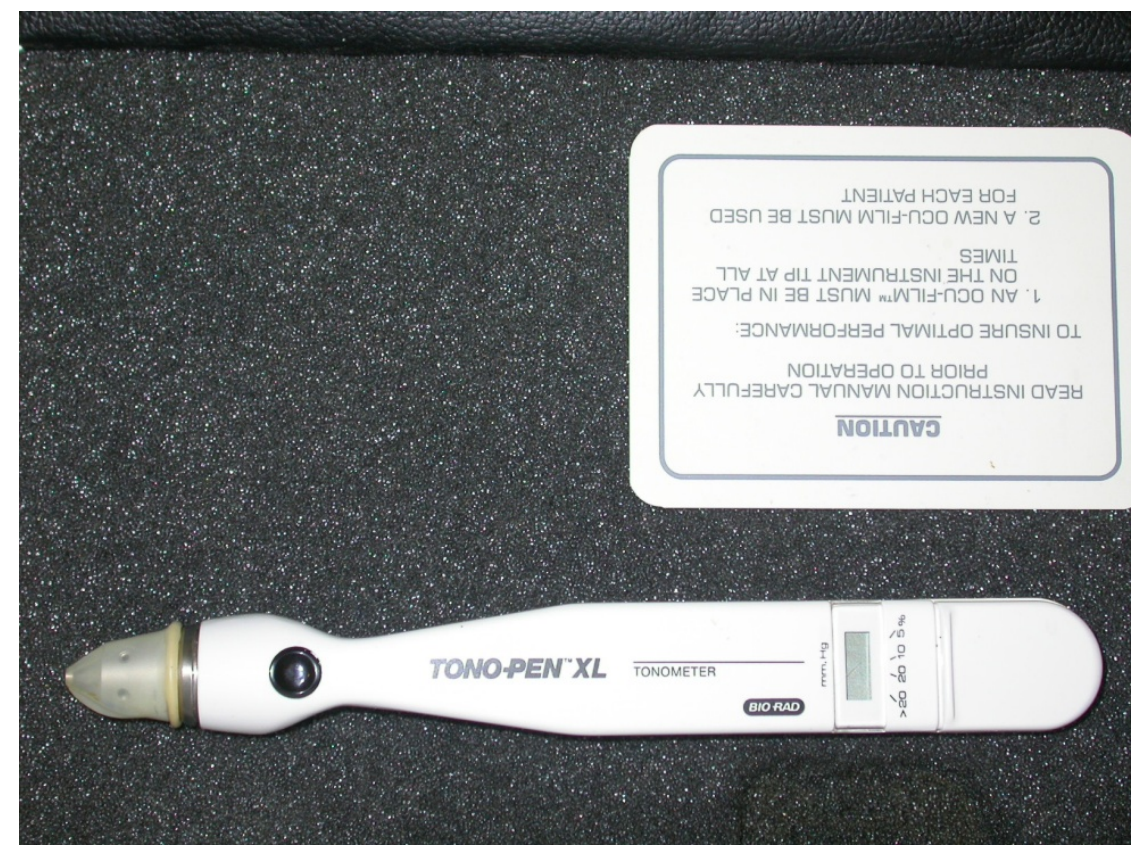

FONTE: Laboratório de Investigação em Oftalmologia Comparada

Figura 1 - Representação fotográfica do tonômetro TonoPen - XL® utilizado neste estudo

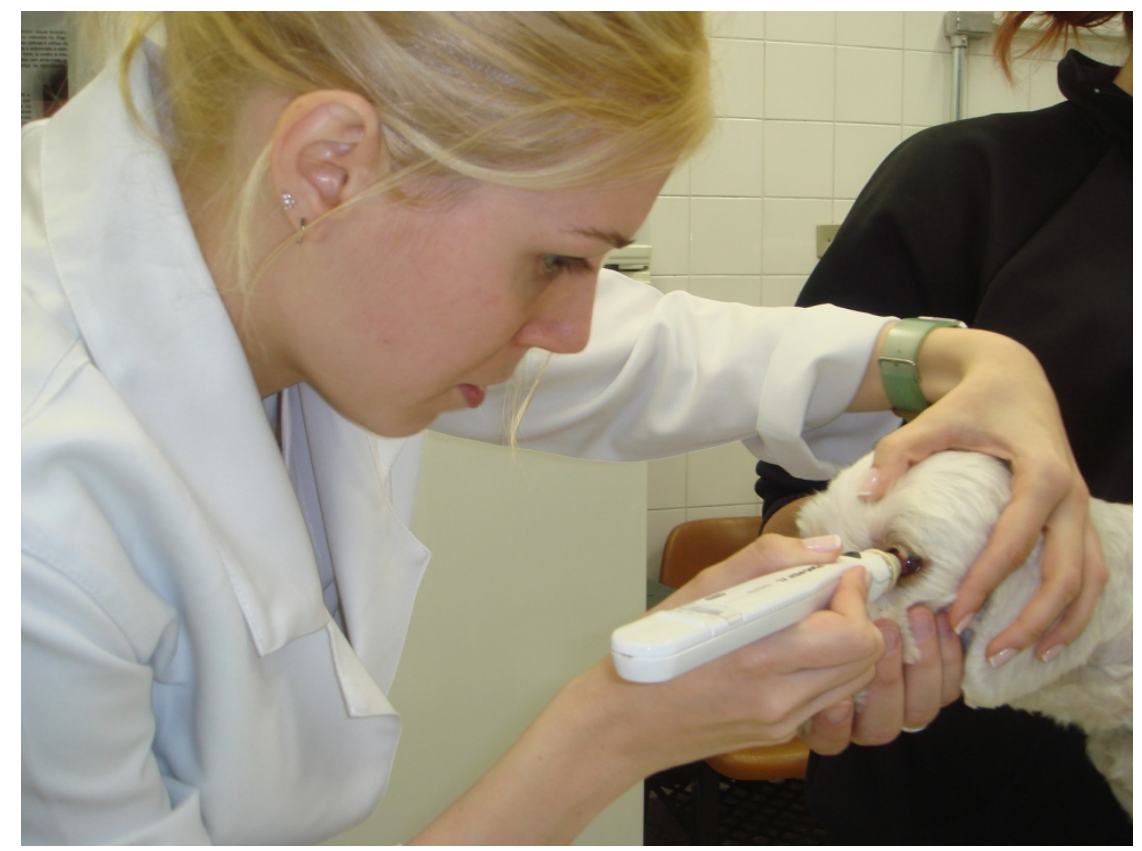

FONTE: Laboratório de Investigação em Oftalmologia Comparada

Figura 2 - Representação fotográfica da realização da tonometria por meio do tonômetro de aplanação TonoPen - XL® em cão da raça Poodle 


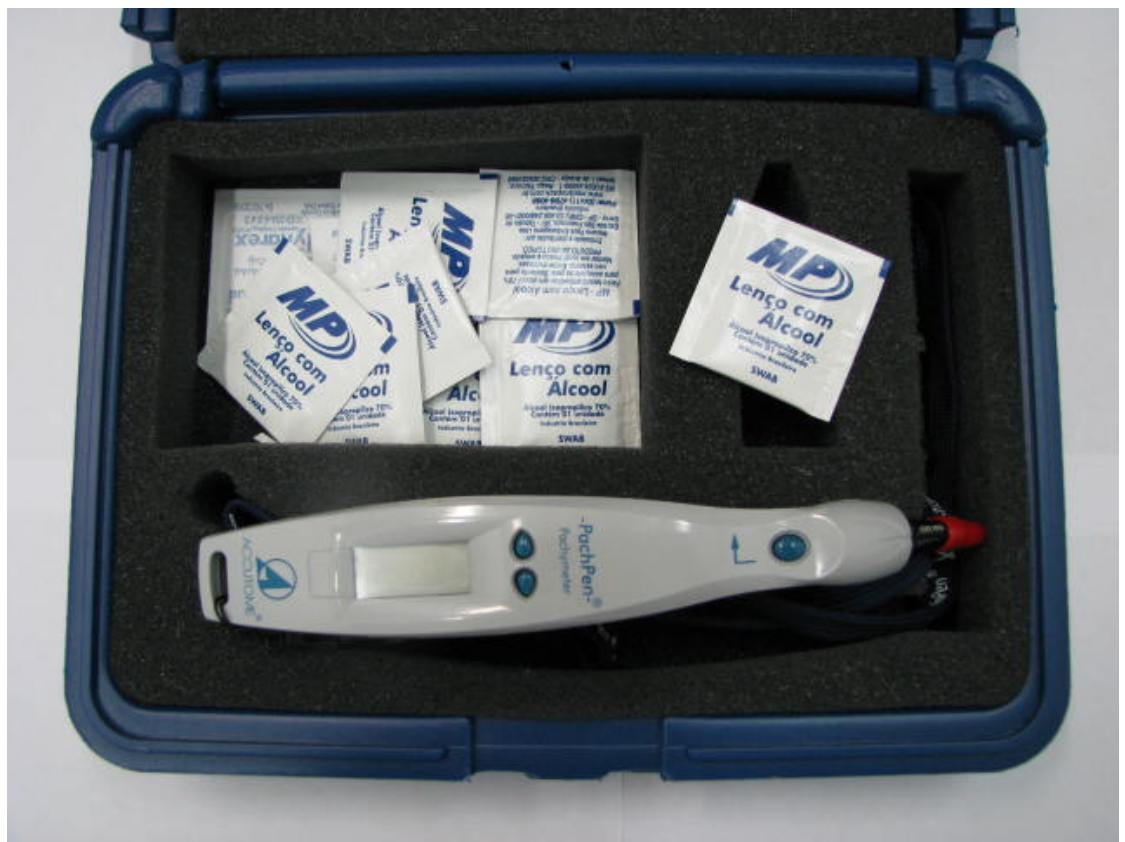

FONTE: Laboratório de Investigação em Oftalmologia Comparada

Figura 3 - Representação fotográfica do paquímetro PachPen® utilizado neste estudo

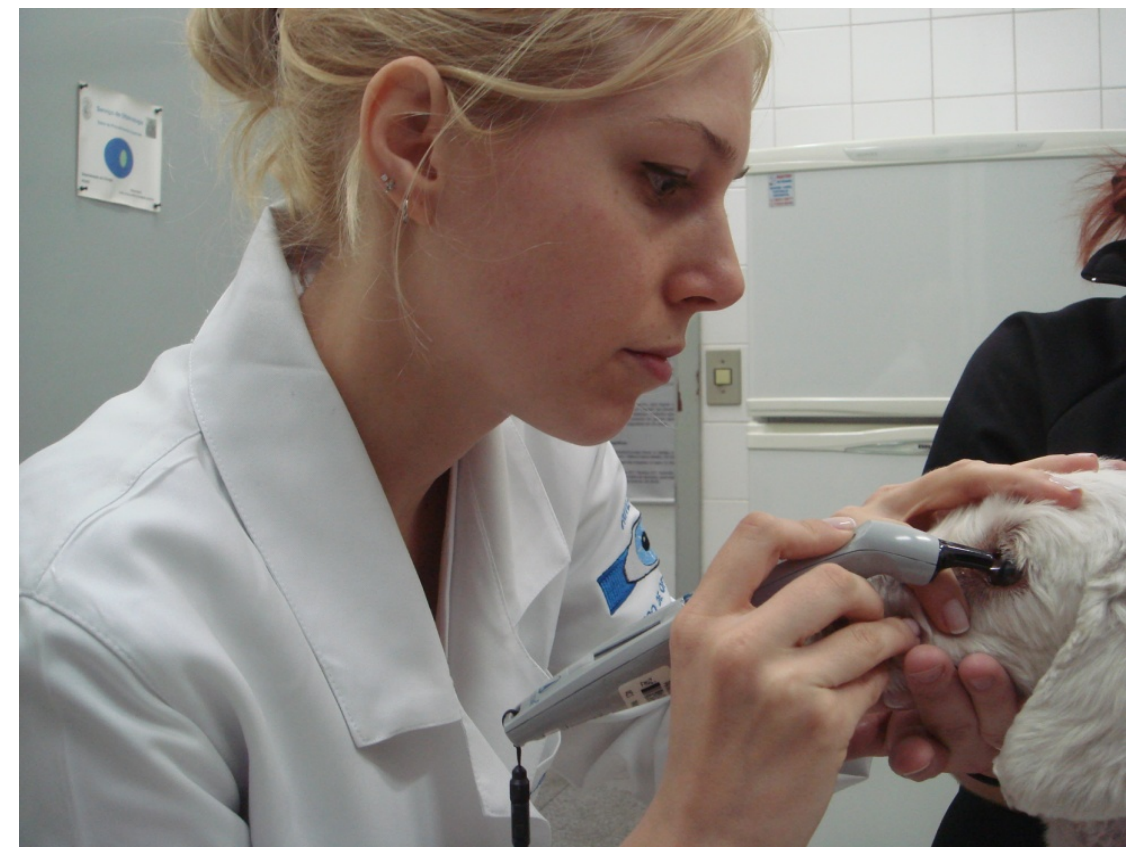

FONTE: Laboratório de Investigação em Oftalmologia Comparada

Figura 4 - Representação fotográfica da realização da paquimetria utilizando paquímetro ultra-sônico PachPen® em cão da raça Poodle 


\subsection{Análise estatística}

As variáveis classificatórias foram descritivamente apresentadas em tabelas de contingência contendo freqüências absolutas ( $n$ ) e relativas (\%). As associações entre elas foram avaliadas com o teste da razão de verossimilhança.

As variáveis quantitativas foram apresentadas descritivamente em tabelas contendo média, desvio padrão, mediana, valores mínimos e máximos. As distribuições das variáveis foram avaliadas com o teste de Kruskal-Wallis, quando significante, utilizou-se o teste de Dunn para discriminar as diferenças.

As variáveis quantitativas avaliadas segundo presença de uveite foram comparadas com o teste de Mann-Whitney.

Os gráficos em "boxplot" ou diagrama em caixas representam a distribuição dos dados. A linha horizontal dentro da caixa é o valor da mediana e os limites inferior e superior da caixa mostram, respectivamente, o percentil 25 e o percentil 75. Os limites inferior e superior, simbolizado pelas linhas verticais, representam o valor mínimo ou máximo não "outliers". Valores "outliers" são os pontos localizados fora do intervalo formado pelo percentil 75 mais 1,5 vez o intervalo interquartílico e pelo percentil 25 menos 1,5 vez o intervalo interquartílico. Valores "outliers" acima de 3 vezes o intervalo interquartílico foram chamados de valores extremos.

As relações da pressão intra-ocular e paquimetria com as demais variáveis foram avaliadas com o coeficiente de correlação de Spearman.

Os sinais de uveite entre os lados direito e esquerdo foram avaliados pelo teste de Mc-Nemar.

Os valores de $p<0,05$ foram considerados estatisticamente significantes (ROSNER, 1994). 


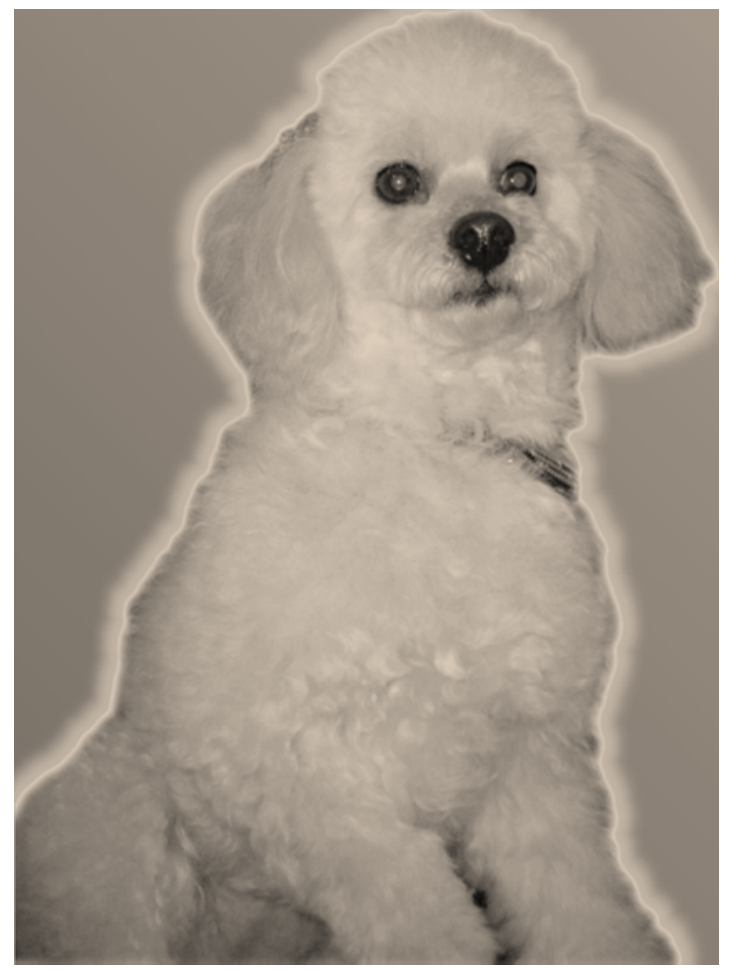

RESULTADOS 


\section{RESULTADOS}

Foram analisados 233 olhos de um total de 122 cães adultos da raça Poodle, que são apresentados na tabela 1. Os 11 olhos não incluídos no estudo são classificados como outros, e apresentavam alterações como cirurgia de catarata prévia (pelo menos 2 anos antes), seqüelas de trauma ou enucleação. Vinte e quatro destes cães apresentavam-se acometidos por diabetes mellitus (DM), e suas cataratas foram diagnosticadas como diabéticas pelo desenvolvimento de opacidade bilateral, usualmente entumescente, de rápida progressão após o diagnóstico da DM. Destes 48 olhos de animais diabéticos, 9 foram classificados como catarata imatura, 11 como matura, 25 como hipermatura e 3 como outros. Trinta e nove olhos formaram o grupo controle (olhos sem acometimento de catarata) e 149 olhos apresentaram catarata não diabética. Destes, 20 apresentaram catarata incipiente, 29 apresentaram catarata imatura, 20 catarata matura e 80 apresentaram catarata hipermatura (Apêndices $\mathrm{A}$ a $\mathrm{H}$ ).

Dos 233 olhos analisados, $134(57,51 \%)$ eram de fêmeas e $99(42,49 \%)$ de machos. A distribuição dos olhos segundo o sexo nos diferentes grupos encontra-se representada na tabela 2. Os sexos foram acometidos por catarata em diferentes proporções nos diversos grupos $(p=0,019)$. Nas cataratas não diabéticas os valores de fêmeas e machos acometidos foram bastante semelhantes; o que não ocorreu nas cataratas diabéticas, tendo as fêmeas sido pronunciadamente mais afetadas. $O$ gráfico 1 demonstra a distribuição percentual dos animais segundo o sexo masculino e os grupos. 
Tabela 1 - Distribuição dos olhos segundo as fases das cataratas - São Paulo - 2008

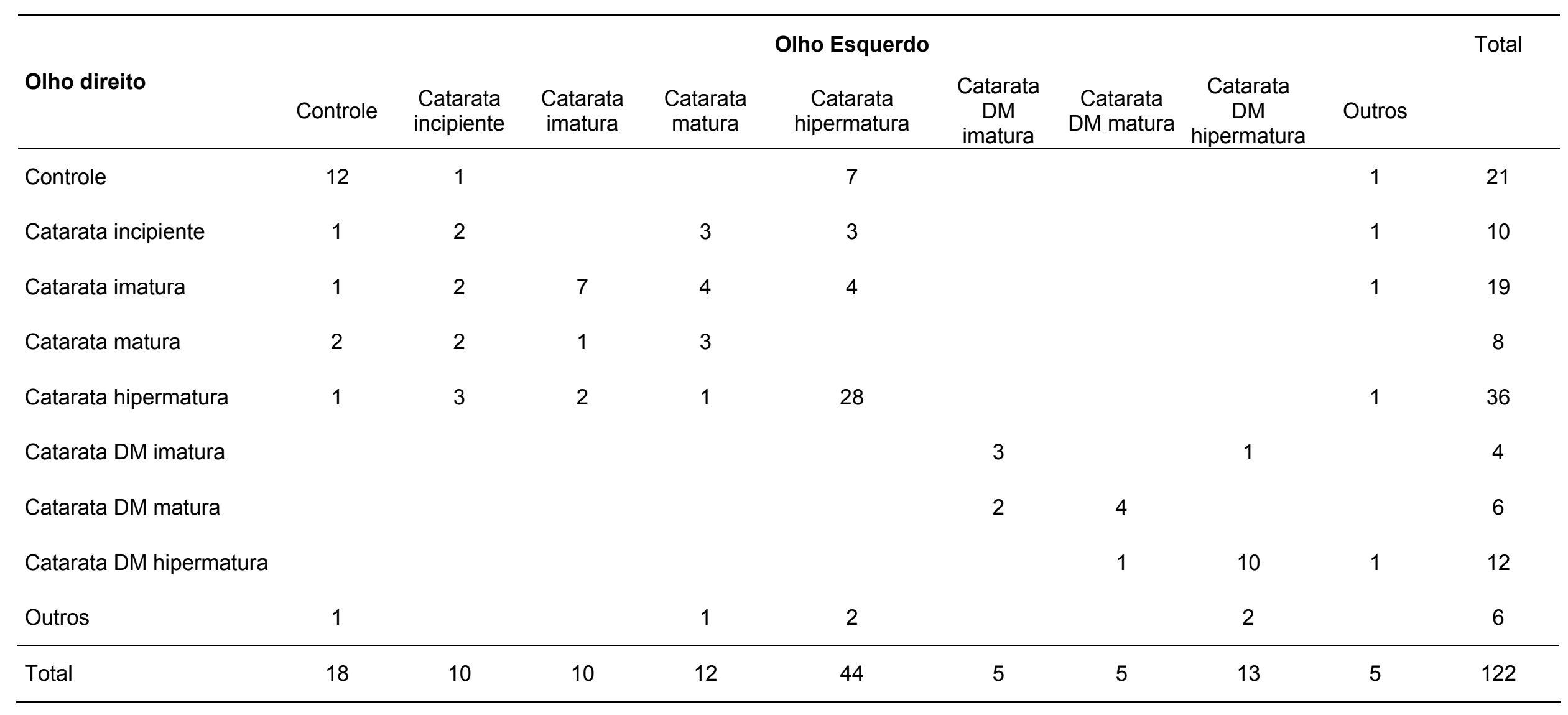


Tabela 2 - Distribuição dos olhos segundo o sexo e os grupos - São Paulo - 2008

\begin{tabular}{llllll}
\hline Grupo & $\begin{array}{l}\text { Sexo } \\
\mathbf{f}\end{array}$ & \multicolumn{3}{l}{ m } & Total \\
\hline Controle & 22 & $56,41 \%$ & 17 & $43,59 \%$ & 39 \\
Catarata incipiente & 8 & $40,00 \%$ & 12 & $60,00 \%$ & 20 \\
Catarata imatura & 15 & $51,72 \%$ & 14 & $48,28 \%$ & 29 \\
Catarata matura & 11 & $55,00 \%$ & 9 & $45,00 \%$ & 20 \\
Catarata hipermatura & 42 & $52,50 \%$ & 38 & $47,50 \%$ & 80 \\
Catarata DM imatura & 9 & $100,00 \%$ & 0 & $0,00 \%$ & 9 \\
Catarata DM matura & 10 & $90,91 \%$ & 1 & $9,09 \%$ & 11 \\
Catarata DM & 17 & $68,00 \%$ & 8 & $32,00 \%$ & 25 \\
\hline hipermatura & 134 & $57,51 \%$ & 99 & $42,49 \%$ & 233 \\
\hline Total & 0,019 (Teste da razão de verossimilhança) & & &
\end{tabular}

DM = Diabetes mellitus; $\mathbf{f}=$ fêmea; $\mathbf{m}=$ macho

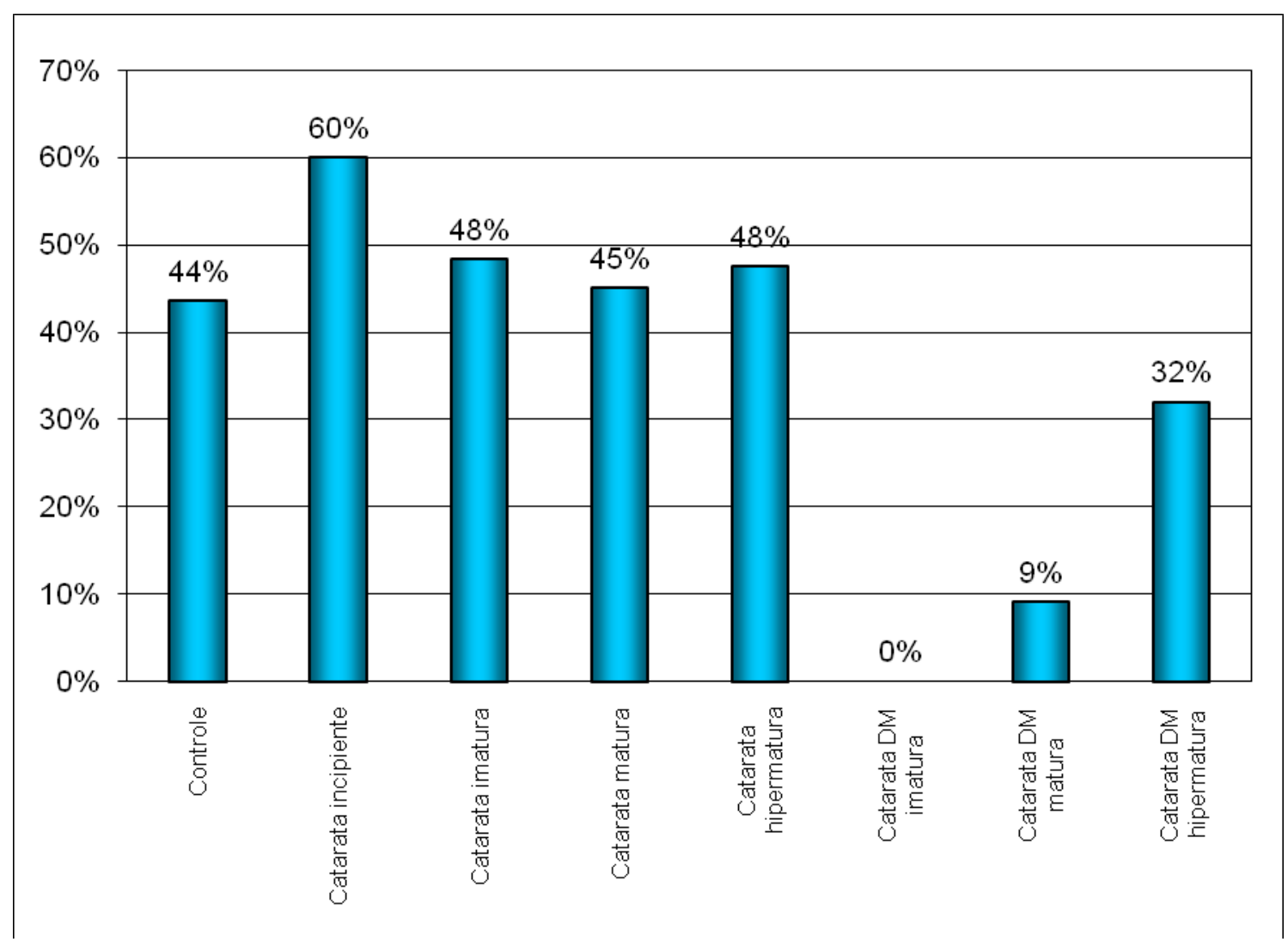

Gráfico 1 - Representação gráfica da distribuição percentual dos olhos segundo o sexo masculino e os grupos 
A média de idade nos diferentes grupos é apresentada na tabela 3 e gráfico 2 . A idade dos cães acometidos por catarata variou de 2 a 16 anos, e sua distribuição nos diversos grupo foi estatisticamente diferente $(p<0,001)$. A média de idade dos cães da raça Poodle acometidos por catarata não diabética variou de 7,03 anos nas cataratas imaturas a 8,45 anos nas hipermaturas. As cataratas maturas obtiveram idade média de 7,25 anos, valor intermediário em relação às anteriores.Cães acometidos por DM foram estatisticamente mais velhos em comparação com certos grupos (Tabela 4). A média de idade encontrada nos grupos diabéticos foi de 10,08 anos em cataras hipermaturas, 10,33 anos em imaturas, e 10,73 anos nas maturas; e não foram estatisticamente diferentes entre si $(p>0,05)$.

Tabela 3 -Distribuição dos olhos segundo a idade e os grupos - São Paulo - 2008

\begin{tabular}{llllllll}
\hline Idade (anos) & $\mathrm{n}$ & Média & $\begin{array}{l}\text { Desvio } \\
\text { padrão }\end{array}$ & Mediana & Mínimo & Máximo $\begin{array}{l}\mathrm{p} \text { (teste Kruskal- } \\
\text { Wallis) }\end{array}$ \\
\hline Controle & 39 & 9,62 & 3,44 & 10 & 2 & 16 & \\
Catarata incipiente & 20 & 7,05 & 2,91 & 8 & 2 & 11 & \\
Catarata imatura & 29 & 7,03 & 3,16 & 6 & 3 & 14 & \\
Catarata matura & 20 & 7,25 & 3,37 & 8 & 2 & 13 & $<0,001$ \\
Catarata hipermatura & 80 & 8,45 & 2,60 & 8 & 2 & 16 & 13 \\
Catarata DM imatura & 9 & 10,33 & 2,35 & 10 & 7 & 13 & \\
Catarata DM matura & 11 & 10,73 & 1,90 & 11 & 8 & 6 & 14 \\
Catarata DM hipermatura & 25 & 10,08 & 2,33 & 10 & 6 &
\end{tabular}

DM = Diabetes mellitus; $\mathbf{n}$ = número da amostra

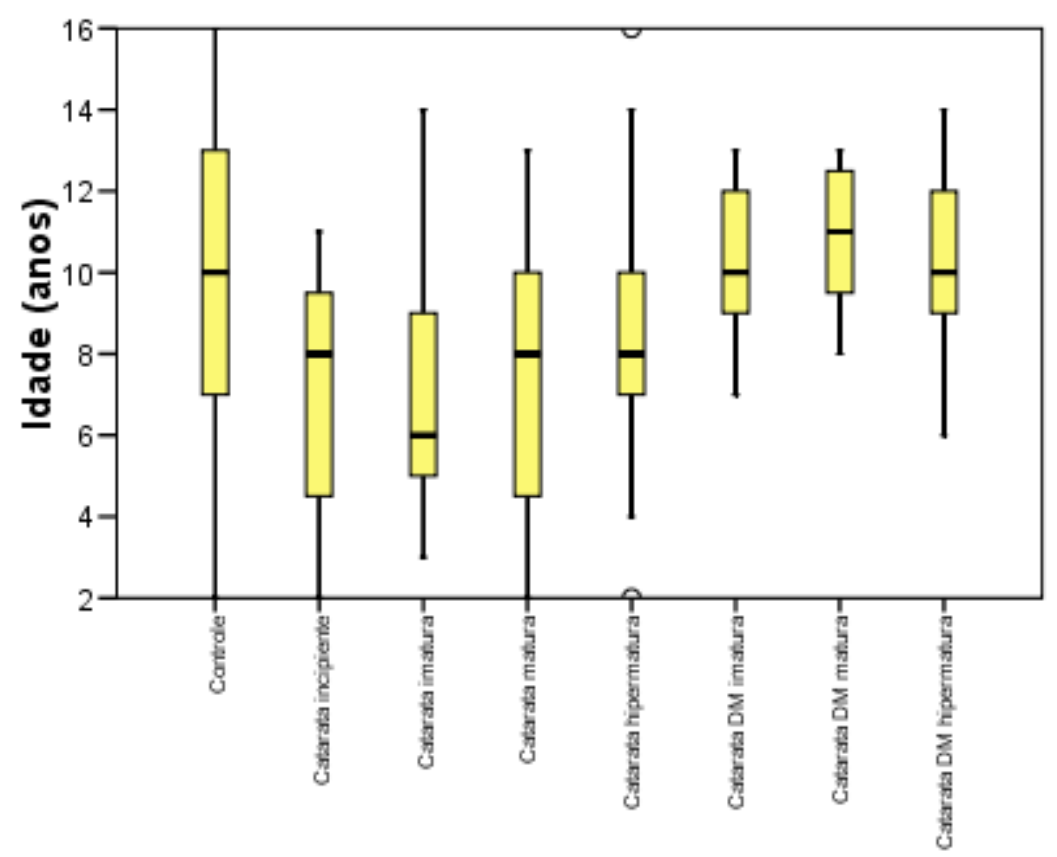

Gráfico 2 - Representação gráfica da distribuição dos olhos segundo a idade e os grupos 
Tabela 4 - Comparação estatística (discriminação) da idade entre os grupos - São Paulo 2008

\begin{tabular}{|c|c|}
\hline Contraste & Teste de Dunn \\
\hline CAT HIPERMATURA x CAT IMATURA & $>0,05$ \\
\hline CAT HIPERMATURA $x$ CAT INCIPIENTE & $>0,05$ \\
\hline CAT HIPERMATURA x CAT MATURA & $>0,05$ \\
\hline CAT HIPERMATURA x DM CAT HIPERMATURA & $>0,05$ \\
\hline CAT HIPERMATURA x DM CAT IMATURA & $>0,05$ \\
\hline CAT HIPERMATURA x DM CAT MATURA & $>0,05$ \\
\hline CAT HIPERMATURA x NORMAIS & $>0,05$ \\
\hline CAT IMATURA x CAT INCIPIENTE & $>0,05$ \\
\hline CAT IMATURA x CAT MATURA & $>0,05$ \\
\hline CAT IMATURA x DM CAT HIPERMATURA & $<0,05$ \\
\hline CAT IMATURA x DM CAT IMATURA & $>0,05$ \\
\hline CAT IMATURA x DM CAT MATURA & $<0,05$ \\
\hline CAT IMATURA x NORMAIS & $<0,05$ \\
\hline CAT INCIPIENTE x CAT MATURA & $>0,05$ \\
\hline CAT INCIPIENTE x DM CAT HIPERMATURA & $>0,05$ \\
\hline CAT INCIPIENTE x DM CAT IMATURA & $>0,05$ \\
\hline CAT INCIPIENTE x DM CAT MATURA & $<0,05$ \\
\hline CAT INCIPIENTE x NORMAIS & $>0,05$ \\
\hline CAT MATURA x DM CAT HIPERMATURA & $>0,05$ \\
\hline CAT MATURA x DM CAT IMATURA & $>0,05$ \\
\hline CAT MATURA $x$ DM CAT MATURA & $>0,05$ \\
\hline CAT MATURA $x$ NORMAIS & $>0,05$ \\
\hline DM CAT HIPERMATURA x DM CAT IMATURA & $>0,05$ \\
\hline DM CAT HIPERMATURA x DM CAT MATURA & $>0,05$ \\
\hline DM CAT HIPERMATURA x NORMAIS & $>0,05$ \\
\hline DM CAT IMATURA x DM CAT MATURA & $>0,05$ \\
\hline DM CAT IMATURA x NORMAIS & $>0,05$ \\
\hline DM CAT MATURA x NORMAIS & $>0,05$ \\
\hline
\end{tabular}

O peso dos cães acometidos por catarata variou de 2,6 a $15,7 \mathrm{~kg}$. A distribuição do peso nos diversos grupos não foi homogênea $(p=0,014)$ e está representada pela tabela 5 e gráfico 3. Cães acometidos por DM foram estatisticamente mais pesados em comparação a certos grupos (Tabela 6). 
Tabela 5 -Distribuição dos olhos segundo o peso e os grupos - São Paulo - 2008

\begin{tabular}{llllllll}
\hline Peso $(\mathrm{kg})$ & $\mathrm{n}$ & Média & $\begin{array}{c}\text { Desvio } \\
\text { padrão }\end{array}$ & Mediana & Mínimo & Máximo $\begin{array}{l}\mathrm{p} \\
\text { (teste Kruskal- } \\
\text { Wallis) }\end{array}$ \\
\hline Controle & 39 & 6,29 & 2,52 & 6,2 & 2,6 & 14,3 & \\
Catarata incipiente & 20 & 6,26 & 2,25 & 5,95 & 2,6 & 10,6 & \\
Catarata imatura & 29 & 8,23 & 3,96 & 6,7 & 2,9 & 18 & \\
Catarata matura & 20 & 6,05 & 1,46 & 5,5 & 4,1 & 9 & 0,014 \\
Catarata hipermatura & 80 & 6,33 & 2,52 & 5,9 & 2,6 & 15,7 & \\
Catarata DM imatura & 9 & 6,30 & 1,54 & 6 & 4,7 & 9,3 & \\
Catarata DM matura & 11 & 7,50 & 2,62 & 7,5 & 4,5 & 12,2 & \\
Catarata DM hipermatura & 25 & 8,44 & 3,27 & 9 & 3,3 & 14 & \\
\hline
\end{tabular}

DM = Diabetes mellitus; $\mathbf{n}=$ número da amostra

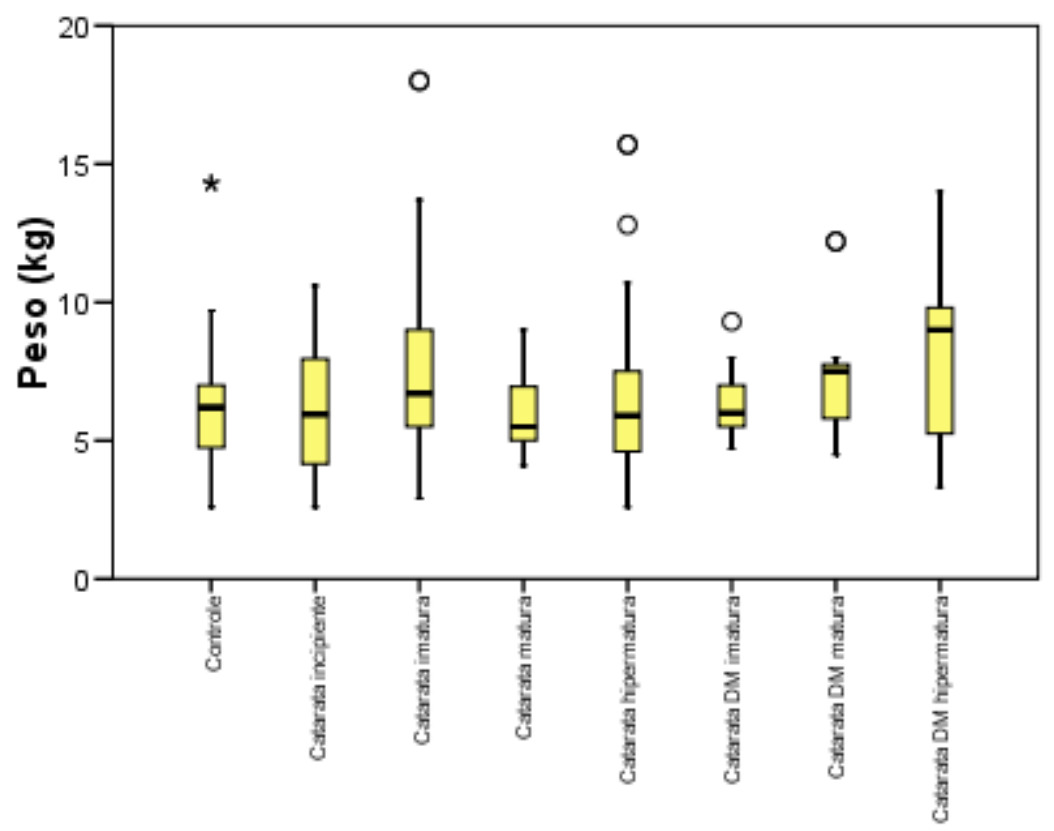

Gráfico 3 - Representação gráfica da distribuição dos olhos segundo o peso e os grupos 
Tabela 6 - Comparação estatística (discriminação) do peso entre os grupos - São Paulo 2008

\begin{tabular}{|c|c|}
\hline Contraste & Teste de Dunn \\
\hline CAT HIPERMATURA x CAT IMATURA & $>0,05$ \\
\hline CAT HIPERMATURA x CAT INCIPIENTE & $>0,05$ \\
\hline CAT HIPERMATURA $\times$ CAT MATURA & $>0,05$ \\
\hline CAT HIPERMATURA x DM CAT HIPERMATURA & $>0,05$ \\
\hline CAT HIPERMATURA x DM CAT IMATURA & $>0,05$ \\
\hline CAT HIPERMATURA x DM CAT MATURA & $>0,05$ \\
\hline CAT HIPERMATURA $x$ NORMAIS & $>0,05$ \\
\hline CAT IMATURA $x$ CAT INCIPIENTE & $>0,05$ \\
\hline CAT IMATURA $x$ CAT MATURA & $>0,05$ \\
\hline CAT IMATURA x DM CAT HIPERMATURA & $<0,05$ \\
\hline CAT IMATURA x DM CAT IMATURA & $>0,05$ \\
\hline CAT IMATURA x DM CAT MATURA & $<0,05$ \\
\hline CAT IMATURA x NORMAIS & $<0,05$ \\
\hline CAT INCIPIENTE x CAT MATURA & $>0,05$ \\
\hline CAT INCIPIENTE x DM CAT HIPERMATURA & $>0,05$ \\
\hline CAT INCIPIENTE x DM CAT IMATURA & $>0,05$ \\
\hline CAT INCIPIENTE $\times$ DM CAT MATURA & $<0,05$ \\
\hline CAT INCIPIENTE x NORMAIS & $>0,05$ \\
\hline CAT MATURA x DM CAT HIPERMATURA & $>0,05$ \\
\hline CAT MATURA x DM CAT IMATURA & $>0,05$ \\
\hline CAT MATURA x DM CAT MATURA & $>0,05$ \\
\hline CAT MATURA x NORMAIS & $>0,05$ \\
\hline DM CAT HIPERMATURA $x$ DM CAT IMATURA & $>0,05$ \\
\hline DM CAT HIPERMATURA $x$ DM CAT MATURA & $>0,05$ \\
\hline DM CAT HIPERMATURA $x$ NORMAIS & $>0,05$ \\
\hline DM CAT IMATURA x DM CAT MATURA & $>0,05$ \\
\hline DM CAT IMATURA $x$ NORMAIS & $>0,05$ \\
\hline DM CAT MATURA $\times$ NORMAIS & $>0.05$ \\
\hline
\end{tabular}

Os tempos de formação das cataratas (referidos como tempo de leucocoria) não foram semelhantes entre si $(p<0,001)$, como demonstra a tabela 7 e gráfico 4 . As cataratas diabéticas tiveram tempos de formação estatisticamente menores do que cataratas imatura e hipermatura não diabéticas (Tabela 8).

Os tempos de diagnóstico da DM são apresentados na tabela 9 e gráfico 5 . Os tempos entre as diferentes fases de maturação das cataratas não foram diferentes entre si $(p=0,390)$.

O tempo médio entre o diagnóstico da DM e a formação de catarata foi de 3,33 meses na catarata imatura; 5,88 na catarata matura e 1,59 na catarata hipermatura (Tabela 10 e Gráfico 6). Esses valores não foram estatisticamente diferentes $(p=0,084)$. 
Tabela 7 -Distribuição dos olhos segundo o tempo de formação da catarata (tempo de leucocoria) e os grupos - São Paulo - 2008

\begin{tabular}{llllllll}
\hline Tempo leucocoria (meses) & $\mathrm{n}$ & Média & $\begin{array}{l}\text { Desvio } \\
\text { padrão }\end{array}$ & Mediana & Mínimo & Máximo $\begin{array}{l}\mathrm{p} \\
\text { (teste Kruskal- } \\
\text { Wallis) }\end{array}$ \\
\hline Catarata imatura & 29 & 9,60 & 5,63 & 6 & 1,5 & 24 & \\
Catarata matura & 20 & 7,80 & 5,45 & 6 & 1 & 18 & \\
Catarata hipermatura & 80 & 13,16 & 9,80 & 12 & 2 & 60 & $<0,001$ \\
Catarata DM imatura & 9 & 10,56 & 18,96 & 1 & 1 & 44 & \\
Catarata DM matura & 11 & 1,94 & 2,03 & 1 & 0,3 & 6 & \\
Catarata DM hipermatura & 25 & 5,83 & 9,25 & 3 & 0,25 & 40 & \\
\hline
\end{tabular}

DM = Diabetes mellitus; $\mathbf{n}=$ número da amostra

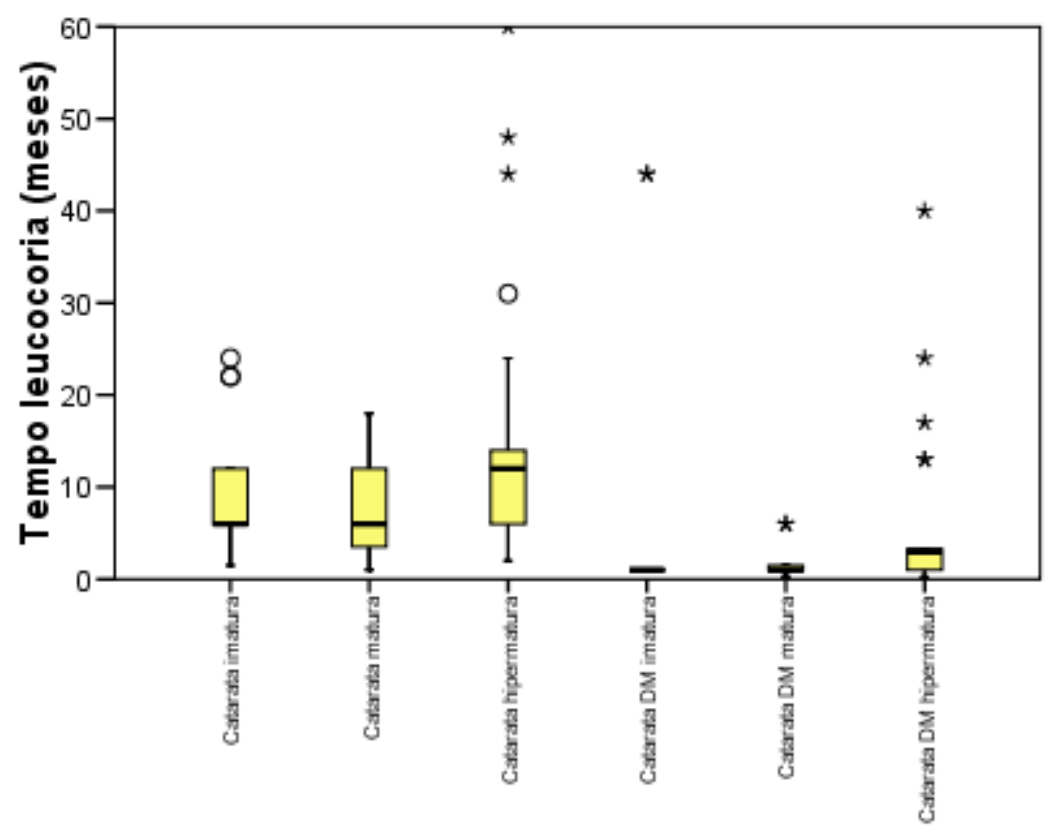

Gráfico 4 - Representação gráfica da distribuição dos olhos segundo o tempo de leucocoria e os grupos 
Tabela 8 - Comparação estatística (discriminação) do tempo de leucocoria entre os grupos - São Paulo - 2008

\begin{tabular}{ll}
\hline Contraste & Teste de Dunn \\
\hline CAT HIPERMATURA x CAT IMATURA & $>0,05$ \\
CAT HIPERMATURA $x$ CAT MATURA & $>0,05$ \\
CAT HIPERMATURA $x$ DM CAT HIPERMATURA & $<0,05$ \\
CAT HIPERMATURA $x$ DM CAT IMATURA & $<0,05$ \\
CAT HIPERMATURA $x$ DM CAT MATURA & $<0,05$ \\
CAT IMATURA x CAT MATURA & $>0,05$ \\
CAT IMATURA x DM CAT HIPERMATURA & $<0,05$ \\
CAT IMATURA x DM CAT IMATURA & $>0,05$ \\
CAT IMATURA x DM CAT MATURA & $<0,05$ \\
CAT MATURA x DM CAT HIPERMATURA & $>0,05$ \\
CAT MATURA x DM CAT IMATURA & $>0,05$ \\
CAT MATURA x DM CAT MATURA & $>0,05$ \\
DM CAT HIPERMATURA x DM CAT IMATURA & $>0,05$ \\
DM CAT HIPERMATURA x DM CAT MATURA & $>0,05$ \\
DM CAT IMATURA x DM CAT MATURA & $>0,05$ \\
\hline
\end{tabular}

Tabela 9 -Distribuição dos olhos segundo o tempo de diabetes mellitus e os grupos - São Paulo - 2008

\begin{tabular}{llllllll}
\hline Tempo DM (meses) & $\mathrm{n}$ & Média & $\begin{array}{l}\text { Desvio } \\
\text { padrão }\end{array}$ & Mediana & Mínimo & Máximo $\begin{array}{l}\mathrm{p} \\
\text { (teste Kruskal- } \\
\text { Wallis) }\end{array}$ \\
\hline Catarata DM imatura & 9 & 13,89 & 17,37 & 7 & 1 & 44 & \\
Catarata DM matura & 11 & 7,82 & 11,10 & 3 & 1 & 30 & 0,390 \\
Catarata DM hipermatura & 25 & 7,42 & 10,53 & 3 & 1 & 40 & \\
\hline
\end{tabular}

DM = Diabetes mellitus; $\mathbf{n}=$ número da amostra

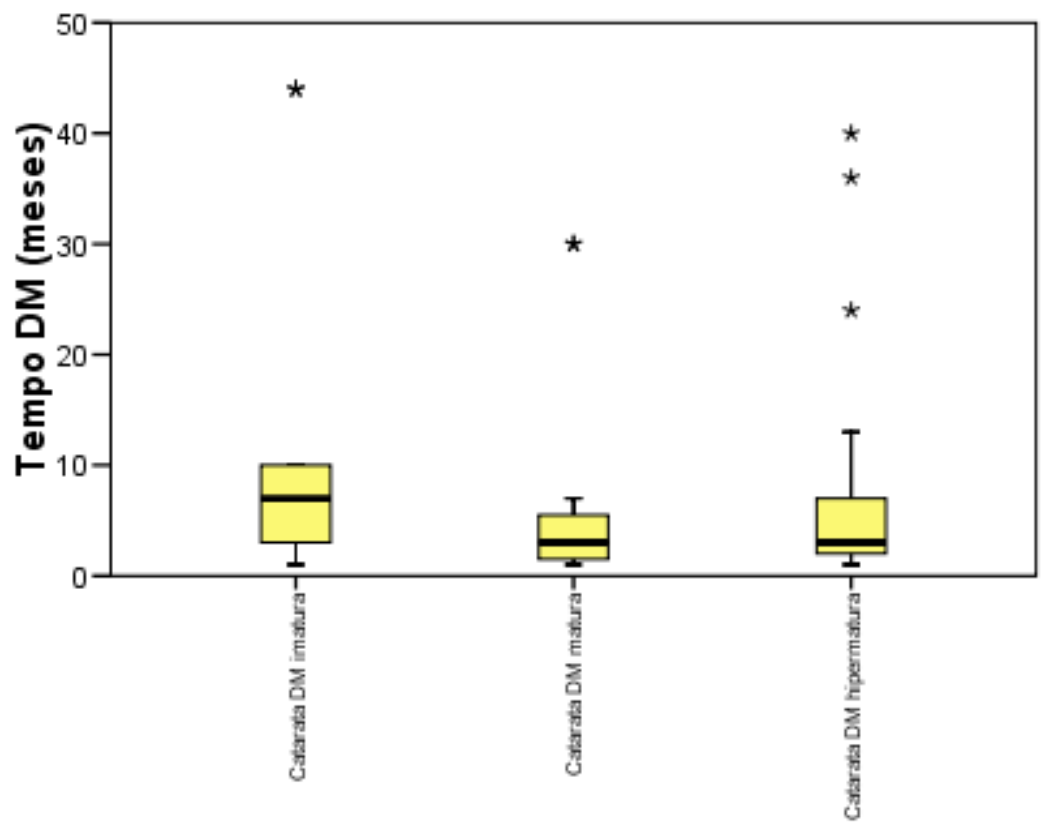

Gráfico 5 - Representação gráfica da distribuição dos olhos segundo o tempo de diabetes mellitus e os grupos 
Tabela 10 -Distribuição dos olhos segundo o tempo de desenvolvimento da catarata após o diagnóstico da diabetes mellitus e os grupos - São Paulo - 2008

\begin{tabular}{llllllll}
\hline $\begin{array}{l}\text { Tempo de desenvolvimento da } \\
\text { catarata após diagnóstico DM } \\
\text { (meses) }\end{array}$ & & Média & $\begin{array}{l}\text { Desvio } \\
\text { padrão }\end{array}$ & Mediana & Mínimo & Máximo $\begin{array}{l}\mathrm{p} \\
\text { (teste Kruskal- } \\
\text { Wallis) }\end{array}$ \\
\hline Catarata DM imatura & 9 & 3,33 & 3,71 & 2 & 0 & 9 & \\
Catarata DM matura & 11 & 5,88 & 9,12 & 1,5 & 0 & 24 & 0,084 \\
Catarata DM hipermatura & 25 & 1,59 & 2,85 & 0,25 & 0 & 12 & \\
\hline
\end{tabular}

DM = Diabetes mellitus; $\mathbf{n}=$ número da amostra

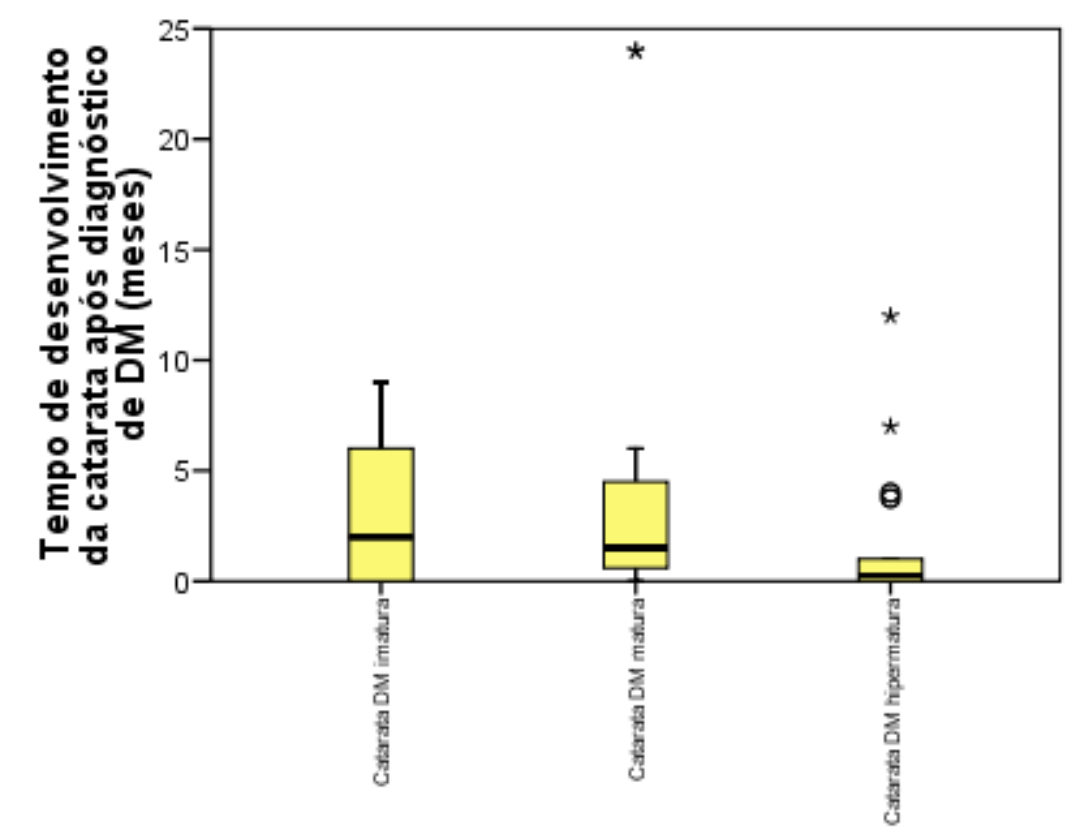

Gráfico 6 - Representação gráfica da distribuição dos olhos segundo o tempo de desenvolvimento da catarata após o diagnóstico da diabetes mellitus e os grupos - São Paulo - 2008

Cataratas diabéticas foram particularmente acometidas por UFI neste estudo. Todos os grupos de catarata diabética apresentaram maior prevalência de UFI em relação aos grupos correspondentes aos seus estágios de maturação nas cataratas não-diabéticas (11,11 versus $10,34 \% ; 27,27$ versus $15,00 \% ; 44,00$ versus $28,75 \%$ ) Neste estudo, a maioria dos cães com catarata $(77,32 \%)$ não foram acometidos por UFI clinicamente diagnosticável (Tabela 11 e Gráfico 7).

Quando comparada a distribuição dos sinais de uveíte entre olhos direitos e esquerdos, os lados tiveram resultados concordantes $(p=1,000)$ (Tabela 12). 
Tabela 11 -Distribuição dos olhos segundo a presença de uveíte faco-induzida e os grupos - São Paulo - 2008

\begin{tabular}{llllll}
\hline \multirow{2}{*}{ Grupo } & \multicolumn{3}{l}{ Sinais de uveite FACO } & \multirow{2}{*}{ Notal } \\
\hline Catarata incipiente & 20 & $100,00 \%$ & 0 & $0,00 \%$ & 20 \\
Catarata imatura & 26 & $89,66 \%$ & 3 & $10,34 \%$ & 29 \\
Catarata matura & 17 & $85,00 \%$ & 3 & $15,00 \%$ & 20 \\
Catarata hipermatura & 57 & $71,25 \%$ & 23 & $28,75 \%$ & 80 \\
Catarata DM imatura & 8 & $88,89 \%$ & 1 & $11,11 \%$ & 9 \\
Catarata DM matura & 8 & $72,73 \%$ & 3 & $27,27 \%$ & 11 \\
Catarata DM hipermatura & 14 & $56,00 \%$ & 11 & $44,00 \%$ & 25 \\
\hline Total & 150 & $77,32 \%$ & 44 & $22,68 \%$ & 194 \\
\hline
\end{tabular}

$\mathrm{p}=0,001$ (Teste da razão de verossimilhança), $\mathbf{F A C O}=$ faco-induzida, $\mathbf{D M}=$ diabetes mellitus

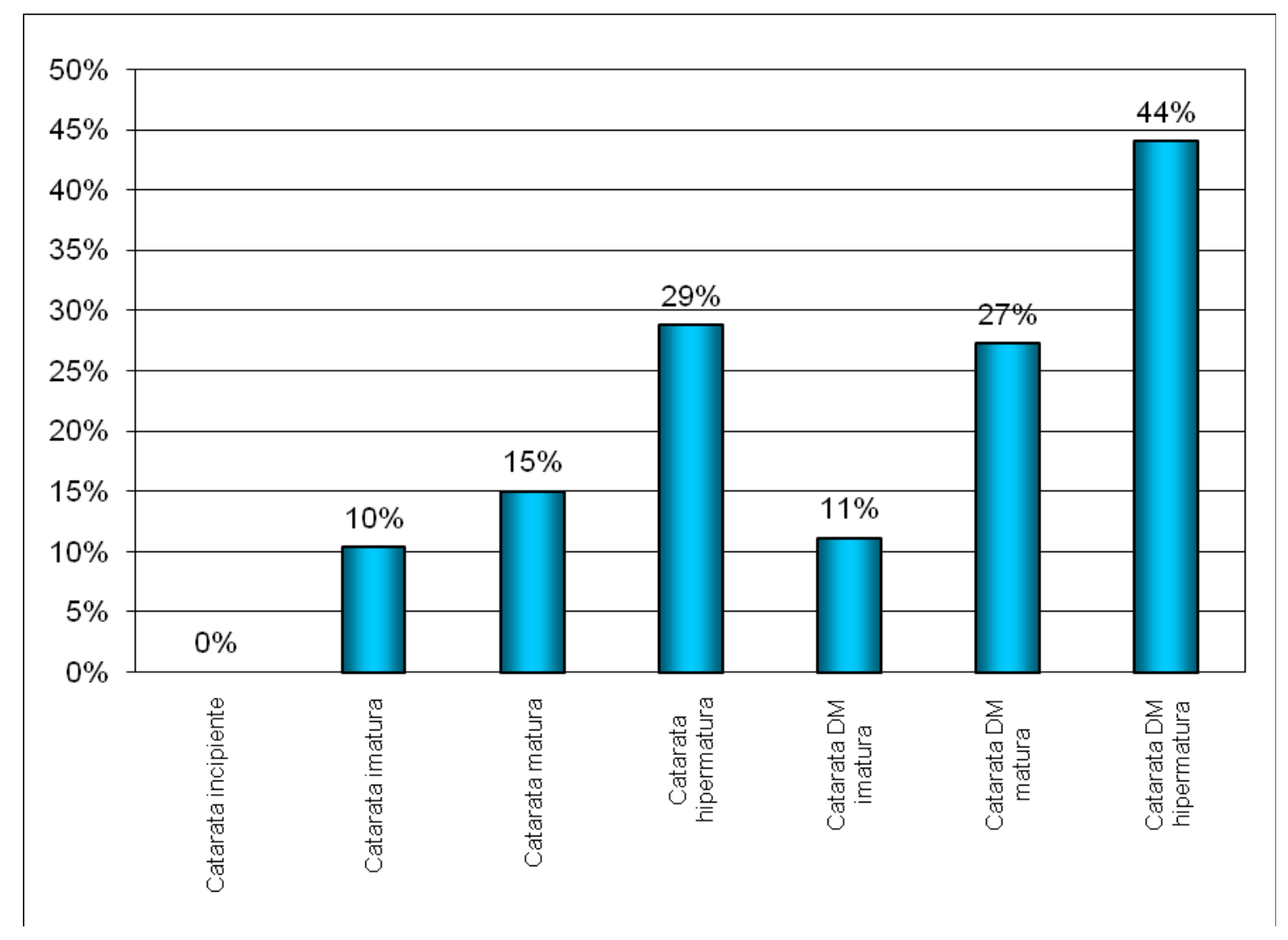

Gráfico 7 - Representação gráfica da distribuição percentual dos olhos segundo a presença de uveíte faco-induzida e os grupos 
Tabela 12 - Distribuição dos olhos segundo os lados direito e esquerdo e a presença de uveíte faco-induzida - São Paulo - 2008

\begin{tabular}{llll}
\hline \multirow{2}{*}{ Direito } & \multicolumn{2}{l}{ Esquerdo } & \multirow{2}{*}{ Total } \\
\hline $\mathrm{N}$ & $\mathrm{N}$ & $\mathrm{S}$ & \\
$\mathrm{S}$ & 61 & 5 & 66 \\
\hline Total & 5 & 15 & 20 \\
\hline
\end{tabular}

$p=1,000$ (Teste de MacNemar). Os lados têm resultados concordantes.

$\mathbf{N}=$ não; $\mathbf{S}=\operatorname{sim}$.

A PIO média ( \pm desvio padrão) do grupo controle foi de $12,05 \pm 3,17 \mathrm{mmHg}$, e não foi estatisticamente diferente dos outros grupos (Tabela 13 e Gráfico 8). Cataratas hipermaturas, tanto diabéticas $(10,40 \pm 4,43 \mathrm{mmHg})$ quanto não diabéticas $(10,60 \pm 3,30 \mathrm{mmHg})$, tiveram PIO estatisticamente menores em relação ao grupo catarata imatura $(13,52 \pm 3,67 \mathrm{mmHg}$ ), em cerca de $3 \mathrm{mmHg}$ (Tabela 14).

A idade foi um fator negativamente correlacionado à PIO $(p=0,007)$. Entretanto não foram encontradas correlações da PIO com o peso $(p=0,567)$, nem com o tempo de formação da catarata $(p=0,143)$ e tempo de desenvolvimento da DM $(p=0.201)$ (Tabela 15).

Olhos com presença de UFI tiveram correlação estatisticamente significativa com a diminuição da PIO ( $p<0,001)$. A diferença de PIO entre olhos com $(9,66 \pm 3,65$ $\mathrm{mmHg})$ e sem a presença de UFI $(11,88 \pm 3,35 \mathrm{mmHg})$ foi de cerca de $2 \mathrm{mmHg}$ (Tabela 16).

Tabela 13 -Distribuição dos olhos segundo a pressão intra-ocular e os grupos - São Paulo 2008

\begin{tabular}{llllllll}
\hline PIO $(\mathrm{mmHg})$ & $\mathrm{n}$ & Média & $\begin{array}{l}\text { Desvio } \\
\text { padrão }\end{array}$ & Mediana & Mínimo & Máximo $\begin{array}{l}\mathrm{p} \\
\text { (teste Kruskal- } \\
\text { Wallis) }\end{array}$ \\
\hline Controle & 39 & 12,05 & 3,17 & 12 & 5 & 21 & \\
Catarata incipiente & 20 & 12,80 & 2,17 & 13 & 8 & 17 & \\
Catarata imatura & 29 & 13,52 & 3,67 & 13 & 8 & 26 & \\
Catarata matura & 20 & 11,60 & 3,50 & 10 & 6 & 18 & $<0,001$ \\
Catarata hipermatura & 80 & 10,60 & 3,30 & 10 & 5 & 23 & \\
Catarata DM imatura & 9 & 12,00 & 2,92 & 13 & 7 & 15 & \\
Catarata DM matura & 11 & 10,09 & 2,26 & 9 & 7 & 14 & \\
Catarata DM hipermatura & 25 & 10,40 & 4,43 & 10 & 5 & 26 &
\end{tabular}

DM = Diabetes mellitus; $\mathbf{n}=$ número da amostra, PIO= pressão intra-ocular 


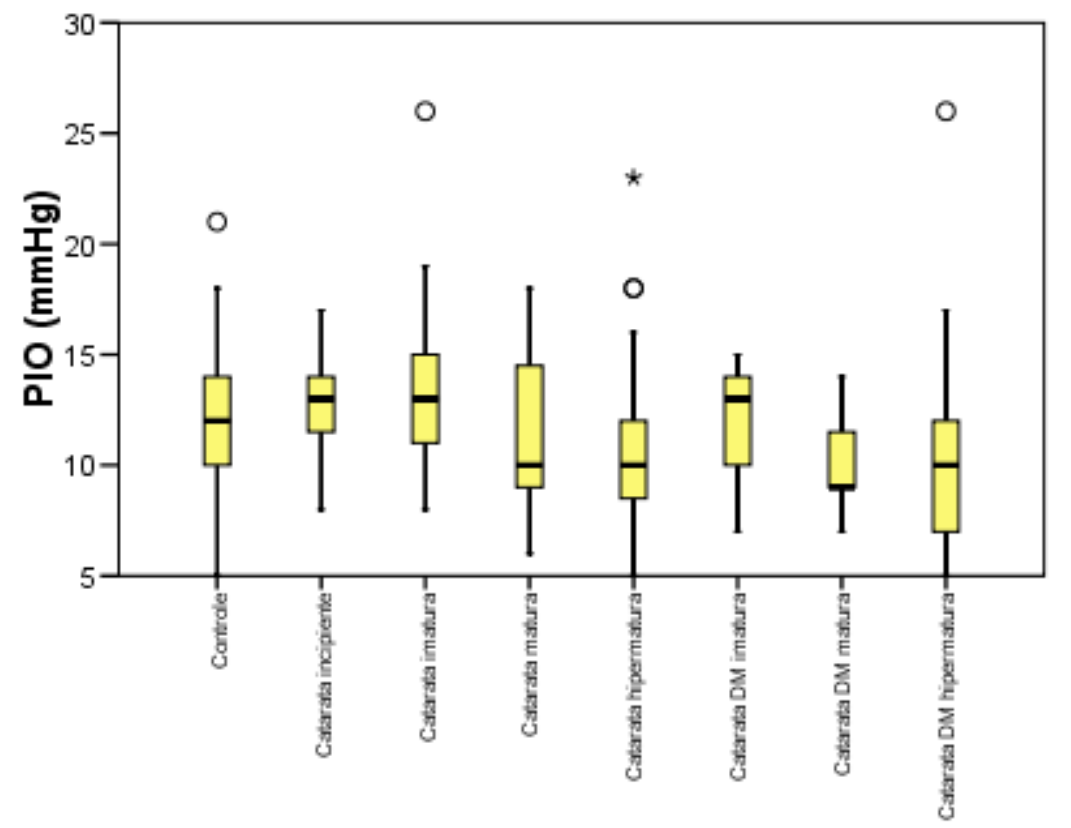

Gráfico 8 - Representação gráfica da distribuição dos olhos segundo a pressão intra-ocular e os grupos - São Paulo - 2008

Tabela 14 - Comparação estatística (discriminação) da pressão intra-ocular entre os grupos - São Paulo - 2008

\begin{tabular}{|c|c|}
\hline Contraste & Teste de Dunn \\
\hline $\begin{array}{l}\text { CAT HIPERMATURA } \times \text { CAT IMATURA } \\
\text { CAT }\end{array}$ & $<0,05$ \\
\hline CAT HIPERMATURA $x$ CAT INCIPIENTE & $>0,05$ \\
\hline CAT HIPERMATURA x CAT MATURA & $>0,05$ \\
\hline CAT HIPERMATURA x DM CAT HIPERMATURA & $>0,05$ \\
\hline CAT HIPERMATURA x DM CAT IMATURA & $>0,05$ \\
\hline CAT HIPERMATURA x DM CAT MATURA & $>0,05$ \\
\hline CAT HIPERMATURA x NORMAIS & $>0,05$ \\
\hline CAT IMATURA x CAT INCIPIENTE & $>0,05$ \\
\hline CAT IMATURA x CAT MATURA & $>0,05$ \\
\hline CAT IMATURA x DM CAT HIPERMATURA & $<0,05$ \\
\hline CAT IMATURA x DM CAT IMATURA & $>0,05$ \\
\hline CAT IMATURA x DM CAT MATURA & $>0,05$ \\
\hline CAT IMATURA x NORMAIS & $>0,05$ \\
\hline CAT INCIPIENTE x CAT MATURA & $>0,05$ \\
\hline CAT INCIPIENTE x DM CAT HIPERMATURA & $>0,05$ \\
\hline CAT INCIPIENTE x DM CAT IMATURA & $>0,05$ \\
\hline CAT INCIPIENTE x DM CAT MATURA & $>0,05$ \\
\hline CAT INCIPIENTE x NORMAIS & $>0,05$ \\
\hline CAT MATURA x DM CAT HIPERMATURA & $>0,05$ \\
\hline CAT MATURA x DM CAT IMATURA & $>0,05$ \\
\hline CAT MATURA x DM CAT MATURA & $>0,05$ \\
\hline CAT MATURA $\times$ NORMAIS & $>0,05$ \\
\hline DM CAT HIPERMATURA x DM CAT IMATURA & $>0,05$ \\
\hline DM CAT HIPERMATURA $x$ DM CAT MATURA & $>0,05$ \\
\hline DM CAT HIPERMATURA x NORMAIS & $>0,05$ \\
\hline DM CAT IMATURA x DM CAT MATURA & $>0,05$ \\
\hline DM CAT IMATURA x NORMAIS & $>0,05$ \\
\hline DM CAT MATURA $\times$ NORMAIS & $>0,05$ \\
\hline
\end{tabular}


Tabela 15 - Correlação entre pressão intra-ocular e paquimetria e as outras variáveis - São Paulo - 2008

\begin{tabular}{llll}
\hline Variável & & $\mathrm{PIO}(\mathrm{mmHg})$ & $\mathrm{PAQ}(\mu \mathrm{m})$ \\
\hline \multirow{2}{*}{ Idade (anos) } & $\mathrm{r}$ & $-0,178$ & 0,183 \\
& $\mathrm{p}$ & 0,007 & 0,005 \\
& $\mathrm{n}$ & 233 & 233 \\
Peso (kg) & $\mathrm{r}$ & $-0,038$ & 0,190 \\
& $\mathrm{p}$ & 0,567 & 0,004 \\
& $\mathrm{n}$ & 233 & 233 \\
\hline \multirow{2}{*}{ Tempo DM (meses) } & $\mathrm{r}$ & 0,194 & $-0,480$ \\
& $\mathrm{p}$ & 0,201 & 0,001 \\
Tempo leucocoria (meses) & $\mathrm{n}$ & 45 & 45 \\
& $\mathrm{r}$ & 0,112 & $-0,293$ \\
& $\mathrm{p}$ & 0,143 & 0,000 \\
PIO (mmHg) & $\mathrm{n}$ & 174 & 174 \\
& $\mathrm{r}$ & & $-0,247$ \\
& $\mathrm{p}$ & & 0,000 \\
& $\mathrm{n}$ & & 233 \\
\hline
\end{tabular}

$\mathrm{r}=$ Coeficiente de correlação de Spearman $p=$ probabilidade de significância $\mathrm{n}=$ tamanho da amostra

$\mathbf{P I O}=$ pressão intra-ocular, $\mathbf{P A Q}=$ paquimetria, $\mathbf{D M}=$ diabetes mellitus

Tabela 16 - Associação da pressão intra ocular e paquimetria com a presença de uveíte faco induzida - São Paulo - 2008

\begin{tabular}{lccllllll}
\hline Variável & $\begin{array}{c}\text { SINAIS } \\
\text { UVEITE FACO }\end{array}$ & $\mathrm{N}$ & Média & $\begin{array}{l}\text { Desvio } \\
\text { Padrão }\end{array}$ & Mediana & Mínimo & \multicolumn{2}{c}{ Máximo $\begin{array}{l}\text { (Mann- } \\
\text { Whitney })\end{array}$} \\
\hline PIO $(\mathrm{mmHg})$ & $\mathrm{N}$ & 150 & 11,88 & 3,35 & 12,00 & 5,00 & 26,00 & $<0,001$ \\
& $\mathrm{~S}$ & 44 & 9,66 & 3,65 & 9,00 & 5,00 & 26,00 & \\
& $\mathrm{~N}$ & 150 & 613,40 & 56,79 & 611,50 & 470,00 & 789,00 & $<0,001$ \\
\hline
\end{tabular}

$\mathbf{P I O}=$ pressão intra-ocular, $\mathbf{P A}=$ paquimetria, $\mathbf{N}=$ número da amostra

O grupo controle apresentou espessura corneal de 608,64 $\pm 45,91 \mu \mathrm{m}$, que variou de 532 a $696 \mu \mathrm{m}$. A distribuição da paquimetria nos diferentes grupos, estatisticamente diferentes, encontra-se representada na tabela 17 e gráfico 9. Os animais diabéticos (catarata diabética matura e hipermatura) apresentaram maiores valores de paquimetria, estatisticamente significantes, em relação a determinados grupos $(p<0,05)($ Tabela 18).

Encontrou-se correlação positiva entre a paquimetria e a idade $(p=0,005)$, bem como entre a paquimetria e o peso $(p=0,004)$. A paquimetria obteve correlação negativa com o tempo de leucocoria $(p=0,000)$ e a PIO $(p=0,000)$ (Tabela 15). 
Encontrou-se diferença média de $60 \mu \mathrm{m}$ entre córneas de olhos com $(675,68$ $\pm 104,14 \mu \mathrm{m})$ e sem sinais de UFI $(613,40 \pm 56,79 \mu \mathrm{m})$ (Tabela 16). A UFI teve efeito significante no aumento da paquimetria $(p<0,001)$.

Encontrou-se correlação negativa entre a PIO e a paquimetria $(p=0,000)$ (Tabela 15).

Tabela 17 -Distribuição dos olhos segundo a paquimetria e os grupos - São Paulo - 2008

\begin{tabular}{llllllll}
\hline PAQ $(\mu \mathrm{m})$ & $\mathrm{n}$ & Média & $\begin{array}{l}\text { Desvio } \\
\text { padrão }\end{array}$ & Mediana & Mínimo & Máximo $\begin{array}{l}\mathrm{p} \\
\text { (teste } \\
\text { Kruskal- } \\
\text { Wallis) }\end{array}$ \\
\hline Controle & 39 & 608,64 & 45,91 & 611 & 532 & 696 & \\
Catarata incipiente & 20 & 594,40 & 34,87 & 595 & 545 & 689 & \\
Catarata imatura & 29 & 611,00 & 47,34 & 615 & 523 & 692 & \\
Catarata matura & 20 & 607,80 & 54,20 & 607 & 495 & 732 & 0,003 \\
Catarata hipermatura & 80 & 622,04 & 64,84 & 620,5 & 470 & 795 & \\
Catarata DM imatura & 9 & 623,00 & 54,68 & 621 & 551 & 726 & \\
Catarata DM matura & 11 & 659,45 & 43,45 & 654 & 605 & 727 & \\
Catarata DM hipermatura & 25 & 694,12 & 129,09 & 693 & 505 & 983 & \\
\hline
\end{tabular}

$\mathbf{D M}=$ Diabetes mellitus; $\mathbf{n}=$ número da amostra, $\mathbf{P A Q}=$ paquimetria

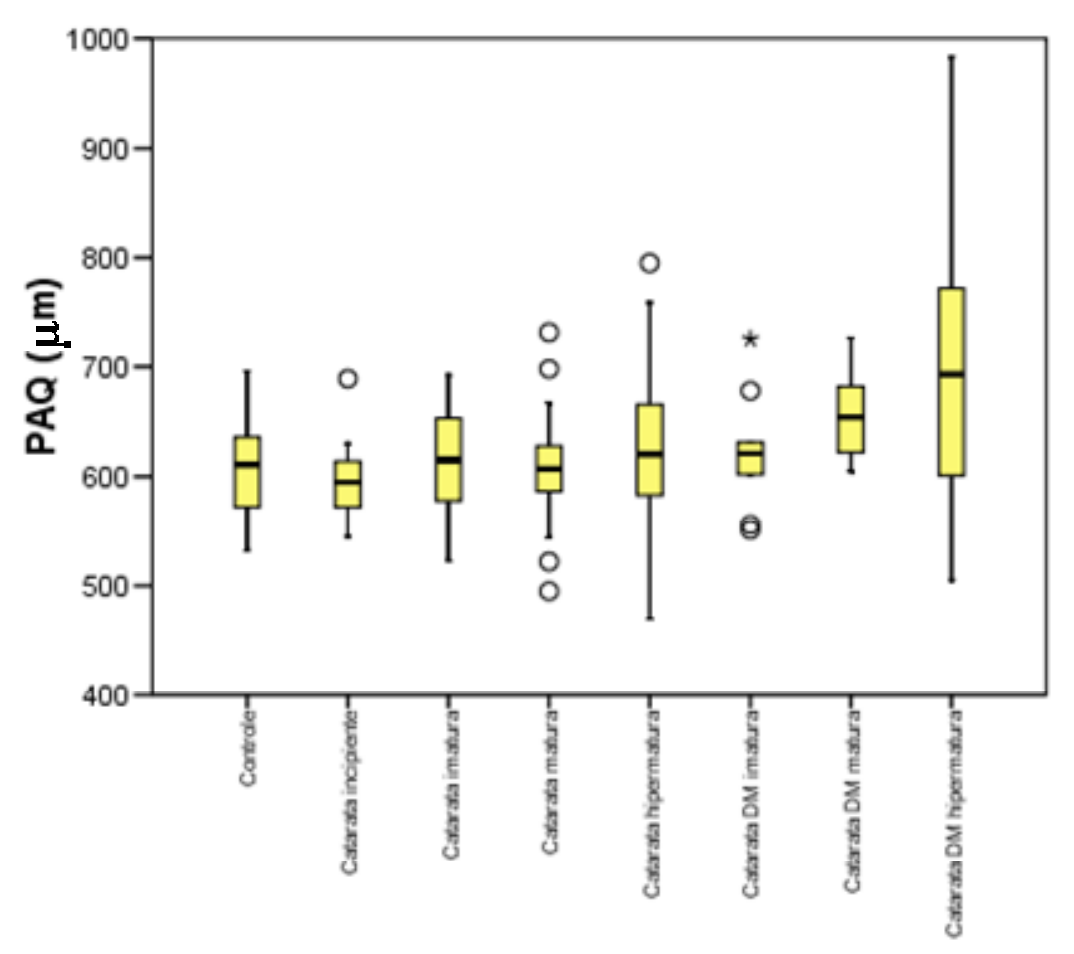

Gráfico 9 - Representação gráfica da distribuição dos olhos segundo a paquimetria e os grupos - São Paulo - 2008 
Tabela 18 - Comparação estatística (discriminação) da paquimetria entre os grupos - São Paulo - 2008

\begin{tabular}{|c|c|}
\hline Contraste & $\begin{array}{l}\text { Teste } \\
\text { Dunn }\end{array}$ \\
\hline CAT HIPERMATURA x CAT IMATURA & $>0,05$ \\
\hline CAT HIPERMATURA x CAT INCIPIENTE & $>0,05$ \\
\hline CAT HIPERMATURA x CAT MATURA & $>0,05$ \\
\hline CAT HIPERMATURA x DM CAT HIPERMATURA & $>0,05$ \\
\hline CAT HIPERMATURA x DM CAT IMATURA & $>0,05$ \\
\hline CAT HIPERMATURA x DM CAT MATURA & $>0,05$ \\
\hline CAT HIPERMATURA x NORMAIS & $>0,05$ \\
\hline CAT IMATURA x CAT INCIPIENTE & $>0,05$ \\
\hline CAT IMATURA x CAT MATURA & $>0,05$ \\
\hline CAT IMATURA x DM CAT HIPERMATURA & $>0,05$ \\
\hline CAT IMATURA x DM CAT IMATURA & $>0,05$ \\
\hline CAT IMATURA x DM CAT MATURA & $>0,05$ \\
\hline CAT IMATURA x NORMAIS & $>0,05$ \\
\hline CAT INCIPIENTE x CAT MATURA & $>0,05$ \\
\hline CAT INCIPIENTE x DM CAT HIPERMATURA & $<0,05$ \\
\hline CAT INCIPIENTE x DM CAT IMATURA & $>0,05$ \\
\hline CAT INCIPIENTE x DM CAT MATURA & $<0,05$ \\
\hline CAT INCIPIENTE x NORMAIS & $>0,05$ \\
\hline CAT MATURA x DM CAT HIPERMATURA & $>0,05$ \\
\hline CAT MATURA x DM CAT IMATURA & $>0,05$ \\
\hline CAT MATURA x DM CAT MATURA & $>0,05$ \\
\hline CAT MATURA $\times$ NORMAIS & $>0,05$ \\
\hline DM CAT HIPERMATURA x DM CAT IMATURA & $>0,05$ \\
\hline DM CAT HIPERMATURA x DM CAT MATURA & $>0,05$ \\
\hline DM CAT HIPERMATURA x NORMAIS & $>0,05$ \\
\hline DM CAT IMATURA x DM CAT MATURA & $>0,05$ \\
\hline DM CAT IMATURA x NORMAIS & $>0,05$ \\
\hline DM CAT MATURA x NORMAIS & $>0,05$ \\
\hline
\end{tabular}




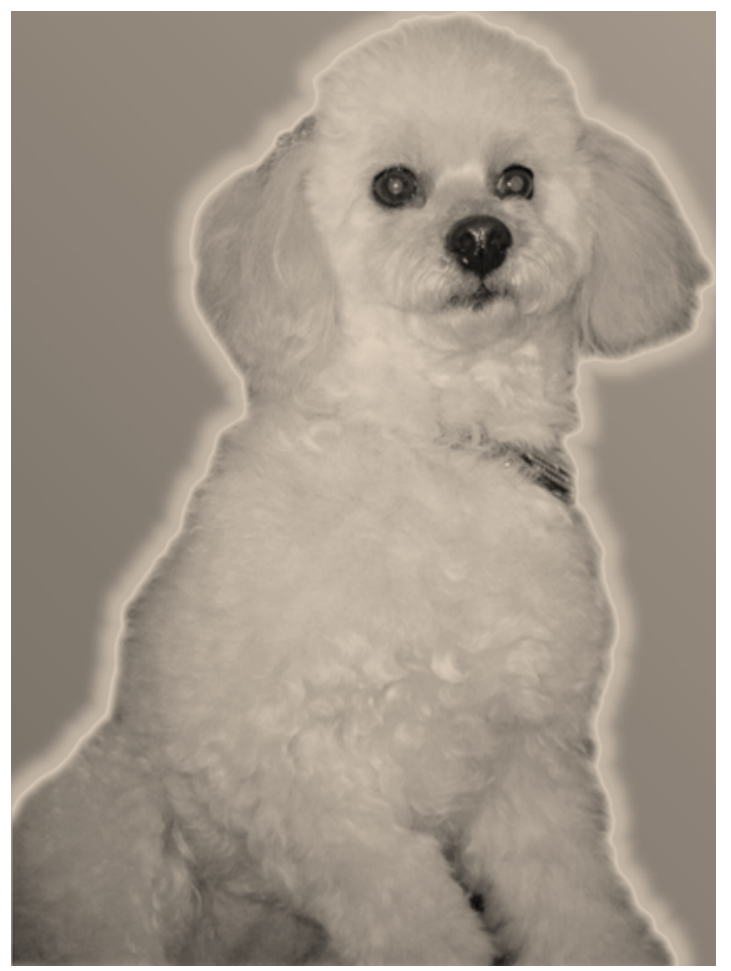

DISCUSSÃO 


\section{DISCUSSÃO}

A catarata é uma das causas mais prevalentes de cegueira em cães, e a extração da catarata é atualmente o procedimento cirúrgico intra-ocular mais comumente realizado na oftalmologia veterinária (DAVIDSON; NELMS, 2007). Em estudo realizado na Florida, Estados Unidos da América, a prevalência de catarata em cães foi estimada em 2,42\% da população, entre os anos de 1994 a 2003 (GELATT; MACKAY, 2005). Os autores identificaram as raças de cães mais freqüentemente acometidas, que incluíam o Fox Terrier, o Havanese, o Bichon Frise, Boston Terrier, Poodle Toy e Poodle Miniatura. O Poodle Standard também ficou dentre as 15 raças mais acometidas.

De fato, os cães da raça Poodle vêm ocupando os primeiros lugares nos estudos das raças mais afetadas por catarata ao longo das décadas; e são predispostos a cataratas de diferentes etiologias: hereditárias, não-hereditárias, primárias, secundárias e mesmo diabéticas (KOCH; RUBIN, 1967; RUBIN; FLOWERS, 1972; MARMOR et al., 1982; BARNETT, 1985; BEAM; CORREA; DAVIDSON, 1999; WILLIAMS; HEATH; WALLIS, 2004; ADKINS; HENDRIX, 2005; LYNCH; BRINKIS, 2006). Gelatt e MacKay (2005) também estabeleceram que a prevalência de catarata entre as raças vem sofrendo modificações e, dentre as raças que têm aumentado sua prevalência nos últimos anos, estão os Poodles.

A diabetes mellitus (DM) é uma endocrinopatia comum em cães, que afeta cerca de 1 em 500 a 1 em 100 cães (MARMOR et al., 1982). A distribuição da DM não é homogênea entre as raças, o que faz com que certas raças sejam consideradas fatores de risco para a doença. Os Poodles foram denominados como raça com risco excessivo de desenvolvimento da DM (GERSHWIN, 1975; MARMOR et al., 1982; HESS; KASS; WARD, 2000), o que provavelmente explica a alta incidência de catarata diabética nesta raça, visto que DM e catarata são significativamente associadas (MARMOR et al., 1982).

$O$ cão possui susceptibilidade única de desenvolver catarata secundária à $D M$ (BEAM; CORREA; DAVIDSON, 1999). Basher e Roberts (1995) e Beam, Correa e Davidson (1999) encontraram valores bastante próximos de cães com catarata atribuída à DM na população de cães diabéticos, 68 e $66 \%$ respectivamente. 
As cataratas possuem diferentes classificações, mas sua classificação segundo o estágio de desenvolvimento é de reconhecida importância na determinação de sua progressão e da baixa de visão associada (PLAYTER, 1977; DAVIDSON; NELMS, 2007). Por esta razão, neste estudo as cataratas foram assim classificadas, tanto as não diabéticas, como as diabéticas.

Fêmeas e machos são acometidos em diferentes proporções pela DM (MARMOR et al., 1982; FALL et al., 2007) e, conseqüentemente, pela catarata diabética (BEAM; CORREA; DAVIDSON, 1999). Apesar disso, após o diagnóstico da DM, fêmeas e machos possuem as mesmas chances de desenvolver catarata secundária à doença (MARMOR et al., 1982; BEAM; CORREA; DAVIDSON, 1999). Tratando-se das cataratas não diabéticas, os sexos são igualmente afetados (WILLIAMS; HEATH; WALLIS, 2004; GELATT; MACKAY, 2005; LYNCH; BRINKIS, 2006). Os sexos foram acometidos por catarata em diferentes proporções nos nossos grupos $(p=0,019)$. Nas cataratas não diabéticas, encontramos um equilíbrio entre fêmeas e machos, o que vai ao encontro da literatura citada. Entretanto, houve um acentuado desequilíbrio entre fêmeas e machos acometidos por catarata diabética, tendo as fêmeas sido pronunciadamente mais afetadas, o que também está de acordo com a literatura.

A média de idade de cães diabéticos é de 8,6 e 8,9 anos em diferentes estudos (FALL et al., 1999; BEAM; CORREA; DAVIDSON, 1999). A rápida progressão de opacidade da lente secundária a DM (BASHER; ROBERTS, 1995), com média estimada de 170 dias entre o diagnóstico da DM e a formação da catarata (BEAM; CORREA; DAVIDSON,1999), faz com que a média de idade de cães acometidos por catarata diabética seja semelhante à média de idade de cães diabéticos. A média de idade encontrada nos grupos diabéticos variou de 10,08 em cataras hipermaturas, 10,33 em imaturas, e 10,73 nas maturas; e não foram estatisticamente diferentes entre si.

As cataratas não diabéticas são encontradas em cães com média de idade de 9,4 $\pm 3,3$ anos, sendo que todos os cães com idade acima de 13,5 anos eram afetados por algum grau de opacidade da lente em estudo desenvolvido por Williams, Heath e Wallis (2004). Gelatt e MacKay (2005) estabeleceram que o aumento da prevalência de catarata ocorre na faixa etária de 10 a 15 anos, o que reflete a alta incidência de catarata senil em cães. Poodles têm prevalência de $50 \%$ do total de cães da raça acometidos por leucocoria em 0,68 a 0,85 de sua 
longevidade (WILLIAMS; HEATH; WALLIS, 2004), o que reflete a alta incidência de catarata senil também nesta raça.

A média de idade dos cães da raça Poodle acometidos por catarata nãodiabética variou de 7,03 anos nas cataratas imaturas a 8,45 anos nas hipermaturas. As cataratas maturas obtiveram idade média de 7,25 anos, valor intermediário em relação às anteriores. Assim, diferentes idades podem ser relacionadas a diferentes estágios de desenvolvimento da catarata, com possível correlação entre o aumento da idade e o avanço das fases de maturação, o que indica a progressão mais lenta da opacidade em cataratas não diabéticas.

A idade dos animais acometidos por cataratas no geral variou de 2 a 16 anos. O acometimento desses cães, com idades tão distintas, possivelmente indica cataratas de diferentes etiologias, visto que Poodles são reconhecidamente predispostos a cataratas primárias, secundárias, hereditárias e não-hereditárias (ANDERSEN; SHULTZ, 1958; KOCH; RUBIN, 1967; RUBIN; FLOWERS, 1972; BARNETT, 1985; DAVIDSON; NELMS, 2007).

Os animais diabéticos apresentaram-se estatisticamente mais velhos em relação aos grupos controle, catarata incipiente e catarata imatura não diabética. A DM é uma doença que usualmente ocorre em animais adultos a idosos, o que pode explicar essa diferença. Além disso, Poodles acometidos por cataratas hereditárias geralmente são bastante jovens, com 1 a 3 anos de idade (BARNETT, 1985), o que pode ter levado a média a valores mais baixos. Outra possível razão é que o avanço da fase de desenvolvimento das cataratas não diabéticas possivelmente pode estar relacionado com o avanço da idade, então, cães com os primeiros estágios (incipiente e imatura) são mais jovens.

As cataratas secundárias à DM são reconhecidas por sua rápida progressão (BASHER; ROBERTS, 1995). As cataratas diabéticas tiveram tempos de formação (referidos como tempo de leucocoria) estatisticamente menores. O tempo médio entre o diagnóstico da DM e a formação de catarata foi de 3,33 meses na catarata imatura; 5,88 na catarata matura e 1,59 na catarata hipermatura. Esses valores não foram estatisticamente diferentes ( $p=0,084)$. BEAM; CORREA; DAVIDSON (1999) encontraram valor médio de 170 dias para este mesmo intervalo, valor bastante próximo aos obtidos neste estudo. 


\subsection{Uveíte faco-induzida}

A uveíte faco-induzida (UFI) é a resposta inflamatória da úvea contra as proteínas lenticulares (WOERDT, 2000). Há dois tipos de uveíte faco-induzida na Medicina Veterinária: a uveíte facoclástica e a uveíte facolítica (WILCOCK; PEIFFER, 1987; WOERDT, 2000). A uveíte facoclástica é associada a ruptura capsular espontânea ou traumática; e a uveíte facolítica ocorre secundariamente à liberação de proteínas lenticulares através da cápsula intacta (WOERDT, 2000).

A cápsula do cristalino permite a passagem de substâncias de baixo peso molecular (RUBIN; GELATT, 1968), e consiste de uma barreira formidável a proteínas e anticorpos (GELATT, 1975). Na catarata avançada sua permeabilidade está aumentada (GELATT, 1975), assim a uveíte facolítica é mais comumente associada à presença de catarata hipermatura (RUBIN; GELATT, 1968; GELATT, 1975; PLAYTER, 1977; WILCOCK; PEIFFER, 1987; WOERDT, 2000; DENIS et al., 2003). Woerdt, Nasisse e Davidson (1992) observaram que $72 \%$ das cataratas associadas à UFI tinham evidência visível de reabsorção. Cães jovens apresentam reabsorção do material lenticular associada a cataratas hipermaturas com maior freqüência do que cães com mais de 6 anos de idade (RUBIN; GELATT, 1968). Entretanto, a uveíte facolítica já foi associada a todas as fases da catarata (WOERDT, NASISSE; DAVIDSON, 1992; KROHNE et al., 1995; WOERDT, 2000; DENIS et al., 2003). Encontramos uma distribuição estatisticamente diferente de UFI nos diversos grupos. Os grupos com cataratas hipermaturas, tanto diabéticas, como não diabéticas, tiveram maior porcentagem de incidência de UFI (44\% e 28,75\% respectivamente), o que reflete os dados já encontrados na literatura.

Woerdt, Nasisse e Davidson, em 1992, notificaram que a UFI se desenvolve rapidamente após a formação da catarata e é menos responsiva a tratamento em cães jovens. Neste estudo não foi avaliada a correlação de UFI e idade. Encontrouse cães de diferentes faixas etárias, o que provavelmente reflete uma incidência mais geral da UFI em relação à idade.

Cataratas diabéticas foram particularmente acometidas por UFI neste estudo. Todos os grupos de catarata diabética apresentaram maior prevalência de UFI em relação aos grupos correspondentes aos seus estágios de desenvolvimento nas cataratas não diabéticas. Paulsen et al., em 1986, encontraram UFI em $92 \%$ das 
cataratas diabéticas, a maior incidência de UFI em todas as categorias de catarata. UFI associada às cataratas secundárias a DM são mais prevalentes em cães provavelmente devido a sua rápida maturação (BASHER; ROBERTS, 1995).

Paulsen et al. encontraram uma prevalência de $71 \%$ de UFI em cães com cataratas de diferentes etiologias. Certas raças, como os Poodles e Cocker Spaniel, são comumente acometidas pela UFI, o que reflete a alta incidência de catarata nessas raças (WOERDT, NASISSE; DAVIDSON, 1992; WOERDT, 2000). Neste estudo, a maioria dos cães com catarata não foram acometidos por UFI clinicamente diagnosticável, isto é, com congestão de vasos episclerais e resistência à midríase medicamentosa.

\subsection{Pressão intra-ocular}

Vários estudos foram realizados, com uso de diferentes métodos de mensuração, para determinar a pressão intra-ocular (PIO) em cães (MAGRANE, 1951; GELATT; MACKAY, 1998). O Tonopen® é um tonômetro de aplanação largamente utilizado na Medicina Veterinária por sua portabilidade e facilidade de utilização nas diferentes espécies. $O$ TonoPen ${ }^{\circledR}$ é bastante acurado na faixa de normalidade da PIO, mas tende a superestimar valores mais baixos e subestimar valores mais elevados, tanto em cães, quanto em gatos e humanos (OLLIVIER; PLUMMER; BARRIE, 2007).

Gelatt e MacKay, em 1998, estabeleceram a PIO em cães em 19,2 \pm 5,9 $\mathrm{mmHg}$, com o uso do TonoPen®. A PIO do grupo controle, mensurada também por meio do Tonopen $\AA$, foi de $12,05 \pm 3,17 \mathrm{mmHg}$, e não foi estatisticamente diferente dos outros grupos. Isso provavelmente se deve à falta de homogeneidade dos grupos, ao tamanho reduzido da amostra, ou mesmo ao fato do grupo controle ser formado por olhos normais, mas não necessariamente por cães normais, isto é, o olho contralateral poderia estar acometido por catarata.

Leasure, Gelatt e MacKay (2001) não encontraram diferenças na PIO de cães com mesma fase de catarata em ambos os olhos em relação a cães com esta mesma fase em um olho, mas com diferentes estágios de maturação no olho contralateral. Woerdt (2000), entretanto, estabeleceu que não houve diferença nas 
taxas de sucesso cirúrgico de extração de catarata entre olhos afetados por UFI e olhos livres de UFI mas com o outro olho afetado. A importância da inflamação intraocular de um olho sobre o contralateral, bem definida na Medicina Humana mesmo pela Oftalmia Simpática, ainda precisa ser estabelecida na Medicina Veterinária.

A PIO sofre variações diurnas de cerca de 2 a $4 \mathrm{mmHg}$ nos cães, sendo maior pela manhã (GELATT; MACKAY, 1998). Todas as mensurações neste estudo foram realizadas pela manhã, em horários bem próximos, o que diminuiu a influência deste fator sobre a PIO.

A PIO também sofre influência da idade; mas em cães não sofre modificações decorrentes do sexo e da raça (GELATT; MACKAY, 1998). A PIO aumenta com o aumento da idade em seres humanos de populações do Ocidente, e o contrário ocorre nas populações do Oriente (KLEIN; KLEIN; MOSS, 1984; SHIOSE, 1984; COSTAGLIOLA; TRAPANESE; PAGANO, 1990; QURESHI, 1997; LEE et al., 2002; NOMURA et al., 2002; ROCHTCHINA; MITCHELL; WANG, 2002; KASHIWAGI; SHIBUYA; TSUKAHARA, 2005; GONZÁLEZ-MÉIJOME et al., 2006). A idade foi um fator estatisticamente correlacionado à PIO por meio de uma relação negativa. Em cães, esse declínio da PIO com o aumento da idade já havia sido reportado por Gelatt e MacKay, em 1998. Entretanto não foram encontradas correlações da PIO com o peso, nem com o tempo de formação da catarata.

A PIO, mensurada por meio do Tonopen-XL®, não foi homogeneamente distribuída entre nossos grupos. Cataratas hipermaturas, tanto diabéticas quanto não diabéticas, tiveram $\mathrm{PIO}$ estatisticamente menores em relação ao grupo catarata imatura, em cerca de $3 \mathrm{mmHg}$. Em 2001, Leasure, Gelatt e MacKay também encontraram diferença de $3 \mathrm{mmHg}$ da PIO entre olhos com catarata imatura e hipermatura. Em 2003, Denis et al. encontraram diferenças nos títulos de anticorpos anti-cristalinas entre cataratas imaturas e hipermaturas, bem como da severidade da UFI Esses grupos de cataratas hipermaturas foram os mesmos que apresentaram maior acometimento por UFI clinicamente diagnosticável. Olhos com presença de UFI tiveram correlação estatisticamente significativa com a diminuição da PIO. A diferença de PIO entre olhos com e sem a presença de UFI foi de cerca de $2 \mathrm{mmHg}$.

Inflamação intra-ocular causa aumento da drenagem de humor aquoso e diminuição da PIO (LEASURE; GELATT; MACKAY, 2001). UFI de grau leve pode passar despercebida caso a tonometria não seja realizada, principalmente em olhos que não apresentam miose (HAKANSON; FORRESTER, 1990). Basher e Roberts 
(1995) referem que PIOs menores que $12 \mathrm{mmHg}$ são usualmente associadas com presença de uveíte. Todos os nossos grupos apresentaram PIOs médias bastante próximas a $12 \mathrm{mmHg}$, inclusive o grupo controle $(12,05 \mathrm{mmHg})$.

Não encontramos correlação de aumento da PIO com presença de catarata diabética. Cães galactosêmicos apresentam PIO normal, apesar da diminuição de formação do humor aquoso (TORIS et al., 2006). Em seres humanos que apresentam DM, a PIO é usualmente elevada (KLEIN; KLEIN; MOSS, 1984; KEOLEIAN et al., 1992).

\subsection{Paquimetria}

A paquimetria representa o estado de deturgescência da córnea (OLLIVIER; PLUMMER; BARRIE, 2007). A transparência corneal é dependente da manutenção de um grau de relativa desidratação contra o estroma corneal fortemente hidrofílico (HERSE, 1990). O principal mecanismo responsável por esse estado de semidesidratação é a atividade da bomba de $\mathrm{Na}^{+} / \mathrm{K}^{+}$ATPase presente no endotélio corneal (MAURICE, 1972). Outros fatores importantes na manutenção da espessura corneal são a barreira epitelial impermeável à entrada de fluido advindo da lágrima; e a resistência à entrada de fluido advindo do humor aquoso pela barreira endotelial (MACDONALD; GEROSKI; EDELHAUSER, 1987; HERSE, 1990; GILGER et al, 1991; WESTON et al., 1995; LYNCH; BRINKIS, 2006).

A densidade celular média do endotélio corneal em cães é de 2.335 e $3.175 \pm$ 776 células $/ \mathrm{mm}^{2}$ segundo diferentes autores (GWIN et al., 1982; KAFARNIK; FRITSCHE; REESE, 2007). Após injúria, a córnea irá aumentar sua espessura devido ao edema gerado, mas retornará aos valores normais apesar do dano endotelial, a não ser que sua densidade seja reduzida a menos de 500 a 1.040 células $/ \mathrm{mm}^{2}$ (GILGER et al., 1991). Se as células remanescentes mantêm a densidade endotelial dentro do limite fisiológico, e o endotélio se encontra saudável após recuperar-se do insulto, a densidade endotelial numérica não se correlaciona diretamente com a espessura corneal (GWIN et al., 1982; MACDONALD; GEROSKI; EDELHAUSER, 1987; HERSE, 1990; GILGER et al, 1991; WESTON et al, 1995; 
LYNCH; BRINKIS, 2006). Assim, a paquimetria é usada para mensurar a função endotelial especialmente após um insulto recente (GILGER et al., 1991).

A paquimetria ultra-sônica é o método mais acurado de mensuração da espessura corneal. Gilger et al., em 1991, estabeleceram a espessura corneal em cães saudáveis em $562 \pm 6,2 \mu \mathrm{m}$, com valores mínimo e máximo de 409 e $743 \mu \mathrm{m}$, por meio da paquimetria ultra-sônica. Montiani-Ferreira e Petersen-Jones (2003) iriam notificar seu aumento fisiológico até 30 semanas de idade.

O grupo controle apresentou espessura corneal de 608,64 \pm 45,91 microns, que variou de 532 a $696 \mu \mathrm{m}$, por meio de paquimetria ultra-sônica com o uso do PachPen®. Não foram encontrados dados relativos à mensuração da espessura corneal com o uso deste paquímetro em específico na Medicina Veterinária.

Os valores da paquimetria em cães adultos aumentam significativamente com o aumento da idade e do peso (GWIN et al., 1982; GILGER et al., 1991). Encontrouse essa mesma correlação positiva nos cães Poodles, tanto para a idade, quanto para o peso (todos os grupos conjuntamente).

Dentre os fatores que alteram os valores da paquimetria em cães saudáveis também estão o sexo, sendo que fêmeas apresentam córneas mais afiladas que machos (GILGER et al., 1991), e a raça, o que provavelmente está relacionado ao peso (MONTIANI-FERREIRA; PETERSEN-JONES, 2003). Todos os valores compreendidos foram de cães da raça Poodle, o que retira a influência da raça sobre esses dados. A influência do sexo na espessura corneal não foi avaliada.

Macdonald, Geroski e Edelhauser (1987) desvendaram o efeito da inflamação sobre o endotélio corneal, comprovando a quebra da barreira endotelial e diminuição da atividade das bombas de $\mathrm{Na}^{+} / \mathrm{K}^{+}$ATPase durante inflamação intra-ocular induzida por injeção intra-vítrea de albumina sérica bovina. As alterações endoteliais foram positivamente correlacionadas com 0 aumento da espessura da córnea (MACDONALD; GEROSKI; EDELHAUSER, 1987). Encontrou-se diferença média de $60 \mu \mathrm{m}$ entre córneas de olhos com e sem sinais de UFI. A UFI teve efeito significante no aumento da paquimetria.

Diversos autores notificaram o aumento da espessura corneal em pessoas diabéticas (BUSTED; OLSEN; SCHMITZ, 1981; WESTON et al., 1995; MCNAMARA et al., 1998; SWANN, 1999; ROSENBERG et al., 2000; LEE et al., 2006), o que também foi relatado em cães, nos quais a DM teve efeito estatisticamente significante sobre a paquimetria (LYNCH; BRINKIS, 2006). Em humanos a 
hiperglicemia já foi relacionada com a perda de controle da hidratação corneal e diminuição da densidade celular do endotélio (MACNAMARA et al., 1998); bem como a duração da DM já foi associada com o aumento da paquimetria (BUSTED; OLSEN; SCHMITZ, 1981; LEE et al., 2006). Cães diabéticos apresentam polimegatismo e pleomorfismo das células endoteliais (YEE et al., 1985), semelhantes aos encontrados na Medicina Humana (KEOLEIAN et al., 1992). Herse (1990) em estudo com coelhos induzidos à doença, comprovou que o aumento da espessura corneal relacionada à DM se deve à redução da atividade das bombas de $\mathrm{Na}^{+} / \mathrm{K}+$ ATPase encontradas no endotélio, o que Weston et al. (1995) vieram a confirmar mais tarde em seres humanos. O estroma corneal na DM não apresenta aumento da pressão osmótica (HERSE, 1990) ou mesmo a presença de aldose redutase (CISARIK-FREDENBURG, 2001), bem como a barreira endotelial não se encontra comprometida (HERSE, 1990; KEOLEIAN et al., 1992; WESTON et al., 1995; MACNAMARA et al., 1998; ROSENBERG et al., 2000). Gekka et al. (2004) notificaram predisposição à quebra da barreira epitelial em seres humanos diabéticos.

Realmente os animais diabéticos apresentaram maiores valores de paquimetria, e isto provavelmente se deve à somatória dos efeitos da DM e da UFI sobre o endotélio. UFI são particularmente presentes na DM, como já discutido. A paquimetria obteve correlação negativa com o tempo de leucocoria. Esse achado oferece suporte ao efeito da UFI sobre o endotélio como resultado da rápida progressão da catarata diabética em cães.

Usualmente o aumento da paquimetria resulta em aumento da tonometria, visto que os métodos de mensuração da PIO mais comumente utilizados são transcorneais, e córneas mais espessas oferecem maior resistência à deformação e aplanação (RECEP et al., 2001; LLEÓ et al., 2003; KOTECHA et al., 2005). Essa correlação também já foi comprovada com o uso do TonoPen® (DOHADWALA; MUNGER; DAMJI, 1998). No entanto, encontrou-se correlação negativa entre essas variáveis. É provável que a influência da UFI na diminuição da PIO supere a influência do aumento da paquimetria em elevar as medidas tonométricas. Contudo, pode-se suspeitar que os valores reais da PIO sejam menores do que os encontrados, tanto pela influência do aumento da paquimetria, quanto pela limitação do TonoPen® que usualmente tende a não ser tão acurado nas baixas PIOs. 
Assim, ambas paquimetria e PIO se mostraram indicadores valiosos da presença de UFI, principalmente se estas variáveis apresentarem correlação negativa entre si. 


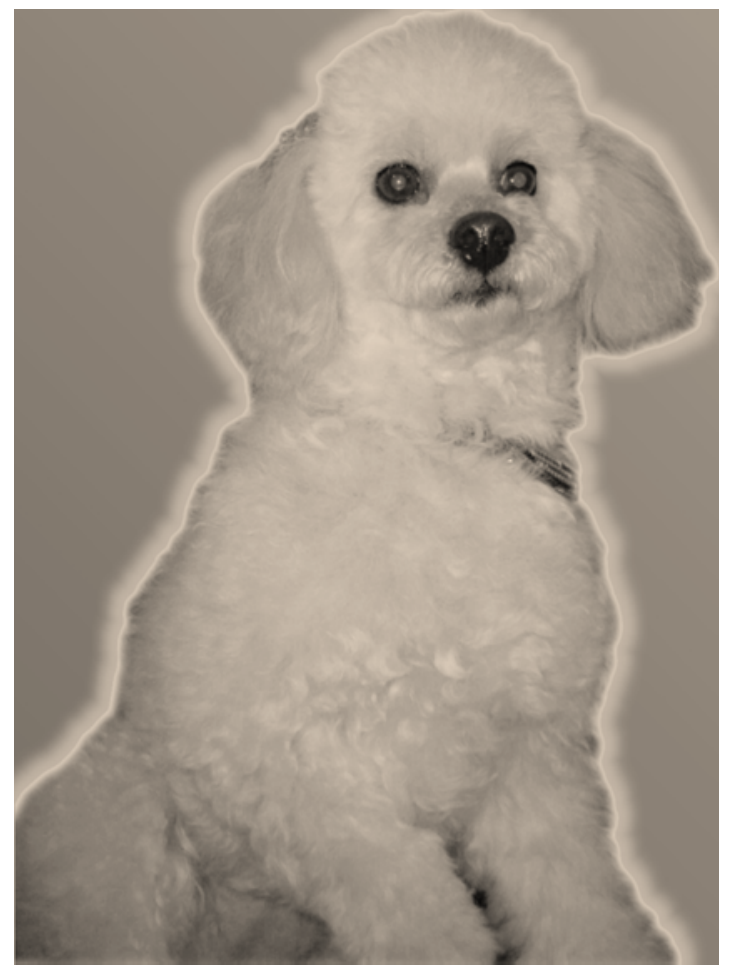

CONCLUSÕES 


\section{CONCLUSÕES}

Com base nos resultados apresentados, podemos concluir que:

1. Olhos com catarata diabética apresentam maior prevalência de UFI em relação aos mesmos estágios de desenvolvimento em cataratas não diabéticas.

2. Cataratas diabéticas possuem menor tempo de formação em relação às cataratas não diabéticas.

3. Hipermaturidade foi correlacionada à presença de UFI.

4. Cataratas hipermaturas, tanto diabéticas quanto não diabéticas, tiveram PIO estatisticamente menores em relação ao grupo catarata imatura.

5. Na UFI houve diminuição de cerca de $2 \mathrm{mmHg}$ na PIO e aumento de cerca de $60 \mu \mathrm{m}$ na paquimetria.

6. Houve correlação negativa entre pressão PIO e idade. Houve também correlação negativa entre paquimetria e tempo de formação da catarata. A paquimetria foi positivamente correlacionada com idade e peso.

7. Os animais diabéticos apresentaram maiores valores de paquimetria, e isto provavelmente se deve à somatória dos efeitos da DM e da UFI sobre o endotélio.

8. PIO e paquimetria mostraram-se instrumentos valiosos na determinação da presença de UFI, e foram negativamente correlacionados entre si. 


\section{REFERÊNCIAS}

ADKINS, E. A.; HENDRIX, D. V. Outcomes of dogs presented for cataracts evaluation: a retrospective study. Journal of American Animal Hospital Association, v. 41, n. 4, p. 235-240, Jul. 2005.

ANDERSEN, A. C.; SHULTZ, F. T. Inherited (congenital) cataract in the dog. American Journal of Pathology, v. 34, n. 5, p. 965-975, Sep. 1958.

BARROS, P. S. M.; ANGELOTTI, A. C.; NOBRE, F.; MORALES, A.; FANTONI, D. T.; BARROS, S. B. M. Antioxidant profile of cataractous english cocker spaniels. Veterinary Ophthalmology, v. 2, p. 83-86, 1999.

BARROS, P. S. M.; SAFATLE, A. M. V.; SILVA, H. A. R.; BARROS, S. B. M. Ascorbic acid levels in plasma and aqueous humor of dogs with diabetic cataract. American College of Veterinary Ophthalmologists, $32^{\text {nd }}$ Meeting, Denver, USA. Veterinary Ophthalmology, v. 5, p. 296, 2002.

BARROS, P. S. M.; SAFATLE, A. M. V.; QUEIROZ, L.; SILVA, V. V.; BARROS, S. B. $M$. Blood and aqueous humor antioxidants in cataractous poodles. Canadian Journal of Ophthalmology, v. 39, n. 1, p. 19-24, 2004.

BASHER, A. W. P.; ROBERTS, S. M. Ocular manifestations of diabetes mellitus: diabetic cataracts in dogs. Veterinary Clinics of North America: Small Animal Practice, v. 25, n. 3, p. 661-676, May. 1995.

BARNETT, K. C. The diagnosis and differential diagnosis of cataract in the dog. Journal of Small Animal Practice, v. 26. p. 305-316, 1985.

BEAM, S.; CORREA, M. T.; DAVIDSON, M. G. A retrospective-cohort study on the development of cataracts in dogs with diabetes mellitus: 200 cases. Veterinary Ophthalmology, v. 2, p. 169-172, 1999.

BEFANIS, P. J.; PEIFFER, R. L.; BROWN, D. Endothelial repair of the canine cornea. American Journal of Veterinary Research, v. 42, n. 4, p. 590-595, Apr. 1981. 
BRON, A. M.; CREUZOT-GARCHER, C.; GOUDEAU-BOUTILLON, S.; D'ATHIS, P. Falsely elevated intraocular pressure due to increased central corneal thickness. Graefe's Archive for Clinical and Experimental Ophthalmology, v. 237, n. 3, p. 220-224, Mar. 1999.

BUSTED, N.; OLSEN, T; SCHMITZ, O. Clinical observations on the corneal thickness and the corneal endothelium in diabetes mellitus. British Journal of Ophthalmology, v. 65, p. 687-690, 1981.

CISARIK-FREDENBURG, P. Discoveries in research on diabetic keratopathy. Optometry. v. 72, n. 11, p. 691-704, Nov. 2001.

COLITZ, C. M. H.; MALARKEY, D.; DYKSTRA, M. J.; MCGAHAN, M. C.; DAVIDSON, M. G. Histologic and immunohistochemical characterization of lens capsular plaques in dogs with cataracts. American Journal of Veterinary Research, v. 61, n. 2, p. 139-143, Feb. 2000.

COSTAGLIOLA, C.; TRAPANESE, A.; PAGANO, M. Intraocular pressure in a healthy population: a survey of 751 subjects. Optometry and vision science : official publication of the American Academy of Optometry, v. 67, n. 3, p. 204-206, Mar. 1990.

COULOMBRE, A. J. Cataractogenesis: developmental inputs and constraints. Ophthalmology, v. 86, n. 9, p. 1559-1570, Sep. 1979.

CULLEN, L. C.; IHLE, L. S.; WEBB, A. A.; McCARVILLE, C. Keratoconjunctival effects of diabetes mellitus in dogs. Veterinary Ophthalmology, v. 8, n. 4, p. 215224, Jul-Aug. 2005.

DANIEL, W. J.; NOONAN, N. E.; GELATT, K. N. Isolation and characterization of the crystallins of the normal and cataractous canine lens. Current Eye Research, v. 3, n. 7, p. 911-922, Jul. 1984.

DATILES, M. B.; KADOR, P. F.; KASHIMA, K.; KINOSHITA, J. H.; SINHA, A. The effects of sorbinil, an aldose reductase inhibitor, on the corneal endothelium in galactosemic dogs. Investigative Ophthalmology and Visual Science, v. 31, n. 11, p. 2201-2204, Nov.1990. 
DAVISON, M. G.; NELMS, S. R. Diseases of the canine lens and cataract formation . In: Veterinary ophthalmology. 4. ed. lowa: Blackwell Publishing, 2007b. p. $859-887$.

DENIS, H. M.; BROOKS, D. E.; ALLEMAN, A. R.; ANDREW, S. E.; PLUMMER, C. Detection of anti-lens crystallin antibody in dogs with and without cataracts. Veterinary Ophthalmology, v. 6, n. 4, p. 321-327, 2003.

DOHADWALA, A. A.; MUNGER, R. DAMJI, K. F. Positive correlation between TonoPen intraocular pressure and central corneal thickness. Ophthalmology, v. 105, n. 10, p. 1849-1854, Oct. 1998.

ENGERMAN, R. L.; KERN, T. S. Aldose reductase inhibition fails to prevent retinopathy in diabetic and galactosemic dogs. Diabetes, v. 42, n. 6, p. 820-825, Jun. 1993.

FALL, T.; HAMLIN, H. H.; HEDHAMMAR, A.; KÄMPE, O.; EGENVALL, A. Diabetes mellitus in a population of 180,000 insured dogs: incidence, survival, and breed distribution. Journal of Veterinary Internal Medicine, v. 21, n. 6, p. 1209-1216, Nov. 2007.

GEKKA, M.; MIYATA, K.; NAGAI, Y.; NEMOTO, S.; SAMESHIMA, T.; TANABE, T.; MARUOKA, S.; NAKAHARA, M.; KATO, S.; AMANO, S. Corneal epithelial barrier function in diabetic patients. Cornea, v. 23, n. 1, p. 35-37, Jan. 2004.

GELATT, K. N. Spontaneous cataract resorption and lens-induced uveitis in the dog. Modern Veterinary Practice, v. 56, n. 5, p. 331-335, May. 1975.

GELATT, K. N.; BRUSS, M.; DECOSTANZA, S. M.; NOONAN, N. E.; DAS, N. D.; WOLF, E. D. Reduced, oxidized, and protein-bound glutathione concentrations in normal and cataractous lenses in the dog. American Journal of Veterinary Research, v. 43, n. 7, p. 1215-1217, Jul. 1982.

GELATT, K. N.; MACKAY, E. O. Distribution of intraocular pressure in dogs. Veterinary Ophthalmology, v. 1, p. 109-114, 1998.

GELATT, K. N; MACKAY, E. O. Prevalence of primary breed-related cataracts in the dog in North America. Veterinary Ophthalmology, v. 8, n. 2, p. 101-111, 2005. 
GELATT, K. N.; MACKAY, E. O. Secondary glaucomas in the dog in North America. Veterinary Ophthalmology, v. 7, n. 4, p. 245-259, 2004.

GERSHWIN, L. J. Familial canine diabetes mellitus. Journal of American Veterinary Medical Association, v. 167, n. 6, p.479-480, Sep. 1975.

GIBLIN, F. J. Glutathione: a vital lens antioxidant. Journal of Ocular Pharmacology and Therapeutics, v. 16, n. 2, p. 121-135, Apr. 2000.

GILGER, B. C.; WHITLEY, R. D.; McLAUGHLIN, S. A.; WRIGHT, J. C.; DRANE, J. W. Canine corneal thickness measured by ultrasonic pachymetry. American Journal of Veterinary Research, v. 52, n. 10, p. 1570-1572, Oct. 1991.

GOEBBELS, M.; SPITZNAS, M. Endothelial barrier function after phacoemulsification: a comparison between diabetic and non-diabetic patients. Graefe's Archive for Clinical and Experimental Ophthalmology, v. 229, n. 3, p. 254-257, 1991.

GONZÁLES-MÉIJOME, J. M.; JORGE, J.; QUEIRÓS, A.; FERNANDES, P.; MONTÉS-MICÓ, R.; ALMEIDA, J. B.; PARAFITA, M.A. Age differences in central and peripheral intraocular pressure using a rebound tonometer. British Journal of Ophthalmology, v. 90, n. 12, p. 1495-1500, Dec. 2006.

GWIN, R. M.; LERNER, I.; WARREN, J. K.; GUM, G. Decrease in canine corneal endothelial cell density and increase in corneal thickness as functions of age. Investigative Ophthalmology \& Visual Science, v. 22, n. 2, p. 267-271, Feb. 1982.

HAKANSON, N.; FORRESTER, D. Uveitis in the dog and cat. Veterinary Clinics of North America: Small Animal Practice, v. 20, n. 3, p. 715-735, May. 1990.

HERSE, P. R. Corneal hydration control in normal and alloxan-induced diabetic rabbits. Investigative Ophthalmology and Visual Science, v. 31, n. 11, p. 22052213, Nov. 1990.

HERSE, P. R. Diurnal and long-term variations in corneal thickness in the normal and alloxan-induced diabetic rabbit. Current Eye Research, v. 9, n. 5, p. 451-457, May.1990. 
HESS, R. S.; KASS, P. H.; WARD, C. R. Breed distribution of dogs with diabetes mellitus admitted to a tertiary care facility. Journal of American Veterinary Medical Association, v. 216, n. 9, p. 1414-1417, May. 2000.

HEYWOOD, R. Intraocular pressures in the beagle dog. Journal of Small Animal Practice, v. 12, p. 119-121, 1971.

ISHIMOTO, S.; WU, G. S.; HAYASHI, S.; ZHANG, J.; RAO, N. A. Free radical tissue damages in the anterior segment of the eye in experimental autoimmune uveitis. Investigative Ophthalmology and Visual Science, v. 37, n. 4, p. 630-636, Mar. 1996.

KAFARNIK, C.; FRITSCHE, J.; REESE, S. In vivo confocal microscopy in the normal corneas of cats, dogs and birds. Veterinary Ophthalmology, v. 10, n. 4, p. 222-230, Jul. 2007

KASHIWAGI, K.; SHIBUYA, T.; TSUKAHARA, S. De novo age-related retinal disease and intraocular-pressure changes during a 10-year period in a Japanese adult population. Japanese Journal of Ophthalmology, v. 49, n. 1, p. 36-40, Jan-Feb. 2005.

KEOLEIAN, G. M.; PACH, J. M.; HODGE, D. O.; TROCME, S. D.; BOURNE, W. M. Structural and functional studies of the corneal endothelium in diabetes mellitus. American Journal of Ophthalmology, v. 113, n. 1, p. 64-70, Jan. 1992.

KLEIN, B. E.; KLEIN, R.; LINTON, K. L. Intraocular pressure in an American community. The Beaver Dam Eye Study. Investigative Ophthalmology and Visual Science, v. 33, n. 7, p. 2224-2228, Jun. 1992.

KLEIN, B. E.; KLEIN, R.; MOSS, S. E. Intraocular pressure in diabetic persons. Ophthalmology, v. 91, n. 11, p. 1356-1360, Nov. 1984.

$\mathrm{KOCH}$, S. A.; RUBIN, L. F. Probable nonhereditary congenital cataracts in dogs. Journal of American Veterinary Medical Association, v. 150, n. 11, p. 1374-1376, Jul. 1967. 
KOTECHA, A.; WHITE, E. T.; SHEWRY, J. M.; GARWAY-HEATH, D. F. The relative effects of corneal thickness and age on Goldmann applanation tonometry and dynamic contour tonometry. British Journal of Ophthalmology, v. 89, n. 12, p. 1572-1575, Dec. 2005.

KROHNE, S. G.; KROHNE, D. T.; LINDLEY, D. M.; WILL, M. T. Use of laser flaremetry to measure aqueous humor protein concentration in dogs. Journal of American Veterinary Medical Association, v. 206, n. 8, p. 1167-1172, Apr. 1995.

LEASURE, J.; GELATT, K. N.; MACKAY, E. O. The relationship of cataract maturity to intraocular pressure in dogs. Veterinary Ophthalmology, v. 4, n. 4, p. 273-276, 2001.

LEE. J. S.; LEE, S. H.; OUM, B. S.; CHUNG, J. S.; CHO, B. M.; HONG, J. W. Relationship between intraocular pressure and systemic health parameters in a Korean population. Clinical and experimental ophthalmology, v. 30, n. 4, p. 237241, Aug. 2002.

LEE, J. S.; OUM, B. S.; CHOI, H. Y.; LEE, J. E.; CHO, B. M. Differences in corneal thickness and corneal endothelium related to duration in diabetes. Eye, v. 20, n. 3, p. 315-318, Mar. 2006.

LLEÓ, A.; MARCOS, A.; CALATAYUD, M.; ALONSO, L.; RAHHAL, S M.; SANCHISGIMENO, J. A. The relationship between central corneal thickness and Goldmann applanation tonometry. Clinical and Experimental Optometry, v. 86, n. 2, p. 104108, Mar. 2003.

LYNCH, G. L.; BRINKIS, J. L. The effect of elective phacofragmentation on central corneal thickness in the dog. Veterinary Ophthalmology, v. 9, n. 5, p. 303-310, 2006.

MACDONALD, J. M.; GEROSKI, D. H.; EDELHAUSER, H. F. Effect of inflammation on the corneal endothelial pump and barrier. Current Eye Research, v. 6, n. 9, p. 1125-1132, Sep. 1987.

MAGRANE, W. G. Tonometry in Ophthalmology. The North American Veterinarian, v. 32, p. 413-415, 1951. 
MARMOR M.; WILLEBERG P.; GLIKMAN L. T.; PRIESTER, W. A.; CYPESS, R. H.; HURVITZ, A. I. Epizootiologic patters of diabetes mellitus in dogs. American Journal of Veterinary Research, v. 43, p. 465-470, 1982.

MAURICE, D. M. The location of the fluid pump in the cornea. Journal of Physiology, v. 221, p. 43-54, 1972.

MCNAMARA, N. A.; BRAND, R. J.; POLSE, K. A.; BOURNE, W. M. Corneal function during normal and high serum glucose levels in diabetes. Investigative Ophthalmology \& Visual Science, v. 39, n. 1, p. 3-17, Jan. 1998.

MONTIANI-FERREIRA, F.; PETERSEN-JONES, S.; CASSOTIS, N.; RAMSEY, D. T.; GEARHART, P.; CARDOSO, F. Early postnatal development of central corneal thickness in dogs. Veterinary Ophthalmology, v. 6, n. 1, p. 19-22, Mar. 2003.

NOMURA, H.; ANDO, F.; NIINO, N.; SHIMOKATA, H.; MIYAKE, Y. The relationship between age and intraocular pressure in a Japanese population: the influence of central corneal thickness. Current Eye Research, v. 24, n. 2, p. 81-85, Feb. 2002.

OLLIVIER, F. J.; PLUMMER, C. E.; BARRIE, K. P. Ophthalmic examination and diagnostics. In: 2007a. p. 438-506. Veterinary ophthalmology. 4. ed. lowa: Blackwell Publishing,

OLSEN, T. Transient changes in specular appearance of the corneal endothelium and in corneal thickness during anterior uveitis. Acta Ophthalmology (Copenhagen), v. 59, n. 1, p. 100-109, Feb. 1981.

PAULSEN, M. E.; LAVACH, J. D.; SEVERIN, G. A.; EICHENBAUM, J. D. The effect of lens-induced uveitis on the success of extracapsular cataract extraction: a retrospective study of 65 lens removals in the dog. Journal of American Animal Hospital Association, v. 22, p. 49-56, Jan-Feb. 1986.

PERLMAN, J. I.; DELANY, C. M.; SOTHERN, R. B.; SKOLNICK, K. A.; MURRAY, D.; JACOBS, R. W.; SHUE, J. L.; KAPLAN, E.; FRIEDMAN, N. C.; NEMCHAUSKY, B. A.; RYAN, M. D.; KANABROCKI, E. L. Relationships between $24 \mathrm{~h}$ observations in intraocular pressure vs blood pressure, heart rate, nitric oxide and age in the medical chronobiology aging project. La Clinica terapeutica, v. 158, n.1, p. 31-47, Jan-Feb. 2007. 
PIERRO, L.; BRANCATO, R.; ZAGANELLI, E. Correlation of corneal thickness with blood glucose control in diabetes mellitus. Acta Ophthalmology (Copenhagen), v. 71, n. 2, p. 169-172, Apr. 1993.

PLAYTER, R. F. The development and maturation of cataract. Journal of American Animal Hospital Association, v. 13, p. 317-322, 1977.

QURESHI, I. A. Intraocular pressure: a comparative analysis in two sexes. Clinical physiology, v. 17, n. 3, p. 247-255, May. 1997.

RAO, G. N.; SHAW, E. L.; ARTHUR, E. J.; AQUAVELLA, J. V. Endothelial cell morphology and corneal deturgescence. Annals of Ophthalmology, v. 11, n. 6, p. 885-899, Jun. 1979.

RECEP, O. F.; HASIRIPI, H.; CAGIL, N.; SARIKATIPOGLU, H. Relation between corneal thickness and intraocular pressure measurement by noncontact and applanation tonometry. Journal of Cataract and Refractive Surgery, v. 27, n. 11, p. 1787-1791, Nov. 2001.

REDDY, V. N.; GIBLIN, F. J. Metabolism and function of glutathione in the lens. Ciba Foundation Symposium, v. 106, p. 65-87, 1984.

REDDY, V. N. Glutathione and its function in the lens-an overview. Experimental Eye Research, v. 50, n. 6, p. 771-778, 1990.

ROCHTCHINA, E.; MITCHELL, P.; WANG, J. J. Relationship between age and intraocular pressure: the Blue Mountain Eye Study. Clinical and Experimental Ophthalmology, v. 30, n. 3, p. 173-175, Jun. 2002.

ROSENBERG, M. E.; TERVO, T. M. T.; IMMONEN, I. J.; MÜLLER, L. J.; GRÖNHAGEN-RISKA, C.; VESALUOMA, M. H. Corneal structure and sensitivity in type 1 diabetes mellitus. Investigative Ophthalmology \& Visual Science, v. 41, n. 10, p. 2915-2921, Sep. 2000.

ROSNER, B. Fundamentals of biostatistics. 4 ed. New York: Duxbury Press, 1994. pp. 682

ROSZKOWSKA, A. M.; TRINGALI, C. G.; COLOSI, P.; SQUERI, C. A.; FERRERI, G. Corneal endothelium evaluation in type I and type II diabetes mellitus. Ophthalmologica, v. 213, n. 4, p. 258-261, 1999. 
RUBIN, L. F.; FLOWERS, R. D. Inherited cataract in a family of Standard Poodles. Journal of American Veterinary Medical Association, v. 161, n. 2, p. 207-208, 1972.

RUBIN, L. F.; GELATT, K. N. Spontaneous resorption of the cataractous lens in dogs. Journal of American Veterinary Medical Association, v. 152, n. 2, p. 139153, Jan. 1968.

SATO, S.; TAKAHASHI, Y.; WYMAN, M.; KADOR, P. F. Progression of sugar cataract in the dog. Investigative Ophthalmology and Visual Science, v. 32, n. 6 , p. 1925-1931, May. 1991.

SCHULTZ, R. O.; GLASSER, D. B.; MATSUDA, M.; YEE, R. W.; EDELHAUSER, H. $F$. Response of the corneal endothelium to cataract surgery. Archives of Ophthalmology, v. 104, n. 8, p. 1164-1169, Aug. 1986.

SHIOSE, Y. Intraocular pressure: new perspectives. Survey of ophthalmology, v. 34, n. 6, p. 413-435, May-Jun. 1990.

SHIOSE, Y. The aging effect on intraocular pressure in an apparently normal population. Archives of Ophthalmology, v. 102, n. 6, p. 883-887, Jun. 1984.

SONMEZ, B.; BOZKURT, B.; ATMACA, A.; IRKEC, M.; ORHAN, M.; ASLAN, U. Effect of glycemic control on refractive changes in diabetic patients with hyperglycemia. Cornea, v. 24, n. 5, p. 531-537, Jul. 2005.

SWANN, P. G. Non-retinal ocular changes in diabetes. Clinical and Experimental Optometry, v. 82, n. 2-3, p. 43-46, Mar. 1999.

TORIS, C. B.; LANE, J. T.; AKAGI, Y.; BLESSING, K. A.; KADOR, P. F. Aqueous flow in galactose-fed dogs. Experimental Eye Research, v. 83, p. 865-870, 2006.

WOERDT, A. Lens-induced uveitis. Veterinary Ophthalmology, v. 3, p. 227-234, 2000.

WOERDT, A.; NASISSE, M. P; DAVIDSON, M. G. Lens-induced uveitis in dogs: 151 cases (1985-1990). Journal of American Veterinary Medical Association, v. 201, n. 6, p. 921-926, Sep. 1992. 
WESTON, B. C.; BOURNE, W. M.; POLSE, K. A.; HODGE, D. O. Corneal hydration control in diabetes mellitus. Investigative Ophthalmology and Visual Science, $v$. 36, n. 3, p. 586-595, Mar. 1995.

WILCOCK, B. P.; PEIFFER Jr., R. L. The pathology of lens-induced uveitis in dogs. Veterinary Pathology, v. 24, p. 549-553, 1987.

WILLIAMS, D. L.; HEATH, M. F.; WALLIS, C. Prevalence of canine cataract: preliminary results of a cross-sectional study. Veterinary Ophthalmology, v. 7, n. 1, p. 29-35, 2004.

WYMAN, M.; SATO, S.; AKAGI, Y.; TERUBAYASHI, H.; DATILES, M. KADOR, P. F.; The dog as a model for for ocular manifestations of high concentrations of blood sugars. Journal of American Veterinary Medical Association, v. 193, n. 9, p. 1153-1156, 1988.

YEE, R. W.; MATSUDA, M.; KERN, T. S.; ENGERMAN, R. L.; EDELHAUSER, H. F. Corneal endothelial changes in diabetic dogs. Current Eye Research, v. 4, n. 7, p. 759-766, Jul. 1985. 
APÊNDICE A - Distribuição das variáveis e olhos do grupo controle segundo os animais - São Paulo - 2008

GRUPO CONTROLE - POODLES NORMAIS

\begin{tabular}{|c|c|c|c|c|c|c|c|c|}
\hline Animal & Sexo & Idade (aa) & Peso (kg) & PIO OD (mmHg) & PAQ OD $(\mu \mathrm{m})$ & PIO OE (mmHg) & PAQ OE $(\mu \mathrm{M})$ & OBSERVAÇÕES \\
\hline 1 & $\mathrm{~m}$ & 11 & 8,1 & 10 & 628 & & & Cat. incipiente $\mathrm{E}$ \\
\hline 6 & $\mathrm{~m}$ & 13 & 7,6 & 14 & 573 & 14 & 558 & \\
\hline 8 & $f$ & 10 & 4,8 & & & 14 & 533 & Cat matura $D$ \\
\hline 12 & $f$ & 13 & 3,7 & 14 & 673 & & & Cat. hipermatura $\mathrm{E}$ \\
\hline 21 & $\mathrm{~m}$ & 7 & 4,3 & 5 & 613 & & & Phthisis OE \\
\hline 22 & $f$ & 6 & 7 & 14 & 560 & 12 & 583 & \\
\hline 29 & $\mathrm{~m}$ & 13 & 5 & 11 & 607 & 11 & 624 & \\
\hline 31 & $\mathrm{~m}$ & 13 & 4,2 & 15 & 638 & & & Cat hipermatura $\mathrm{E}$ \\
\hline 34 & $\mathrm{~m}$ & 6 & 9,6 & 12 & 633 & & & Cat. hipermatura $\mathrm{E}$ \\
\hline 38 & $\mathrm{~m}$ & 9 & 5,3 & & & 12 & 589 & Cat matura D \\
\hline 48 & $f$ & 13 & 6,5 & & & 11 & 630 & Trauma OD antigo \\
\hline 49 & $\mathrm{~m}$ & 12 & 6,5 & 12 & 650 & 11 & 630 & \\
\hline 63 & $f$ & 8 & 6 & 21 & 585 & 18 & 580 & \\
\hline 67 & $f$ & 6 & 7 & 10 & 627 & 14 & 634 & \\
\hline 71 & $f$ & 8 & 4,5 & & & 9 & 544 & Cat. incipiente D \\
\hline 73 & $\mathrm{~m}$ & 14 & 6,2 & 7 & 683 & 5 & 680 & \\
\hline 82 & $f$ & 16 & 3,2 & & & 14 & 558 & Cat. Hipermatura D \\
\hline 83 & $f$ & 8 & 6,5 & 12 & 604 & 15 & 606 & \\
\hline 85 & $f$ & 13 & 6,4 & 16 & 645 & 14 & 648 & \\
\hline 90 & $\mathrm{~m}$ & 7 & 4 & 13 & 696 & & & Cat. hipermatura $\mathrm{E}$ \\
\hline 92 & $\mathrm{~m}$ & 9 & 8 & 12 & 690 & & & Cat. hipermatura $\mathrm{E}$ \\
\hline 98 & $f$ & 4 & 14,3 & 10 & 546 & 10 & 538 & \\
\hline 103 & $f$ & 4 & 4,7 & & & 14 & 532 & Cat. imatura D \\
\hline 107 & $f$ & 2 & 2,6 & 15 & 566 & & & Cat. hipermatura $\mathrm{E}$ \\
\hline
\end{tabular}

(continua)

BSERVAÇÕES

Cat matura D

Phthisis OE

Cat hipermatura $\mathrm{E}$

$\mathrm{m}=$ macho, $\mathrm{f}=$ fêmea, $\mathrm{Cat}=$ catarata, $\mathrm{PIO}=$ pressão intra-ocular, $\mathrm{PAQ}=$ paquimetria, $\mathrm{OD}=$ olho direito, $\mathrm{OE}=$ olho esquerdo, $\mathrm{D}=$ direito, $\mathrm{E}=$ esquerdo, aa= anos. 
APÊNDICE A - Distribuição das variáveis e olhos do grupo controle segundo os animais - São Paulo - 2008

(conclusão)

GRUPO CONTROLE - POODLES NORMAIS

Animal Sexo Idade (aa) Peso (kg) PIO OD (mmHg)

$110 \quad \mathrm{~m} \quad 11$

$\begin{array}{llll}112 & f & 11 & 3\end{array}$

818

$12 \quad 571$

PIO OE $(\mathrm{mmHg})$

10

OBSERVAÇÕES

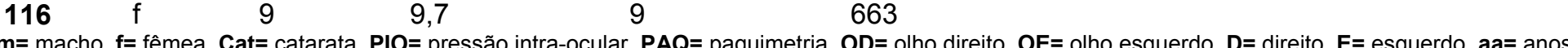

Cat. hipermatura E 
APÊNDICE B - Distribuição das variáveis e olhos do grupo catarata incipiente segundo os animais - São Paulo - 2008

\begin{tabular}{|c|c|c|c|c|c|c|c|c|c|c|}
\hline \multicolumn{11}{|c|}{ GRUPO POODLES COM CAT. INCIPIENTE } \\
\hline Animal & Sexo & Idade (aa) & Peso(kg) & PIO OD & PAQ OD & SINAIS UVEITE FACO & PIO OE & PAQ OE & SINAIS UVEITE FACO & OBSERVAÇÕES \\
\hline 1 & $\mathrm{~m}$ & 11 & 8,1 & & & & 12 & 629 & $\mathrm{~N}$ & OD: ndr \\
\hline 2 & $\mathrm{~m}$ & 10 & 10 & 12 & 605 & $\mathrm{~N}$ & & & & FEC OE há 2 anos \\
\hline 47 & $f$ & 8 & 7 & 13 & 551 & $\mathrm{~N}$ & 17 & 545 & $\mathrm{~N}$ & \\
\hline 50 & $\mathrm{~m}$ & 4 & 4,2 & & & & 16 & 630 & $\mathrm{~N}$ & Cat. hipermatura $\mathrm{D}$ \\
\hline 51 & $f$ & 11 & 8,8 & 11 & 603 & $\mathrm{~N}$ & & & & Cat. hipermatura $\mathrm{E}$ \\
\hline 58 & $f$ & 2 & 4,1 & 14 & 555 & $\mathrm{~N}$ & & & & Cat. matura $\mathrm{E}$ \\
\hline 69 & $\mathrm{~m}$ & 10 & 3,8 & 11 & 581 & $\mathrm{~N}$ & 13 & 601 & $\mathrm{~N}$ & \\
\hline 71 & $f$ & 8 & 4,5 & 10 & 549 & $\mathrm{~N}$ & & & & OE:ndr \\
\hline 77 & $\mathrm{~m}$ & 6 & 4 & & & & 15 & 591 & $\mathrm{~N}$ & Cat hipermatura $\mathrm{D}$ \\
\hline 78 & $\mathrm{~m}$ & 7 & 10,6 & & & & 13 & 576 & N & Cat. hipermatura $\mathrm{D}$ \\
\hline 81 & $\mathrm{~m}$ & 5 & 5,5 & & & & 12 & 627 & $\mathrm{~N}$ & Cat matura $\mathrm{D}$ \\
\hline 89 & $f$ & 6 & 5,9 & & & & 14 & 585 & $\mathrm{~N}$ & Cat.imatura D \\
\hline 91 & $\mathrm{~m}$ & 2 & 6,8 & 13 & 610 & $\mathrm{~N}$ & & & & Cat. matura $\mathrm{E}$ \\
\hline 95 & $\mathrm{~m}$ & 3 & 7,8 & 11 & 689 & $\mathrm{~N}$ & & & & Cat. matura $\mathrm{E}$ \\
\hline 108 & $\mathrm{~m}$ & 9 & 8,8 & & & & 16 & 599 & $\mathrm{~N}$ & Cat. imatura D \\
\hline 114 & $\mathrm{~m}$ & 9 & 5,8 & 13 & 618 & $\mathrm{~N}$ & & & & Cat. hipermatura $\mathrm{E}$ \\
\hline 115 & $f$ & 8 & 6 & & & & 8 & 569 & $\mathrm{~N}$ & Cat. matura $\mathrm{D}$ \\
\hline $\begin{array}{l}117 \\
m=\text { mach }\end{array}$ & $f$ & 4 & $\begin{array}{l}2,6 \\
\text { PIO= } \mathrm{pr}\end{array}$ & $\begin{array}{l}12 \\
\text { intra-ocul }\end{array}$ & $\begin{array}{c}575 \\
\operatorname{lar}, \mathrm{PAQ}=\mathrm{p}\end{array}$ & tria, $\mathrm{OD}=$ olho direito, $\mathrm{OE}=\mathrm{o}$ & (2) & D-dirit & 2 & $\begin{array}{l}\text { Cat. hipermatura } \\
\text { o-induzida., FEC= }\end{array}$ \\
\hline
\end{tabular}


APÊNDICE C - Distribuição das variáveis e olhos do grupo catarata imatura segundo os animais - São Paulo - 2008

GRUPO POODLES COM CAT. IMATURA

Animal Sexo Idade (aa) Peso PIO OD PAQ OD LEUCO(mm)

\begin{tabular}{|c|c|c|c|c|c|c|c|c|c|c|c|c|}
\hline Inima & Sexo & Idade (aa) & Peso & PIO OD & PAQ OD & LEUCO(mm) & FACO & PIO OE & PAQ OE & LEUCO(mm) & FACO & OBSERVAÇOES \\
\hline 4 & $f$ & 14 & 13 & 9 & 692 & 12 & $\mathrm{~N}$ & 12 & 671 & 12 & $\mathrm{~N}$ & \\
\hline 19 & $\mathrm{~m}$ & 5 & 2,9 & 12 & 572 & 12 & $\mathrm{~N}$ & 12 & 578 & 12 & $\mathrm{~N}$ & \\
\hline 23 & $f$ & 12 & 12,8 & 11 & 621 & 12 & $\mathrm{~N}$ & & & & & Cat. hipermatura $\mathrm{E}$ \\
\hline 24 & $\mathrm{~m}$ & 7 & 13,7 & 15 & 567 & 24 & $\mathrm{~N}$ & & & & & OE: outros \\
\hline 30 & $f$ & 9 & 9 & 13 & 570 & 12 & $\mathrm{~N}$ & 15 & 585 & 12 & $\mathrm{~N}$ & \\
\hline 32 & $f$ & 10 & 6,1 & & & & & 13 & 655 & 22 & $\mathrm{~N}$ & Cat. hipermatura D \\
\hline 33 & $\mathrm{~m}$ & 5 & 6,6 & 15 & 692 & 6 & $\mathrm{~N}$ & 16 & 691 & 6 & $\mathrm{~N}$ & \\
\hline 35 & $f$ & 9 & 10 & 13 & 626 & 6 & $\mathrm{~N}$ & & & & & Cat. hipermatura $\mathrm{E}$ \\
\hline 43 & $\mathrm{~m}$ & 7 & 4,5 & 11 & 615 & 12 & $\mathrm{~N}$ & & & & & Cat. matura $\mathrm{E}$ \\
\hline 46 & $\mathrm{~m}$ & 8 & 5,5 & 13 & 580 & 6 & $\mathrm{~N}$ & & & & & Cat. matura $\mathrm{E}$ \\
\hline 54 & $\mathrm{~m}$ & 4 & 7,1 & 10 & 539 & 5 & $\mathrm{~N}$ & & & & & Cat. matura $\mathrm{E}$ \\
\hline 55 & $f$ & 10 & 5 & & & & & 19 & 602 & 6 & $\mathrm{~N}$ & Cat. matura $\mathrm{D}$ \\
\hline 56 & $\mathrm{~m}$ & 6 & 9 & 13 & 610 & 6 & S & 10 & 658 & 6 & S & \\
\hline 57 & $\mathrm{~m}$ & 11 & 5 & 8 & 668 & 12 & S & & & & & Cat. hipermatura $\mathrm{E}$ \\
\hline 60 & $f$ & 6 & 7,8 & & & & & 8 & 615 & 12 & $\mathrm{~N}$ & Cat. hipermatura D \\
\hline 80 & $f$ & 6 & 5,2 & 14 & 628 & 6 & $\mathrm{~N}$ & & & & & Cat. hipermatura E \\
\hline 89 & $f$ & 6 & 5,9 & 13 & 590 & 22 & $\mathrm{~N}$ & & & & & Cat. incipiente $\mathrm{E}$ \\
\hline 101 & $f$ & 3 & 6,7 & 26 & 653 & 4 & $\mathrm{~N}$ & & & & & Cat. matura $\mathrm{E}$ \\
\hline 103 & $f$ & 4 & 4,7 & 14 & 523 & 1,5 & $\mathrm{~N}$ & & & & & OE: ndn \\
\hline 108 & $\mathrm{~m}$ & 9 & 8,8 & 11 & 615 & 12 & $\mathrm{~N}$ & & & & & Cat. incipiente E \\
\hline 118 & $f$ & 4 & 18 & 18 & 562 & 6 & $\mathrm{~N}$ & 17 & 540 & 6 & $\mathrm{~N}$ & \\
\hline 122 & $\mathrm{~m}$ & 3 & 6,5 & 14 & 580 & 4 & $\mathrm{~N}$ & 17 & 621 & 4 & $\mathrm{~N}$ & 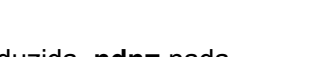 \\
\hline
\end{tabular}


Apêndice D - Distribuição das variáveis e olhos do grupo catarata matura segundo os animais - São Paulo - 2008

GRUPO POODLES COM CAT. MATURA

Idade

\begin{tabular}{|c|c|c|c|c|c|c|c|c|c|c|c|c|}
\hline Animal & Sexo & $\begin{array}{l}\text { Idade } \\
\text { (aa) }\end{array}$ & Peso & PIO OD & PAQ OD & $\begin{array}{c}\text { TEMPO } \\
\text { LEUCO }(\mathrm{mm})\end{array}$ & $\begin{array}{c}\text { SINAIS } \\
\text { UVEITE FACO }\end{array}$ & PIO OE & PAQ OE & $\begin{array}{c}\text { TEMPO } \\
\text { LEUCO(mm) }\end{array}$ & $\begin{array}{c}\text { SINAIS } \\
\text { UVEITE FACO }\end{array}$ & OBSERVAÇÕES \\
\hline 8 & $f$ & 10 & 4,8 & 16 & 495 & 12 & $\mathrm{~N}$ & & & & & OE:ndn \\
\hline 26 & $f$ & 11 & 9 & 14 & 623 & 17 & $\mathrm{~N}$ & 10 & 614 & 17 & $\mathrm{~N}$ & \\
\hline 38 & $\mathrm{~m}$ & 9 & 5,3 & 10 & 604 & 4 & $\mathrm{~N}$ & & & & & OE:ndn \\
\hline 43 & $\mathrm{~m}$ & 7 & 4,5 & & & & & 13 & 633 & 18 & $\mathrm{~N}$ & Cat. imatura D \\
\hline 46 & $\mathrm{~m}$ & 8 & 5,5 & & & & & 9 & 589 & 6 & $\mathrm{~N}$ & Cat. imatura D \\
\hline 54 & $\mathrm{~m}$ & 4 & 7,1 & & & & & 10 & 522 & 5 & $\mathrm{~N}$ & Cat. imatura D \\
\hline 55 & $f$ & 10 & 5 & 10 & 610 & 6 & $\mathrm{~N}$ & & & & & Cat. imatura $E$ \\
\hline 58 & $f$ & 2 & 4,1 & & & & & 6 & 571 & 1 & $S$ & Cat. incipiente D \\
\hline 76 & $\mathrm{~m}$ & 5 & 5,5 & 15 & 611 & 12 & $\mathrm{~N}$ & 17 & 603 & 12 & $\mathrm{~N}$ & \\
\hline 79 & $f$ & 10 & 5 & 7 & 601 & 2 & $\mathrm{~N}$ & 10 & 598 & 2 & $\mathrm{~N}$ & \\
\hline 81 & $\mathrm{~m}$ & 5 & 5,5 & 8 & 642 & 3 & $\mathrm{~N}$ & & & & & Cat. incipiente $\mathrm{E}$ \\
\hline 86 & $f$ & 13 & 8 & & & & & 11 & 698 & 8 & $\mathrm{~N}$ & Cat. hipermatura D \\
\hline 91 & $\mathrm{~m}$ & 2 & 6,8 & & & & & 14 & 615 & 5 & $\mathrm{~N}$ & Cat. incipiente $D$ \\
\hline 95 & $\mathrm{~m}$ & 3 & 7,8 & & & & & 9 & 667 & 2 & $\mathrm{~N}$ & Cat. incipiente D \\
\hline 101 & $f$ & 3 & 6,7 & & & & & 16 & 732 & 4 & S & Cat. imatura D \\
\hline 113 & $f$ & 9 & 4,8 & & & & & 18 & 544 & 12 & $\mathrm{~N}$ & OD: outros \\
\hline 115 & $\begin{array}{c}\mathrm{f} \\
\text { aach }\end{array}$ & $\begin{array}{l}8 \\
\text { fême }\end{array}$ & $\begin{array}{c}6 \\
\text { at }=\text { cat }\end{array}$ & $\begin{array}{c}9 \\
a, \text { PIO }\end{array}$ & $\begin{array}{l}584 \\
\text { ssão intra-oc }\end{array}$ & $\begin{array}{c}8 \\
\text { cular, } P A Q=\text { paquin }\end{array}$ & $\stackrel{S}{\text { tria, } O D=\text { olho direit }}$ & $O E=o l h o E$ & querdo, & direito, $E=$ esque & $a a=a n o s, F A C$ & $\begin{array}{l}\text { Cat. incipiente E } \\
\text { nduzida, } \mathbf{n d n}=\text { nada }\end{array}$ \\
\hline
\end{tabular}


Apêndice E - Distribuição das variáveis e olhos do grupo catarata hipermatura segundo os animais - São Paulo - 2008

(continua)

GRUPO POODLES COM CAT. HIPERMATURA

\begin{tabular}{|c|c|c|c|c|c|c|c|c|c|c|c|c|}
\hline Animal & Sexo & $\begin{array}{l}\text { Idade } \\
\text { (aa) }\end{array}$ & Peso & PIO OD & PAQ OD & $\begin{array}{c}\text { TEMPO } \\
\text { LEUCO }(\mathrm{mm})\end{array}$ & $\begin{array}{c}\text { SINAIS } \\
\text { UVEITE FACO }\end{array}$ & PIO OE & PAQ OE & $\begin{array}{c}\text { TEMPO } \\
\text { LEUCO(mm) }\end{array}$ & $\begin{array}{c}\text { SINAIS } \\
\text { UVEITE FACO }\end{array}$ & OBSERVAÇÕES \\
\hline 3 & $f$ & 11 & 7 & 6 & 739 & 12 & $\mathrm{~N}$ & 6 & 759 & 12 & $\mathrm{~N}$ & \\
\hline 11 & $f$ & 8 & 5,2 & 15 & 574 & 17 & $\mathrm{~N}$ & 18 & 568 & 17 & $\mathrm{~N}$ & \\
\hline 12 & $f$ & 13 & 3,7 & & & & & 7 & 752 & 12 & $S$ & OD:ndn \\
\hline 14 & $f$ & 6 & 4,6 & & & & & 9 & 522 & 44 & $\mathrm{~N}$ & FEC OD \\
\hline 23 & $f$ & 12 & 12,8 & & & & & 15 & 591 & 12 & $\mathrm{~N}$ & Cat. imatura D \\
\hline 27 & $\mathrm{~m}$ & 5 & 5,4 & 7 & 688 & 14 & $S$ & 9 & 642 & 14 & $S$ & \\
\hline 28 & $\mathrm{~m}$ & 5 & 4,6 & 14 & 620 & 6 & $S$ & 11 & 624 & 12 & $S$ & \\
\hline 31 & $\mathrm{~m}$ & 13 & 4,2 & & & & & 7 & 692 & 3 & $\mathrm{~N}$ & OD: ndn \\
\hline 32 & $f$ & 10 & 6,1 & 10 & 684 & 31 & $\mathrm{~N}$ & & & & & Cat. imatura $\mathrm{E}$ \\
\hline 34 & $\mathrm{~m}$ & 6 & 9,6 & & & & & 8 & 661 & 4 & $S$ & OD:ndn \\
\hline 35 & $f$ & 9 & 10 & & & & & 7 & 648 & 10 & $\mathrm{~N}$ & Cat. imatura D \\
\hline 40 & $\mathrm{~m}$ & 7 & 6 & 16 & 502 & 24 & $S$ & & & & & Leucoma OE \\
\hline 41 & $f$ & 8 & 7,5 & 11 & 546 & 14 & $\mathrm{~N}$ & 10 & 532 & 14 & $\mathrm{~N}$ & \\
\hline 42 & $\mathrm{~m}$ & 9 & 4,5 & 5 & 795 & 18 & $S$ & 6 & 744 & 12 & $S$ & \\
\hline 44 & $f$ & 7 & 6,2 & 18 & 649 & 24 & $\mathrm{~N}$ & 23 & 648 & 24 & $\mathrm{~N}$ & \\
\hline 50 & $\mathrm{~m}$ & 4 & 4,2 & 16 & 647 & 3 & $\mathrm{~N}$ & & & & & Cat. incipiente $\mathrm{E}$ \\
\hline 51 & $f$ & 11 & 8,8 & & & & & 10 & 647 & 6 & $\mathrm{~N}$ & Cat. incipiente D \\
\hline 52 & $\mathrm{~m}$ & 11 & 8,5 & 13 & 565 & 13 & $\mathrm{~N}$ & 12 & 666 & 13 & $\mathrm{~N}$ & \\
\hline 53 & $\mathrm{~m}$ & 7 & 4 & 13 & 619 & 4 & $\mathrm{~N}$ & 10 & 597 & 4 & $\mathrm{~N}$ & \\
\hline 57 & $\mathrm{~m}$ & 11 & 5 & & & & & 10 & 668 & 12 & $\mathrm{~S}$ & Cat. imatura D \\
\hline 59 & $f$ & 6 & 7,3 & 10 & 550 & 12 & $S$ & 9 & 587 & 12 & $S$ & \\
\hline 60 & $f$ & 6 & 7,8 & 11 & 614 & 12 & $S$ & & & & & Cat. imatura $\mathrm{E}$ \\
\hline 62 & $f$ & 8 & 7,4 & 10 & 498 & 24 & $S$ & 7 & 525 & 18 & $S$ & \\
\hline
\end{tabular}


Apêndice E - Distribuição das variáveis e olhos do grupo catarata hipermatura segundo os animais - São Paulo - 2008

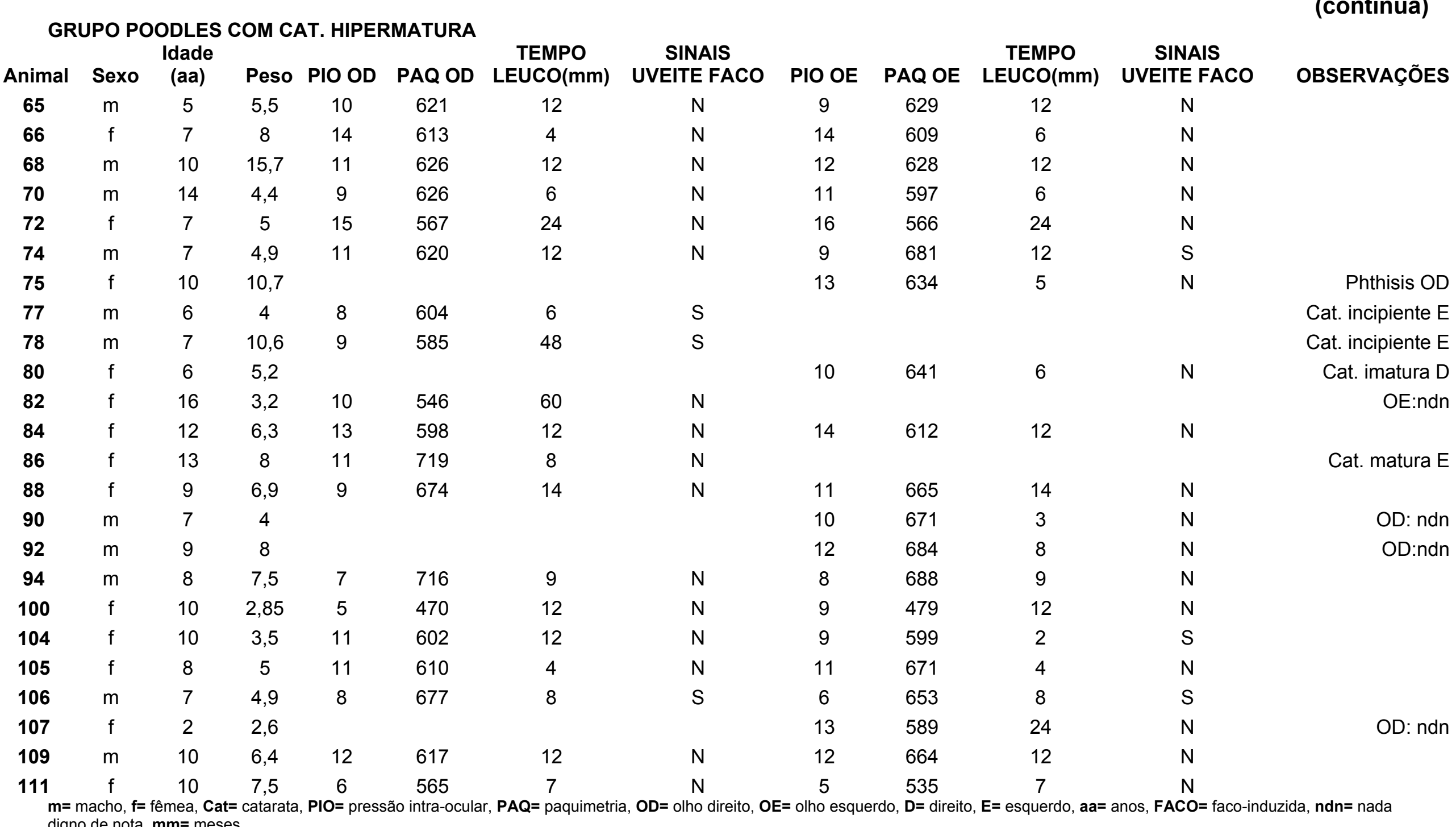


Apêndice E - Distribuição das variáveis e olhos do grupo catarata hipermatura segundo os animais - São Paulo - 2008

\begin{tabular}{|c|c|c|c|c|c|c|c|c|c|c|c|c|}
\hline \multicolumn{6}{|c|}{$\begin{array}{l}\text { GRUPO POODLES COM CAT. HIPERMATURA } \\
\text { Idade }\end{array}$} & \multirow[b]{2}{*}{$\begin{array}{c}\text { TEMPO } \\
\text { LEUCO }(\mathrm{mm})\end{array}$} & \multirow[b]{2}{*}{$\begin{array}{c}\text { SINAIS } \\
\text { UVEITE FACO }\end{array}$} & \multirow[b]{2}{*}{ PIO OE } & \multirow[b]{2}{*}{ PAQ OE } & \multirow[b]{2}{*}{$\begin{array}{c}\text { TEMPO } \\
\text { LEUCO(mm) }\end{array}$} & \multirow[b]{2}{*}{$\begin{array}{l}\text { SINAIS } \\
\text { UVEITE FACO }\end{array}$} & \\
\hline Animal & Sexo & $\begin{array}{c}\text { Idade } \\
\text { (aa) }\end{array}$ & Peso & PIO OD & PAQ OD & & & & & & & \\
\hline 114 & $\mathrm{~m}$ & 9 & 5,8 & & & & & 12 & 602 & 12 & $\mathrm{~N}$ & Cat. incipiente D \\
\hline 116 & $f$ & 9 & 9,7 & & & & & 10 & 672 & 12 & $\mathrm{~N}$ & OD: ndn \\
\hline 117 & $f$ & 4 & 2,6 & & & & & 11 & 581 & 6 & $\mathrm{~N}$ & Cat. incipiente D \\
\hline $\begin{aligned} & 119 \\
= & \text { mach }\end{aligned}$ & $\mathrm{m}$ & $\begin{array}{l}10 \\
= \\
=\end{array}$ & 5 & 8 & $\begin{array}{l}568 \\
568\end{array}$ & 24 & $\begin{array}{l}S \\
O E\end{array}$ & $\begin{array}{c}8 \\
\text { do, }\end{array}$ & $\begin{array}{l}525 \\
E=e s\end{array}$ & $\begin{array}{l}24 \\
=a n\end{array}$ & $\underset{\text {-indu }}{\mathrm{N}}$ & \\
\hline
\end{tabular}
$\mathrm{mm}=$ meses. 
Apêndice F - Distribuição das variáveis e olhos do grupo catarata diabética imatura segundo os animais - São Paulo - 2008

\section{GRUPO POODLES DM COM CAT. IMATURA}

\begin{tabular}{|c|c|c|c|c|c|c|c|c|c|c|c|c|c|}
\hline Animal & Sexo & $\begin{array}{l}\text { Idade } \\
\text { (aa) }\end{array}$ & Peso & $\begin{array}{c}\text { Tempo DM } \\
\text { (mm) }\end{array}$ & $\begin{array}{l}\text { PIO } \\
\text { OD }\end{array}$ & $\begin{array}{l}\text { PAQ } \\
\text { OD }\end{array}$ & $\begin{array}{c}\text { TEMPO } \\
\text { LEUCO(mm) }\end{array}$ & $\begin{array}{c}\text { SINAIS } \\
\text { UVEITE } \\
\text { FACO }\end{array}$ & $\begin{array}{l}\text { PIO } \\
\text { OE }\end{array}$ & $\begin{array}{c}\text { PAQ } \\
\text { OE }\end{array}$ & $\begin{array}{c}\text { TEMPO } \\
\text { LEUCO }(\mathrm{mm})\end{array}$ & $\begin{array}{c}\text { SINAIS } \\
\text { UVEITE } \\
\text { FACO }\end{array}$ & OBSERVAÇÕES \\
\hline 9 & $F$ & 12 & 5,5 & 44 & 13 & 551 & 44 & $\mathrm{~N}$ & 14 & 556 & 44 & $\mathrm{~N}$ & \\
\hline 17 & $\mathrm{~F}$ & 13 & 9,3 & 3 & 8 & 628 & 1 & $\mathrm{~s}$ & & & & & Cat. Hipermatura E \\
\hline 36 & $\mathrm{~F}$ & 10 & 6 & 10 & 14 & 631 & 1 & $\mathrm{~N}$ & 15 & 614 & 1 & $\mathrm{~N}$ & \\
\hline 45 & $\mathrm{~F}$ & 13 & 7 & 7 & & & & & 10 & 678 & 1 & $\mathrm{~N}$ & Cat. Matura D \\
\hline 87 & $\mathrm{~F}$ & 9 & 8 & 1 & & & & & 7 & 726 & 1 & $\mathrm{~N}$ & Cat. Matura D \\
\hline 93 & $F$ & 7 & 4,7 & 3 & 13 & 621 & 1 & $\mathrm{~N}$ & 14 & 602 & 1 & $\mathrm{~N}$ & \\
\hline
\end{tabular}
nada digno de nota, $\mathbf{m m}=$ meses 
Apêndice G - Distribuição das variáveis e olhos do grupo catarata diabética matura segundo os animais - São Paulo - 2008

\section{GRUPO POODLES DM COM CAT. MATURA}

\begin{tabular}{|c|c|c|c|c|c|c|c|c|c|c|c|c|c|}
\hline Animal & Sexo & $\begin{array}{c}\text { Idade } \\
\text { (aa) }\end{array}$ & Peso & $\begin{array}{c}\text { Tempo } \\
\text { DM (mm) }\end{array}$ & $\begin{array}{l}\text { PIO } \\
\text { OD }\end{array}$ & $\begin{array}{c}\text { PAQ } \\
\text { OD }\end{array}$ & $\begin{array}{c}\text { TEMPO } \\
\text { LEUCO(mm) }\end{array}$ & $\begin{array}{r}\text { SINAIS } \\
\text { UVEITE } \\
\text { FACO }\end{array}$ & $\begin{array}{l}\text { PIO } \\
\text { OE }\end{array}$ & $\begin{array}{r}\text { PAQ } \\
\text { OE }\end{array}$ & $\begin{array}{c}\text { TEMPO } \\
\text { LEUCO(mm) }\end{array}$ & $\begin{array}{c}\text { SINAIS } \\
\text { UVEITE } \\
\text { FACO }\end{array}$ & OBSERVAÇÕES \\
\hline 10 & $M$ & 12 & 7,5 & 1 & & & & & 9 & 727 & 0,3 & $S$ & Cat. Hipermatura D \\
\hline 16 & $\mathrm{~F}$ & 13 & 4,5 & 30 & 13 & 611 & 6 & $\mathrm{~N}$ & 14 & 633 & 6 & $\mathrm{~N}$ & \\
\hline 45 & $F$ & 13 & 7 & 7 & 10 & 651 & 1 & $\mathrm{~N}$ & & & & & Cat. Imatura E \\
\hline 61 & $\mathrm{~F}$ & 10 & 5,8 & 3 & 9 & 610 & 1,5 & $\mathrm{~N}$ & 7 & 605 & 1,5 & $\mathrm{~N}$ & \\
\hline 87 & $\mathrm{~F}$ & 9 & 8 & 1 & 10 & 726 & 1 & $\mathrm{~N}$ & & & & & Cat. Imatura E \\
\hline 99 & $\mathrm{~F}$ & 11 & 12,2 & 1,5 & 8 & 654 & 1 & $\mathrm{~N}$ & 9 & 674 & 1 & $\mathrm{~N}$ & \\
\hline 102 & $\mathrm{~F}$ & 8 & 7,5 & 4 & 9 & 673 & 1 & $S$ & 13 & 690 & 1 & $S$ & \\
\hline
\end{tabular}

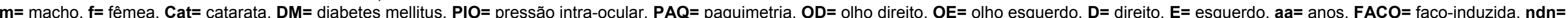
nada digno de nota, $\mathbf{m m}=$ meses. 
Apêndice H - Distribuição das variáveis e olhos do grupo catarata diabética hipermatura segundo os animais - São Paulo - 2008 GRUPO POODLES DM COM CAT. HIPERMATURA

\begin{tabular}{|c|c|c|c|c|c|c|c|c|c|c|c|c|c|}
\hline Animal & Sexo & $\begin{array}{l}\text { Idade } \\
\text { (aa) }\end{array}$ & Peso & $\begin{array}{c}\text { Tempo DM } \\
(\mathrm{mm})\end{array}$ & $\begin{array}{l}\text { PIO } \\
\text { OD }\end{array}$ & $\begin{array}{c}\text { PAQ } \\
\text { OD }\end{array}$ & $\begin{array}{c}\text { TEMPO } \\
\text { LEUCO }(\mathbf{m m})\end{array}$ & $\begin{array}{c}\text { SINAIS } \\
\text { UVEITE } \\
\text { FACO }\end{array}$ & $\begin{array}{r}\text { PIO } \\
\text { OE }\end{array}$ & $\begin{array}{r}\text { PAQ } \\
\text { OE }\end{array}$ & $\begin{array}{r}\text { TEMPO } \\
\text { LEUCO(mm) }\end{array}$ & $\begin{array}{r}\text { SINAIS } \\
\text { UVEITE } \\
\text { FACO }\end{array}$ & OBSERVAÇÕES \\
\hline 5 & $\mathrm{~F}$ & 9 & 3,3 & 2,5 & 5 & 693 & 2,5 & $S$ & 26 & 812 & 2,5 & $S$ & \\
\hline 7 & $f$ & 13 & 9 & 2 & 15 & 612 & 1 & $\mathrm{~N}$ & 17 & 601 & 1 & $\mathrm{~N}$ & \\
\hline 10 & $M$ & 12 & 7,5 & 1 & 12 & 697 & 0,3 & $S$ & & & & & Cat. Matura E \\
\hline 13 & $f$ & 11 & 12,5 & 36 & & & & & 9 & 708 & 24 & $\mathrm{~N}$ & FEC OD \\
\hline 15 & $f$ & 9 & 8 & 7 & 10 & 589 & 3 & $\mathrm{~N}$ & 8 & 541 & 3 & $\mathrm{~N}$ & \\
\hline 17 & $\mathrm{~F}$ & 13 & 9,3 & 3 & & & & & 10 & 705 & 3 & $S$ & Cat. Imatura D \\
\hline 18 & $f$ & 12 & 10,5 & 40 & & & & & 13 & 658 & 40 & $\mathrm{~N}$ & FEC OD \\
\hline 20 & $\mathrm{~m}$ & 12 & 5,2 & 24 & 10 & 670 & 17 & $S$ & & & & & FEC OE \\
\hline 25 & $f$ & 9 & 14 & 13 & 6 & 554 & 13 & $\mathrm{~N}$ & 13 & 537 & 13 & $\mathrm{~N}$ & \\
\hline 37 & $f$ & 10 & 13 & 2 & 8 & 983 & 1 & $S$ & 6 & 887 & 1 & $S$ & \\
\hline 39 & $f$ & 14 & 7,5 & 3 & 7 & 789 & 3 & $\mathrm{~N}$ & 8 & 772 & 3 & $\mathrm{~N}$ & \\
\hline 96 & $\mathrm{M}$ & 9 & 9,8 & 4 & 9 & 654 & 0,25 & $\mathrm{~N}$ & 7 & 616 & 0,25 & $\mathrm{~N}$ & \\
\hline 97 & $f$ & 7 & 9,2 & 1 & 11 & 814 & 0,75 & $S$ & 13 & 938 & 0,75 & $S$ & \\
\hline 120 & $\mathrm{M}$ & 10 & 4 & 3 & 12 & 505 & 3 & $\mathrm{~N}$ & 11 & 520 & 3 & $\mathrm{~N}$ & \\
\hline 121 & $M$ & 6 & 5,25 & 3,25 & 7 & 759 & 3,25 & $S$ & 7 & 739 & 3,25 & $S$ & \\
\hline
\end{tabular}

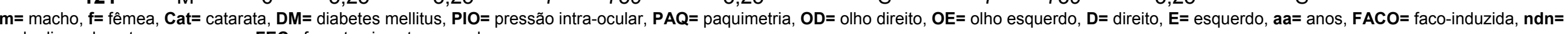
nada digno de nota, $\mathbf{m m}=$ meses, $\mathrm{FEC}=$ facectomia extra-capsular. 